\title{
SOURCES OF UNCERTAINTY IN REMOTE STRATIGRAPHIC \\ OBSERVATIONS
}

A Thesis
Submitted

to

the Temple University Graduate Board

In Partial Fulfillment

of the Requirements for the

Degree MASTER OF SCIENCE

by

JoAnna G. Marlow

August 2021

Thesis Approvals:

Dr. Alexandra Krull Davatzes, Thesis Advisor Department of Earth and Environmental Science

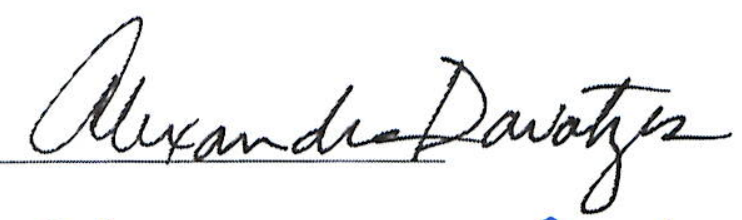

Dr. Allison Tumarkin-Deratzian

Department of Earth and Environmental Science

Dr. Nicholas Davatzes

Department of Earth and Environmental Science

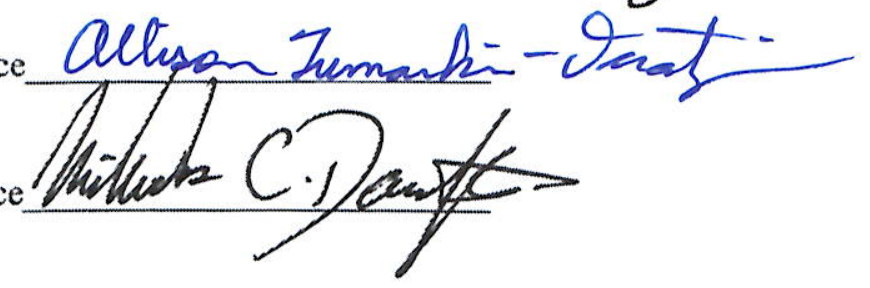




\title{
SOURCES OF UNCERTAINTY IN REMOTE STRATIGRAPHIC OBSERVATIONS
}

\author{
A Thesis \\ Submitted to \\ the Temple University Graduate Board \\ In Partial Fulfillment \\ of the Requirements for the Degree \\ MASTER OF SCIENCE \\ by \\ JoAnna G. Marlow \\ August 2021 \\ Thesis Approvals: \\ Dr. Alexandra Davatzes, Thesis Advisor, Dept. of Earth and Environmental Science \\ Dr. Allison Tumarkin-Deratzian, Dept. of Earth and Environmental Science \\ Dr. Nicholas Davatzes, Dept. of Earth and Environmental Science
}




\begin{abstract}
Small UAVs (drones) are increasingly useful for field data acquisition in the geosciences. Drone images and videos can be processed via digital photogrammetry to produce a 3D digital outcrop model (DOM). DOMs provide opportunities to "return" to an outcrop after fieldwork is complete, collect data from outcrops that are inaccessible, or may even provide opportunities to radically increase data volume of geometric characterizations of geological structures. Our study focuses on understanding the limitations of digital measurements and interpretations used to create stratigraphic columns by comparing $2 \mathrm{D}$ and $3 \mathrm{D}$ results to traditional stratigraphic descriptions and measurements from fieldwork.
\end{abstract}

In this study, a drone collected photos and videos of a well-exposed section of the Palm Spring Formation in the Mecca Hills, California, which is divided into lower and upper units by an angular unconformity and a change in overall texture. In the field, 100 meters of section were measured in 10-cm increments. Markers were placed on the beds throughout the section and surveyed by GPS; these markers were captured by subsequent high resolution aerial imagery. A low-resolution DOM, a highresolution DOM, and a high-resolution with video DOM were created in Pix4DMapper via Structure from Motion (SfM) photogrammetry. The resulting dense point clouds and 3D textured meshes were used to measure projected 3D lengths for each DOM and to create stratigraphic columns from each DOM. Additionally, a stratigraphic section from a simple photomosaic of the UAV photos was created.

The comparisons between the five methods yielded inconsistent bed thickness measurements and lithologic facies. Overall, the discrepancies suggest that differences 
between a digitally produced stratigraphic log and a stratigraphic log produced using traditional field techniques are not systematic nor due to distortion of digital models, and simple scaling will not produce a completely accurate representation of the section. DOM-based measurements provide more accurate strike and dip measurements of stratigraphic layers, leading to more accurate bed thickness measurements than 2-dimensional photomosaic measurements or field measurements. However, all of the digital stratigraphic sections misrepresent lithology due to image distortion and smearing at the grain scale when producing the digital model, so that clear identification of lithology is difficult even when major lithofacies are known based on prior fieldwork. Sensitivity of errors in bed thickness are due to the number and the types of images and video data collected and utilized in the point cloud as well as the processing template chosen. While DOMs can provide access across large outcrops and potentially generate large data sets, understanding sources of error is critical to assess uncertainty in these results and thus the potential for misinterpretation. This assessment requires initial fieldwork with traditional methods to calibrate the DOM's analysis followed by fieldwork to validate DOM's results. Thus, if used in conjunction with fieldwork, the digital techniques may be able to substantially improve data collection, serve as a long-term record for continued research, and provide a critical platform for integrating new data sets and research collaborations. 
To Aiden Jude.

I hope you stay passionately curious. 


\section{ACKNOWLEDGMENTS}

I would like to acknowledge the NSF grant from the Future of Work at the HumanTechnology Frontier for making this research possible.

I would like to especially thank my advisor, Dr. Alix, for always making sure I had everything I needed to be successful over the past two years as well as anything I need for future endeavors. Thank you for all the energy you put into mentoring me, especially during a pandemic. I will always appreciate that the first question you asked at the start of our weekly Zoom meetings was, "how are you doing?" - I could not have asked for a better advisor. I would also like to thank my committee members, Dr. Allison and Dr. Nick, for all the helpful edits and guidance.

Thank you to all the friendships I have made within the EES department, especially my cohort. I wish the cohort that bravely started grad school during the pandemic the best of luck. I would also like to thank the first years for teaching us it is okay to eat lunch, go for coffee breaks, or play darts. Thank you Shelah, for going above and beyond and for truly caring about our well-being.

Most importantly, I am eternally grateful for my family and friends that provided so much unconditional love and support. I recognize all the sacrifices you all made to help me get to this point in life. I hope I have made you all proud. 


\section{TABLE OF CONTENTS}

Page

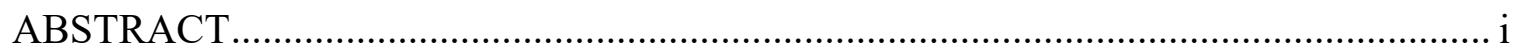

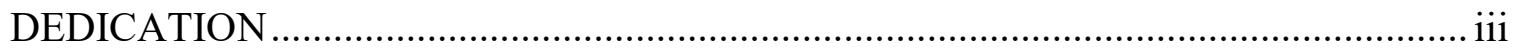

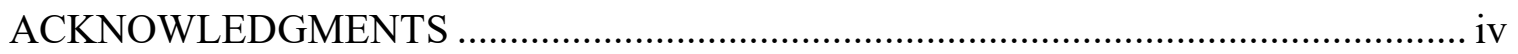

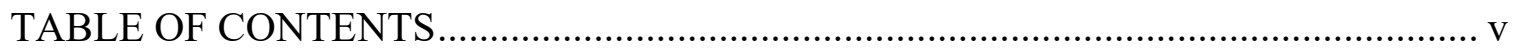

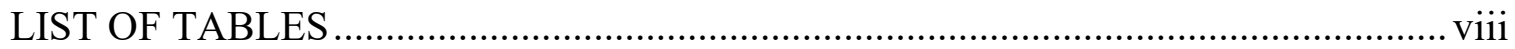

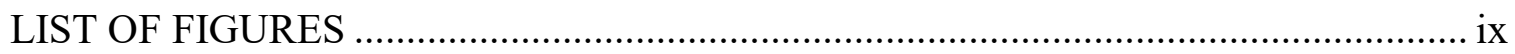

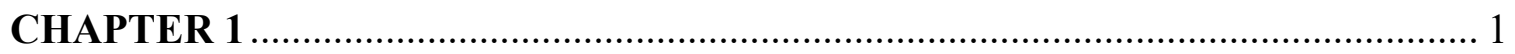

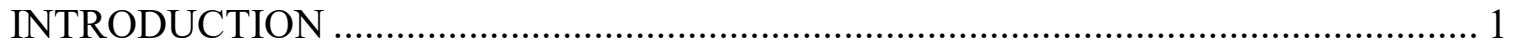

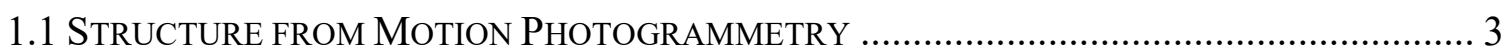

1.2 SEDIMENTOLOGY AND STRATIGRAPHY WITH DRONES ............................................... 6

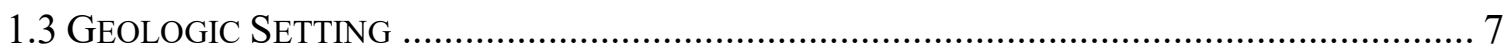

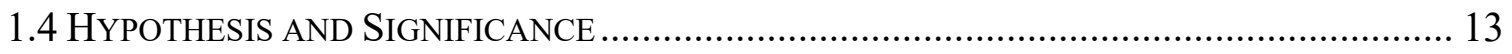

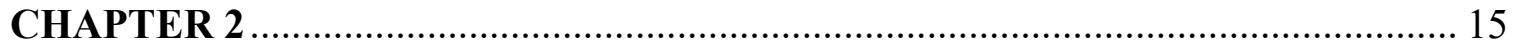

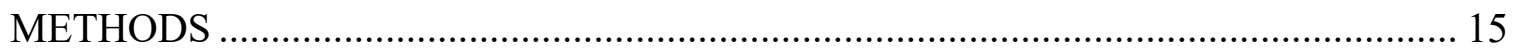

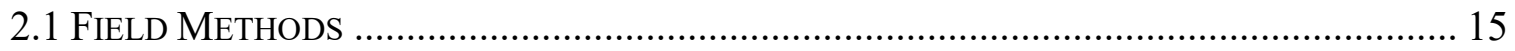

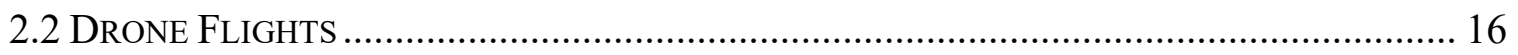

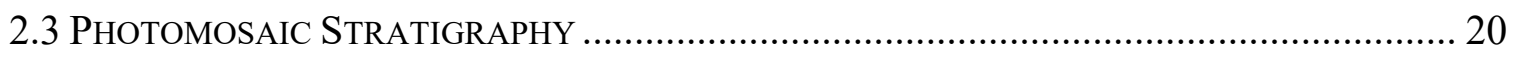

2.4 StRUCtURE FROM Motion PHOTOGRAMMETRY AND StRATIGRAPHY ......................... 21 


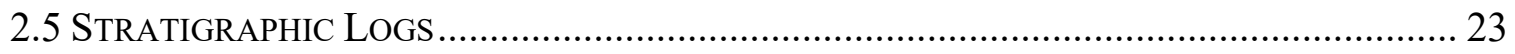

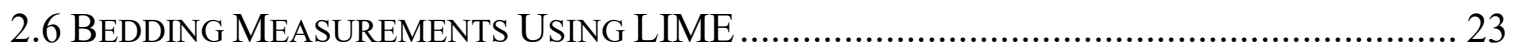

2.7 Spacing AND Attitude OF Planes from SuRVey PointS ......................................... 25

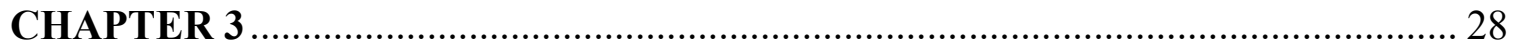

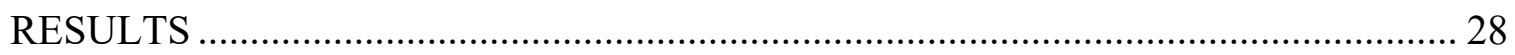

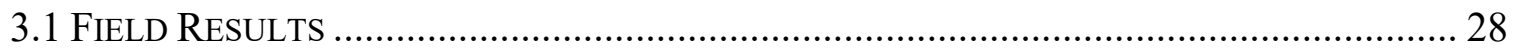

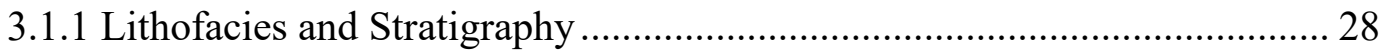

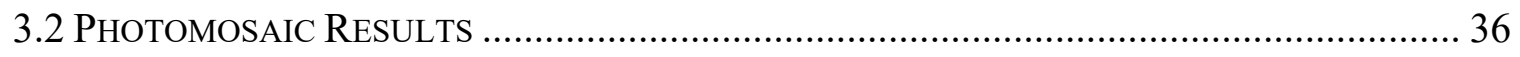

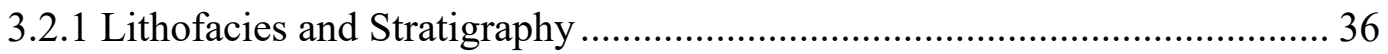

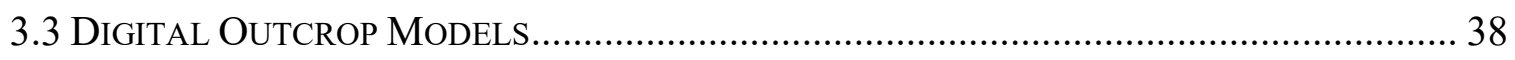

3.3.1 Low Resolution Digital Outcrop Model ...................................................... 38

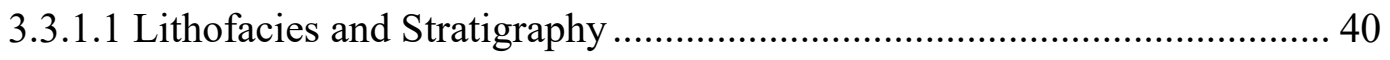

3.3.2 High Resolution Digital Outcrop Model........................................................ 42

3.3.2.1 Lithofacies and Stratigraphy …….......................................................... 44

3.3.3 High Resolution with Video Digital Outcrop Model.................................... 45

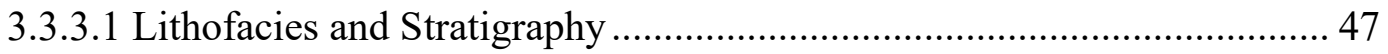

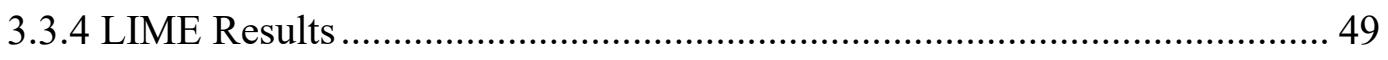

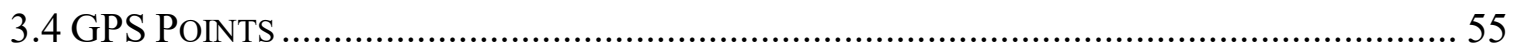

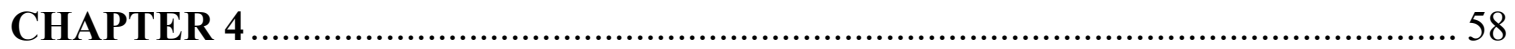

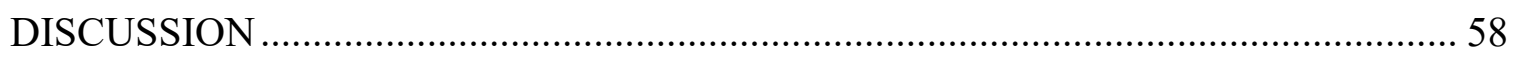

4.1 Comparison of Stratigraphic SeCtions BetweEn Markers................................ 58

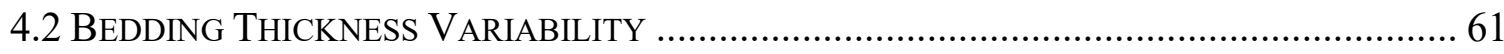




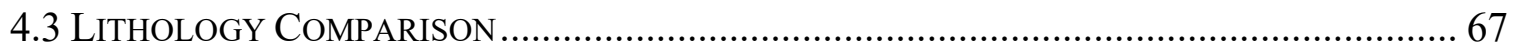

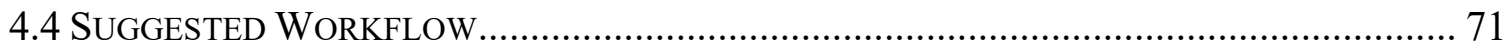

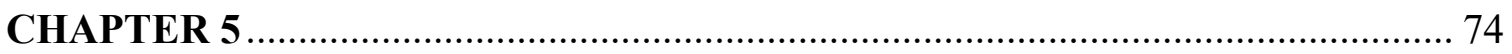

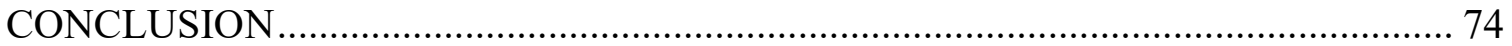

REFERENCES

APPENDIX A

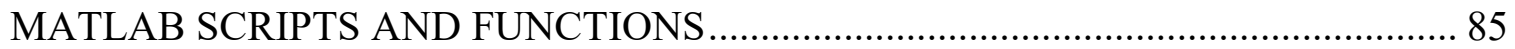

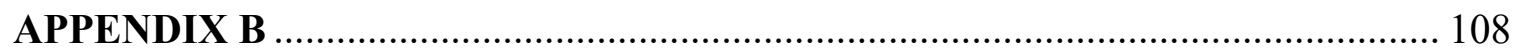

UTM COORDINATES FOR GROUND CONTROL POINTS.................................. 108 


\section{LIST OF TABLES}

Table

Page

1. DJITM Mavic 2 Pro drone specifications including camera properties imported into Pix4Dmapper required for the SfM workflow.

2. Quality report information for each DOM processed

in Pix4Dmapper

3. The three points $(X, Y, Z)$, strike, and dip values that defined the eight planes used in the true thickness calculations for the low-resolution DOM.

4. The three points $(X, Y, Z)$, strike, and dip values that defined the eight planes used in the true thickness calculations for the high-resolution DOM

5. The three points $(\mathrm{X}, \mathrm{Y}, \mathrm{Z})$, strike, and dip values that defined the eight planes used in the true thickness calculations for the high-resolution with video DOM

6. utm coordinates for orange gcps a-h and associated horizontal and vertical precision from processed differential GPS data

7. Northing Residuals from each DOM to the marker GPS coordinates ........................ 57

8. Comparisons of outcrop characteristics between the five techniques.

9. A summary of the findings between the five techniques and brief review of SfM.

A1. List of custom scripts used to extract attitude and thickness data from DOM....

B1. UTM coordinates for the orange ground control points a-h, the low-resolution DOM, the high-resolution DOM, and the high-resolution with video DOM 


\section{LIST OF FIGURES}

Figure

Page

1. A map of the Salton Trough (modified from Babcock, 1974).

The Mecca Hills are located within the red square.

2. (A) A simplified geologic map of the Coachella Valley portion of the Salton

Trough in the San Andreas fault zone. Modified from Bergh et al. (2019)

after Sylvester and O'Black-Gans (2016). The Miocene-Pliocene sedimentary

rocks shown in orange include the Palm Spring Fm. in Mecca Hills (MH).

The Indio Hills (IH), Mecca Hills, and Durmid Hills (DH) have been uplifted by

transpression along the San Andreas Fault (SAF) and the Hidden Springs

Fault (HSF). The red rectangle denotes the location of the Mecca Hills, where

the angular unconformity is exposed, shown in (B). (B) The unconformity

between the lower and upper Palm Spring Fm. Alluvium is covering most

of the deposits in the lower right portion of the image. Note person for

scale in the center of the image, just below the unconformity....

3. A Google Earth image with an interpretation of the three major crustal

blocks and major faults in the Mecca Hills (modified from

Bergh et al., 2019). The field site for my study is shown

by a red arrow within the Central Block

4. A generalized stratigraphic section of the Mecca Hills from

Sylvester and O'Black-Gans (2016).

5. Possible flight orientations executed by adjusting the pitch or tilt $(\mathrm{X})$, roll (Y), and yaw or pan (Z) axes. The camera orientation is constant during tracking and variable during pedestal and sweeping flights. The red, teal, and yellow boxes in a, b, c, d, e, and f show oblique and plan-view perspectives that each configuration allows.

From Bateman et al., in prep

6. The photomosaic produced from drone flight images. Analysis in ImageJ utilized the 1-m Jacob Staff in the pop-out photo for scale. The pop-out image is a 200-x magnification of the photomosaic showing the measurement of the Jacob Staff set as the photo scale. The photomosaic did not include the entire outcrop in the upper right section of the image.

7. The workflow for Pix4Dmapper SfM processing separated into three main steps. The first two, initial processing and point cloud and mesh generation, are the most important.

8. Example of the data output from three manually chosen points defining

a plane in the LIME. The coordinates are "project coordinates" rather than "global coordinates". LIME automatically reduces the origin of the 3D textured mesh to coordinates that are close to $(0,0,0)$ using the following operation: Project $(\mathrm{XYZ})=$ Global $(\mathrm{XYZ})-\operatorname{offset}(\mathrm{XYZ})$ 25 
9. The five lithofacies identified in the field. (A) Red arrow pointing at shale facies (B) Red arrow pointing at the interbedded sand and mud facies (C) Medium-grained sandstone with a finger for scale (D) Coarse-grained sandstone with a finger pointing to a bed displaying pebble lag (E) Pebbly sandstone with a finger for scale.

10. Five different stratigraphic sections of independently measured sections. From left to right, these are: (A) field measurements, (B) photomosaic, (C) low-resolution DOM, (D) high-resolution DOM, and (E) high-resolution with video DOM. The red line in each section is the angular unconformity. All stratigraphic sections start with the same basal unit.

11. Pie diagrams for the relative proportions of each lithofacies observed for the five separate methods between marker a and $h$. This is calculated as the total relative stratigraphic thickness of each lithofacies. (A) Field measurements (B) Photomosaic (C) Low-resolution DOM.

(D) High-resolution DOM. (E) High-resolution with video DOM.

12. Oblique views of the low-resolution DOM. Note the car in the bottom center area in $\mathrm{B}$. The orientation is shown in the lower left where $\mathrm{x}$ (easting) is red, $\mathrm{y}$ (northing) is green, and z (elevation) is blue. (A) Shows the densified point cloud and (B) shows the 3D textured mesh

13. Oblique views of the high-resolution DOM. The orientation is shown in the lower left where $\mathrm{x}$ (easting) is red, $\mathrm{y}$ (northing) is green, and $\mathrm{z}$ (elevation) is blue. (A) Shows the densified point cloud and (B) shows the 3D textured mesh. Note the textured mesh fills in a lot of the missing data in the dense point cloud.

14. Oblique views of the high-resolution with video DOM. The orientation is shown in the lower left where $x$ (easting) is red, $y$ (northing) is green, and $z$ (elevation) is blue. (A) Shows the densified point cloud and (B) shows the 3D textured mesh.

15. Planes created in LIME that were used for the true thickness measurements.

(A) Planes for low resolution DOM. (B) Planes for high resolution DOM.

(C) Planes for high resolution with video DOM.

16. Visualization of planes and points from the MATLAB workflow that calculated true thicknesses based on the three points that created each plane in LIME. The planes were placed so that they intersected each bed with a GCP. The points seen on the planes are the three upper and three lower points for each plane. (A) Low resolution DOM. (B) High resolution DOM.

(C) High resolution with video DOM. 51

17. The strike, azimuth of dip direction, and the dip angle values measured using the high-resolution DOM for (A) ten planes below the unconformity and $(B)$ ten planes above the unconformity.

18. Comparisons of the original UTM coordinates of the GCP markers (a-h) and the coordinates of the markers after the SfM process. Most of the variations 
from the locations of the DOMs compared to the locations of the GCPs are shown in the northing direction. (A) Shows the (XYZ) coordinates and (B) shows the easting $(\mathrm{m})$ on the $\mathrm{x}$-axis and the northing $(\mathrm{m})$ on the $\mathrm{y}$-axis.

19. The five stratigraphic columns between the orange GCPs. They are labeled as markers a-h and represent meters below the unconformity. (A) Field measurements, (B) Photomosaic, (C) Low-resolution DOM, (D) High-resolution DOM, and (E) High-resolution with video DOM.

20. True thickness measurements from MATLAB for each DOM. The layers represent the thicknesses between two planes generated in LIME. Layer 1 is the thickness between planes $a-b$, layer 2 is the thickness between planes $b-c$, layer 3 is the thickness between planes $\mathrm{c}-\mathrm{d}$, layer 4 is the thickness between planes d-e, layer 5 is the thickness between planes e-f, layer 6 is the thickness between planes $\mathrm{f}-\mathrm{g}$, and layer 7 is the thickness between planes $\mathrm{g}$-h, The six data points for each layer represent the distance from the 3 points on the lower bed to the upper bed and the three points from the upper bed down to the lower bed. The single points observed in layers $1,3,4,5$, and 6 indicate that the thickness measurements were similar because the planes were parallel and the multiple points in layers 2 and 7 for the low-resolution and high-resolution as well as layer 2, 3, 4, and 7 in the high-resolution with video DOM indicate large ranges in the six calculated thickness measurements due to sub-parallel bedding planes

21. Calculated thicknesses from the stratigraphic measurements for the DOMs, the photomosaic, and the field, along with the thickness calculated between bedding planes in the high-resolution DOM using the LIME planes technique. The solid lines for the LIME measurements represent the range of thickness measurements due to the bedding planes being subparallel. 66

22. Comparisons of the quality and colors of the drone images and the 3D textured meshes for the low-resolution DOM and the high-resolution DOM. (A) and (D) are drone images used in the SfM processing. (B) and (E) are images of the same areas seen in the low-resolution DOM and (C) and (F) are images of the same areas seen in the high-resolution DOM.

The triangle meshes smooth out the surfaces reducing the detail that is observable in original photos or in the field.

23. Comparisons of the lithology between markers a-h for each method. Note the pebbly sandstone was only seen in the field observation and the general sandstone with no associated grain size was seen in the low-resolution DOM and high-resolution with video DOM. 


\section{CHAPTER 1}

\section{INTRODUCTION}

The orientation, vertical and lateral extent, and friability of outcrops are important factors that determine whether outcrops are accessible for geologic research. Data collection in the field requires that safety be prioritized, and small unmanned aerial vehicles (sUAVs,) also commonly known as drones, provide opportunities to collect data from outcrops that are otherwise difficult or impossible to observe safely (Nieminski and Graham, 2017; Mezghani et al., 2018; Senger et al., 2020). Further, drone images and videos can be processed via digital photogrammetry, such as Structure from Motion (SfM), to produce a georeferenced 3D digital outcrop model (DOM) (Whitmeyer et al., 2010; Westoby et al., 2012). DOMs, also known as virtual outcrop models, are manipulatable digitized outcrops that allow users to study and extract geologic data from the outcrop using various view directions and magnifications.

While drones are not the only way to acquire DOMs, they are more accessible and reliable than other methods such as terrestrial and aerial light detection and ranging (LiDAR) (Johnson et al., 2014; Cawood et al., 2017). Aerial LiDAR can penetrate vegetation more than terrestrial LiDAR via sensors that record only the last returns of a laser pulse, thus effectively removing returns from overlying vegetation (Johnson et al., 2014). Terrestrial LiDAR cannot remove all vegetation, but the scanners are movable and allow for optimal viewing positions (Johnson et al., 2014). LiDAR maps thousands of highly accurate data points per second, at scales ranging from centimeters to kilometers, which provides a well understood and valuable data collection method in the field (Rarity 
et al., 2014). A major disadvantage to using LiDAR in geosciences is that they are very expensive - even terrestrial scanners are a minimum of thousands of dollars (Johnson et al., 2014).

An advantage of using an sUAV for fieldwork is that there are different forms of sUAVs which range in affordability and ease of use. Types of drones commonly used in the geosciences include powered paragliders, blimps, kites, balloons, fixed-wing drones, and rotary-wing drones (Ouédraogo et al., 2014). In contrast to LiDAR, drones are much more affordable, commercially available, and provide higher spatial resolution for DOMs as they can fly at lower altitudes (Westoby et al., 2012; Johnson et al., 2014). In addition, drones flight paths can be easily designed to include a diverse set of view angles, thus mitigating likely gaps in data due to obstructions. Though many LiDAR systems employ cameras to map color imagery onto the LiDAR point cloud, drone platforms provide a high degree of flexibility in choosing the camera system that best serves the application. The primary disadvantages to drone use are the inability to easily remove the impact of vegetative cover and that flight depends heavily on environmental factors like wind speed, temperature, Federal Aviation Administration (FAA) regulations for the desired flight area, and time of day which affects lighting in images. In all, drones are useful for efficient mapping, increased data collection, and studying Earth's processes in areas that are not easily accessed (Bond et al., 2007; Westoby et al., 2012; Hansman and Ring, 2019). 


\subsection{Structure from Motion Photogrammetry}

Structure-from-Motion (SfM) with Multi-View Stereo (MVS) was originally developed for the computer vision and visual perception collective and became more popular alongside the development of automatic feature matching algorithms (Spetsakis and Aloimonos, 1991; Boufama et al., 1994; Szeliski and Kang, 1994; Bilmes et al., 2019). It is a type of photogrammetric technique that is based on stereoscopy which allows the determination of 3D structures from overlapping images (Trinks et al., 2005; Favalli et al., 2012; Westoby et al., 2012; Bistacchi et al., 2015; Cawood et al., 2017; Chesley et al., 2017).

Traditionally, the SfM procedure involves extracting 3D coordinates of image points which are then used in projection transformations that modify $2 \mathrm{D}$ coordinates to $3 \mathrm{D}$ coordinates in space or vice versa (Bistacchi et al., 2015; Hansman and Ring, 2019). Current SfM workflows consist of automatic feature matching via the scale-invariant feature transform (SIFT) for a set of images that can be taken with different cameras from several perspectives as long as there is substantial overlap between the images (Lowe 1999; Lowe 2004; Bistacchi et al., 2015; Chesley et al., 2017; Nesbit et al., 2018; Bilmes et al., 2019). Successful triangulation of feature coordinates results in a sparse point cloud which also contains information about the camera specifications like geometry, optical information, and spatial orientation (Chesley et al., 2017; Bilmes et al., 2019). In the final stages of the workflow, a colorized dense point cloud is obtained once the tangential and spherical distortion are removed from the mathematically oriented images (Bilmes et al., 2010; Bistacchi et al., 2015; Chesley et al., 2017; Bubniak et al., 2019). 
Drone technology and flight capabilities are constantly improving. Most drones are equipped with cameras mounted on gimbals which allow operators to acquire images from numerous perspectives which is important in SfM processing. $\mathrm{DJ}{ }^{\mathrm{TM}}$ drones have flight controller systems that contain inertial measurement units (IMUs) and satellite positioning technology for advanced flight stabilization. Flight paths can be predetermined and programmed to ensure at least $60 \%$ overlap in images which optimizes the number of points used in image alignment during DOM construction. Once images with the DJI ${ }^{\mathrm{TM}}$ drone are acquired, they can be downloaded along with metadata that contains important information for SfM processing, like geolocation, coordinate systems, and optical/geometric camera specifications.

As a result of the continued growth in use of SfM, the combination of drones and $\mathrm{SfM}$ in the geosciences has provided the ability to generate high-resolution DOMs and digital terrain models (DTMs) which have proven useful in many different subfields (Chesley et al., 2017; Bilmes et al., 2019). For instance, DOMs can be projected onto planes that provide true strike and dip orientations while preserving the outcrop scale and geometry (Bellian et al., 2005; Groshong Jr, 2006). Another important aspect of using DOMs in geoscience is the ability to generate reconstructions of outcrops in inaccessible areas like environments with hazardous conditions, or even on other planets (Jordan, 2019; Caravaca et al., 2019). Furthermore, because of their high data density, DOMs support Bayesian statistical analysis such as the analysis used by Hilley et al. (2010) to infer the fault geometry and slip accounting for the Raplee Ridge anticline in Utah. Similarly, Anderson and Segall (2013) used DOMs jointly with other field measurements captured over multiple years to model the magma chamber responsible for deformation of the Mount 
Saint Helens volcanic edifice. In both studies, though care had to be taken to assess which parts of the DOMs were relevant to the analysis, the DOMs were critical to Bayesian modeling because they provided a large (measurement density and extent) data set for model testing not available from traditional field measurements alone. For instance, at Raplee Ridge, the DOM required by the analysis must represent the surface of a stratigraphic surface deflected by underlying fault slip. Though overall useful, dependable geologic interpretations rely on the quality of the constructed DOMs or DTMs along with supporting observations that confirm data such as observations from fieldwork (Chesley et al., 2017; Bilmes et al., 2019).

Generally, drones with powerful specifications are more expensive, but depending on the type of project or quality of DOM desired, they are not always necessary. If a project requires high-resolution images, enhancing low-resolution images could be possible using computational super-resolution imaging reconstruction. Multiple low-resolution images that are noisy and/or blurred can be combined to reconstruct a higher resolution image (Sunkara et al., 2011). Since each initial pixel intensity is an average of the features within the pixel footprint, smaller pixels can be extracted by solving for the pixel intensities that best represent the information from the set of intensities of overlapping initial pixels. Additionally, commercial processing programs are very expensive, but there are opensource programs available (de Paor, 2016). Open-source programs might need multiple steps including additional programs to process the images and generate a model, but workflow implemented in commercial programs like Pix4Dmapper and Agisoft Metashape can be replicated. This saves money, although it may be less efficient and take longer than the commercial programs. Lastly, there are multiple algorithms to work with for SfM 
processing and open-source programs share those algorithms and steps while the commercial programs do not entirely disclose the algorithms they use during each step. Namely, Pix4Dmapper disclosed that they use SfM algorithms like SIFT, but that they also apply additional algorithms for all processing steps (Lowe 1999; Lowe 2004; Nesbit et al., 2018; Strecha et al., 2012).

\subsection{Sedimentology and Stratigraphy with Drones}

The integration of drones and SfM to augment fieldwork is increasingly being used for data collection and interpretation, especially for friable sedimentary rocks in areas with sparse vegetation over large distances. Many geoscience-related studies using drones focus on digital field mapping (e.g. Pavlis et al., 2017; Nesbit et al., 2018), mapping active geomorphic processes such as landslides using differential imaging, monitoring seismic hazards (Cirillo, 2020), or other structural-related projects (e.g. Maerten et al., 2001; Bemis et al., 2014; Vollgger and Cruden, 2016; Triantafyllou et al., 2019), but they are also useful for sedimentary studies, including, but not limited to, stratigraphic analyses for oil exploration, clinoform mapping, measurements of lake level changes, meander belt reconstruction, fluvial architecture and facies mapping, mapping of glacial deposits, and sedimentary growth strata (e.g. Labourdette and Jones, 2007; Fabuel-Perez et al., 2010; Calvo and Ramos, 2014; Westoby et al., 2015; Chesley et al., 2017; Durkin et al., 2017; Nieminski and Graham, 2017; Vázquez-Tarrío et al., 2017; Burnham and Hodgetts, 2018).

DOMs of sedimentary outcrops provide ways to study the outcrop after fieldwork is over, or during periods of inaccessibility including inclement weather, which is cheaper 
and more convenient compared to returning to the field site. Furthermore, there are programs that import 3D point clouds and support extraction of $2 \mathrm{D}$ planes from $3 \mathrm{D}$ structures (Dewez et al., 2016; Trinks et al., 2005). The attitude of a plane, which can be determined using the three-point-problem, includes information about the strike, dip, apparent dip, and pitch (McCaffrey et al., 2008). In a study comparing DOMs created by LiDAR data, drones, and compass clinometers, Cawood et al. (2017) reported that the DOM produced by drone images resulted in the greatest number of measurable bedding planes. Sedimentary outcrops are characteristically 3D - they consist of laterally stacked strata as exposed by an irregular erosional surface. The DOMs provide a consistent framework for relating field observations such as bed geometry, lithology, bedding attitude, and sedimentary structures as different locations into a set of measurements that best represent that three-dimensional geometry and thus internally consistent interpretations of the sedimentary history (Labourdette and Jones, 2007; de Paor, 2016; Zahm et al., 2016; Chesley et al., 2017; Bilmes et al., 2019).

\subsection{Geologic Setting}

The San Andreas fault (SAF) began forming approximately 30 million years ago as a result of subduction of the Farallon Plate beneath what is now California (Fuis and Mooney, 1990). It is part of the larger San Andreas Fault System (SAFS), which is a complex strike-slip fault system composed of northern, central, and southern segments (Wallace, 1990). The Salton Trough (Figure 1) is an active continental rift-related basin in southern California that presents as a northern extension of the Gulf of California from the Mexicali Valley in the southeast to the Coachella Valley in the northwest (Sylvester and 
Smith, 1987; Axen and Fletcher, 1998; Dorsey and Umhoefer, 2011; Han et al., 2016; McNabb et al., 2017; Jänecke et al., 2018). The Salton Trough began forming roughly 16 million years ago due to the interaction between the SAF and the Gulf of California Rift Zone (GCRZ) (Sylvester and Smith, 1976). The GCRZ is the northern portion of the East Pacific Rise (EPR) which is the source of separation of the Pacific Plate and the North American Plate (Sylvester and Smith, 1976). As crustal extension, sediment accumulation, and subsidence continue in the central portion of the Salton Trough, the northeast Coachella Valley region is being uplifted as a result of crustal shortening alongside strikeslip faults, including the southern segment of the SAF (Sylvester and Smith, 1987; Dorsey and Umhoefer, 2011; Han et al., 2016; McNabb et al., 2017; Jänecke et al., 2018). Wellexposed examples of this deformation in the San Andreas Fault Zone (SAFZ) are seen at the northeastern end of the Salton Trough, east of the Coachella Valley, in the Mecca Hills (Sylvester and Smith, 1987; McNabb et al., 2017). 


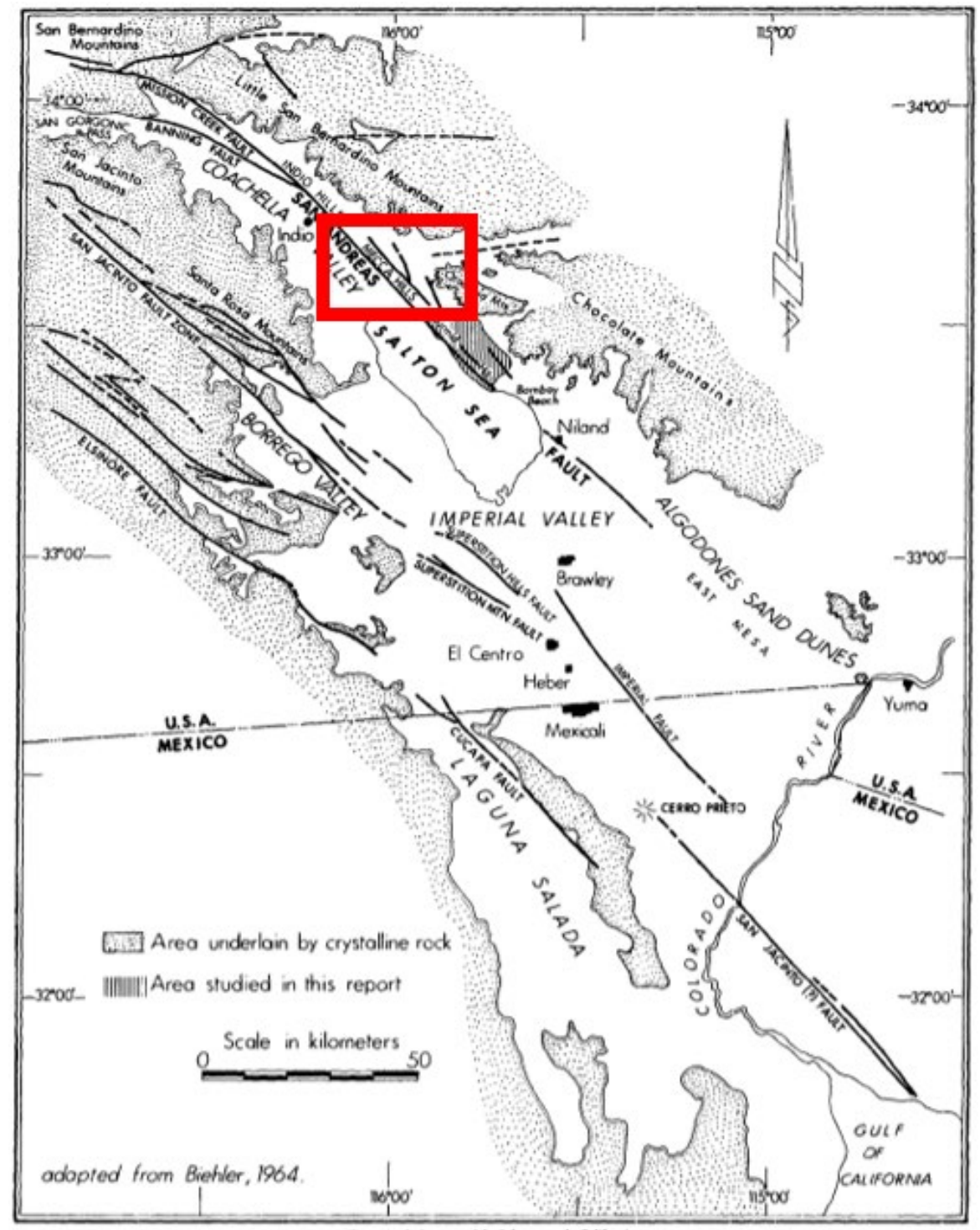

Figure 1. A map of the Salton Trough (modified from Babcock, 1974). The Mecca Hills are located within the red square.

The Mecca Hills (Figure 2) are composed of Plio-Pleistocene sediments of the Mecca, Palm Spring, and Ocotillo Formations that were deposited on basement rocks that consist of Mid-Tertiary rhyolite dikes, Mesozoic intrusive rocks, the Mesozoic Orocopia Schist, and the Proterozoic Chuckwalla Complex (Sylvester and Smith, 1987; Sylvester and O’Black-Gans, 2016; McNabb et al., 2017). 

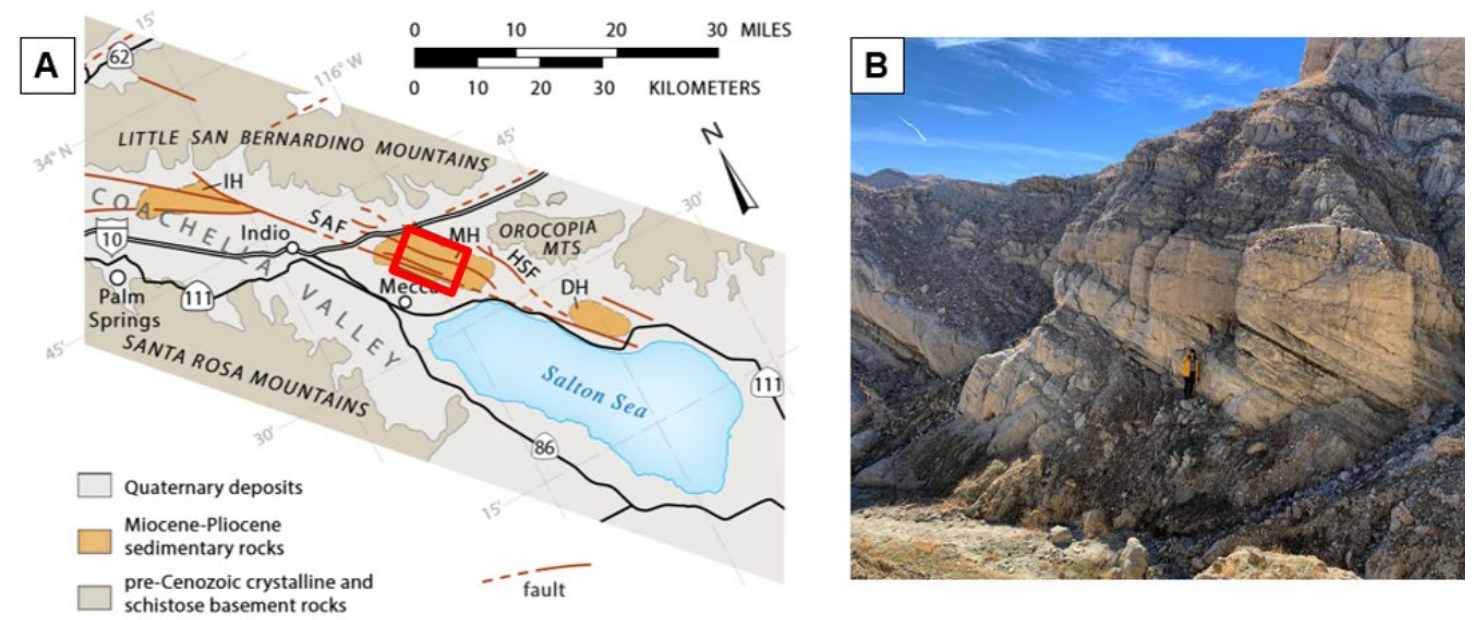

Figure 2. (A) A simplified geologic map of the Coachella Valley portion of the Salton Trough in the San Andreas fault zone. Modified from Bergh et al. (2019) after Sylvester and O'Black-Gans (2016). The Miocene-Pliocene sedimentary rocks shown in orange include the Palm Spring Fm. in Mecca Hills (MH). The Indio Hills (IH), Mecca Hills, and Durmid Hills (DH) have been uplifted by transpression along the San Andreas Fault (SAF) and the Hidden Springs Fault (HSF). The red rectangle denotes the location of the Mecca Hills, where the angular unconformity is exposed, shown in (B). (B) The unconformity between the lower and upper Palm Spring Fm. Alluvium is covering most of the deposits in the lower right portion of the image. Note person for scale in the center of the image, just below the unconformity.

The central Mecca Hills in the SAFZ is divided into three fault-bound blocks: The Basin Block, the Central Block, and the Platform Block (Figure 3; Bergh et al., 2019). The study focused on exposures of the Palm Spring Fm. within the Central Block, which is bound by the SAF and the Painted Canyon Fault. Box Canyon and Painted Canyon run roughly perpendicular to the SAF and have near-vertical cliffs of exposed basement and sedimentary rocks (Sylvester and Smith, 1987; McNabb et al., 2017; Bergh et al., 2019). 


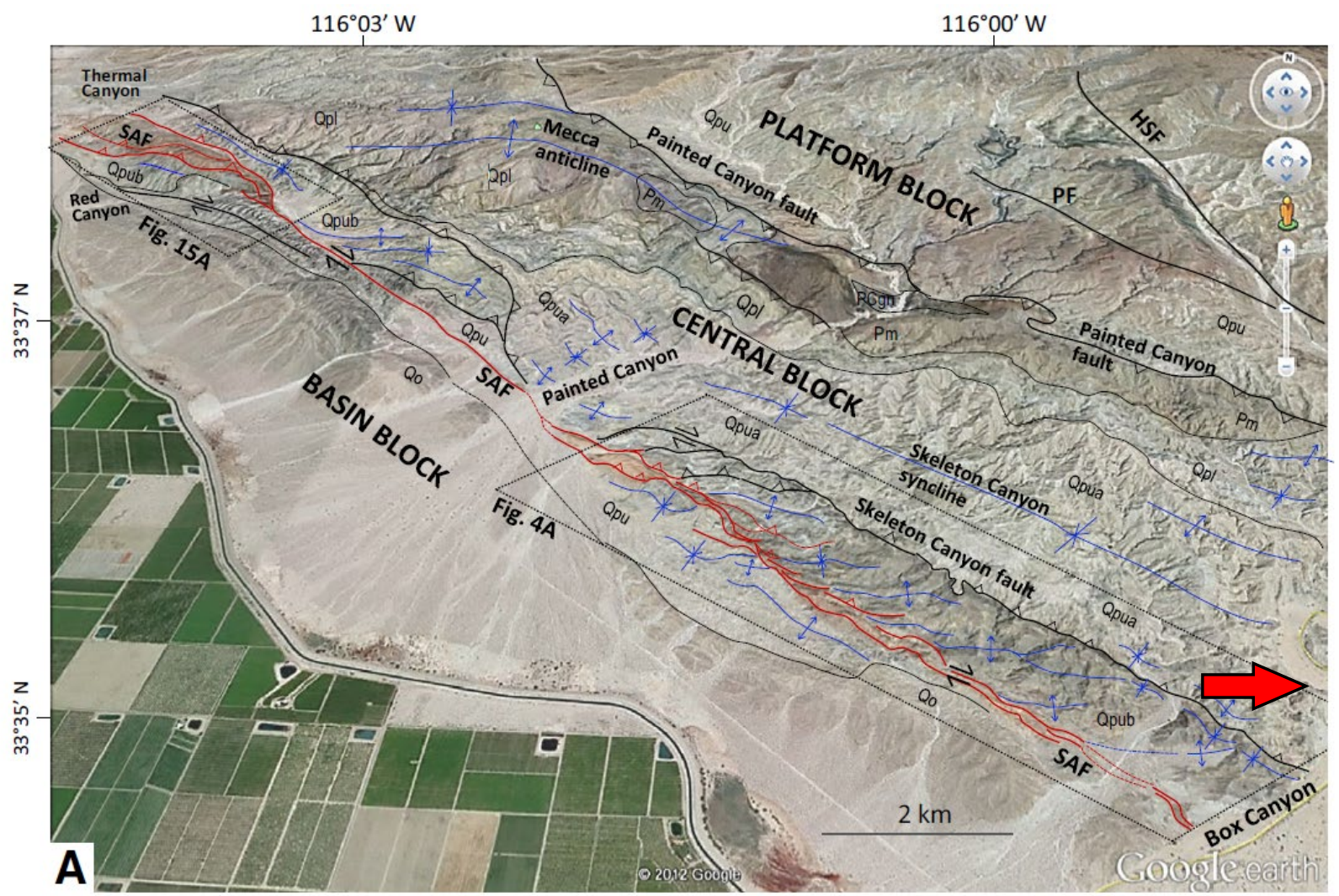

Figure 3. A Google Earth image with an interpretation of the three major crustal blocks and major faults in the Mecca Hills (modified from Bergh et al., 2019). The field site for my study is shown by a red arrow within the Central Block.

Stratigraphic units above basement rock were first mapped by Dibblee (1954) and consist of the Mecca Conglomerate, the Palm Spring Fm., and the Ocotillo Formation (Figure 4). The Mecca Conglomerate lies nonconformably over the deformed basement rocks in Painted Canyon (Sylvester and Smith, 1976; Sylvester and O'Black-Gans, 2016; McNabb et al., 2017). The Mecca Conglomerate is characterized as a reddish sandstone interbedded with reddish shale, conglomerate, and breccia (Sylvester and O'Black-Gans, 2016; McNabb et al., 2017).

The Palm Spring Fm. in the Central Block is divided into lower and upper units by an angular unconformity and a change in overall texture (Figure 4; Chang et al., 1987; 
Sylvester and Smith, 1987; Boley et al., 1994; McNabb et al., 2017) that is most easily traceable in portions of Box Canyon. The lower Palm Spring Fm. consists of matrixsupported cobble to boulder-sized conglomerates, a very coarse-grained to pebbly trough cross-bedded sandstone with interbedded medium-grained, biotite rich sandstones, and siltstones with laminations and ripples that stand out as greenish-gray layers (McNabb et al., 2017). The upper Palm Spring Fm. consists of a horizontally stratified, matrixsupported cobble to boulder conglomerate with clasts of Orocopia Schist, felsic plutonic rocks, and gneiss (McNabb et al., 2017). Both the lower and upper Palm Spring Fm. are alluvial fan deposits; however, the lower Palm Spring Fm. contains fluvial and overbank fines represented by the interbedded sandstones and siltstones (McNabb et al., 2017).

The Ocotillo Conglomerate is the youngest stratigraphic unit and is described as a very coarse and poorly lithified conglomerate composed of felsic-plutonic and Orocopia Schist clasts (Sylvester and O'Black-Gans, 2016; McNabb et al. (2017). 


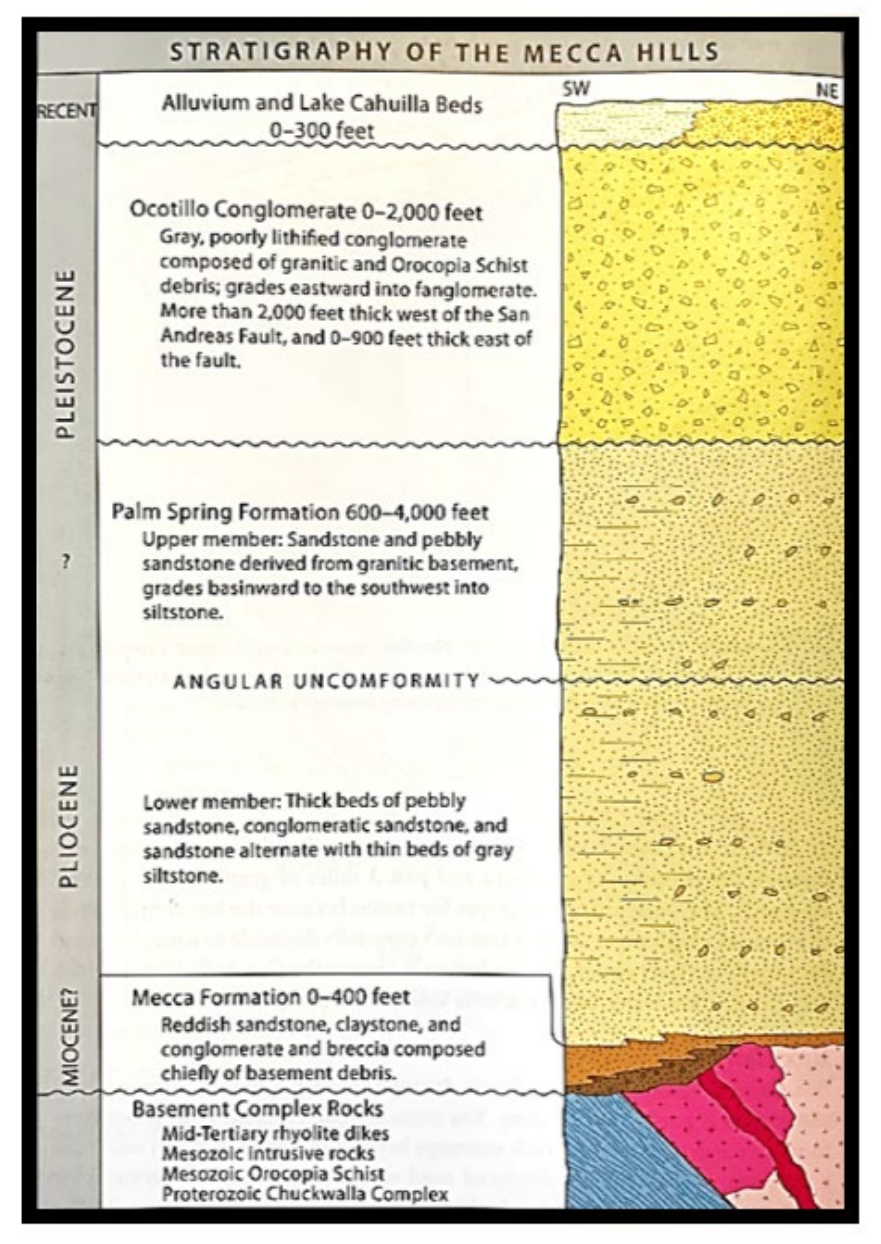

Figure 4. A generalized stratigraphic section of the Mecca Hills from Sylvester and O’Black-Gans (2016).

\subsection{Hypothesis and Significance}

I hypothesize that digital outcrop models can be used to replicate stratigraphic sections measured traditionally in the field. Consistent and accurate lithological identification may be limited by the quality and resolution of the triangulated mesh, but overall, DOMs may provide more accurate bed thickness measurements by (1) accounting 
for 3D projection and (2) their potential to span larger outcrops and increase the volume and density of thickness and attitude measurements. These attributes provide redundancy that allows a statistical assessment of measurement variability and reproducibility; it may also capture natural heterogeneity actually representative of the depositional or tectonic environment. 


\section{CHAPTER 2}

\section{METHODS}

Approximately 700 meters of section of the lower and upper Palm Spring Fm. is exposed throughout Box Canyon. Up to approximately 100 meters of section spanning from the uppermost Lower Palm Spring across the unconformity into the Upper Palm Spring were measured at a single location using five different techniques. This exposure of the unconformity was selected because it allowed access for field measurements and placement of survey markers, was clear of vegetation, and had clear line-of-site for flying the drone. Furthermore, it has sufficient three-dimensional relief to derive an accurate DOM (discussed below) but without obstructions that might compromise the model. Thus, it has all of the attributes to support comparison of traditional field-based stratigraphic measurements, photomosaic analysis, and measurements obtained from the DOM created from photos and videos.

\subsection{Field Methods}

In the field, just over 100 meters of section were measured in 10-cm increments using a 1-meter Jacob Staff, starting with the lowermost layer exposed at the far end of the outcrop near to the road. Descriptions of the sedimentary layers included texture, grain size and shape, composition, color, sedimentary structures, bedding geometry, bedding contacts, and presence or absence of fossils. Units were not sampled for laboratory analysis of the exact grain sizes or the presence or absence of fossils. Due to the change in attitude orientation above the unconformity to sub-horizontal, only 20 meters of the upper Palm 
Spring Fm. were accessible on the cliff face for direct measurement. Colleagues at University of Wisconsin-Madison placed 10 ground control points (GCPs) in the main Box Canyon site, eight of which were placed on the lower Palm Spring Fm. wall. The other two markers included the base station and a marker located on the ground in front of the wall face. The coordinates were measured using a differential Global Positioning System (GPS) and the GPS data was processed using the AUSPOS system. The base station was set up for a minimum of 8 hours at a fixed location and the rover unit remained at each GCP for 10 minutes. Each of the 8 markers from the cliff wall are labeled a through h in this study, with marker a on the lowermost stratigraphic unit, and the rest labeled alphabetically up through the section so that $\mathrm{h}$ is on the uppermost bed.

\subsection{Drone Flights}

A DJI Mavic 2 Pro drone was used in the field for images and video acquisition. The Mavic 2 Pro has a Hasselblad L1D-20c camera (1-inch sensor 20 megapixels) and a video resolution of $4 \mathrm{~K}$ 10-bit HDR. It also has $\mathrm{f} / 2.8-\mathrm{f} / 11$ adjustable aperture; however, the settings used in the field were set to adjust automatically. The drone supports 31-minutes of flight time and automatically splits videos into five-minute segments. Flights were manually controlled via the live view feature on the flight controller. Supplementary specifications are detailed in Table 1. Pix4Dmapper automatically extracts the external and internal camera properties from the metadata for their SfM algorithms. 
TABLE 1. DJITM MAVIC 2 PRO DRONE SPECIFICATIONS INCLUDING CAMERA PROPERTIES IMPORTED INTO PIX4DMAPPER REQUIRED FOR THE SFM WORKFLOW.

\begin{tabular}{|c|c|}
\hline \multicolumn{2}{|c|}{ Drone Specifications } \\
\hline Lens Type & Perspective \\
\hline Still Image Size & $5472 \times 3648$ \\
\hline Video Resolution 4K & $3840 \times 2160$ \\
\hline Focal Length (pixel) & 4470.83 \\
\hline Effective Pixels & 20 million \\
\hline Field of View & $\sim 77^{\circ}$ \\
\hline Aperture & $f / 2.8-f / 11$ \\
\hline ISO Range, Video & $100-6400$ \\
\hline ISO Range, Photo & $100-3200$ (auto); $100-12800$ (manual) \\
\hline Shutter Speed & $8-1 / 8000 s$ \\
\hline Principal Point $x$ (pixel) & 2736 \\
\hline Principal Point y (pixel) & 1824 \\
\hline Radial Distortion R1 & 0.00874622 \\
\hline Radial Distortion R2 & 0.0404995 \\
\hline Radial Distortion R3 & -0.0496908 \\
\hline Tangential Distortion T1 & -0.00341694 \\
\hline Tangential Distortion T2 & 0.00219427 \\
\hline GNSS & GPS + GLONASS \\
\hline Takeoff Weight (g) & 907 \\
\hline Folded Dimensions (mm) & $214 \times 91 \times 84$ \\
\hline Unfolded Dimensions (mm) & $322 \times 242 \times 84$ \\
\hline
\end{tabular}

Images and videos were taken over the span of three days. The videos were recorded before noon and the images were taken in the early afternoon. Images were taken at elevations ranging from $35-\mathrm{m}$ and $110-\mathrm{m}$ above the take-off site. In addition to different 
elevations, the camera angle and the $\mathrm{XY}$ positions were also varied to ensure that many perspectives with significant overlap between images of the outcrop were captured for successful SfM processing (Figure 5). All photos and videos were collected to fully cover the entire outcrop wall from the tip of the outcrop where the field stratigraphic column starts to the end of the outcrop where the stratigraphy flattens out. There were no environmental constraints that affected image and video acquisition. 
Tracking (fixed view direction, UAV moves freely in XYZ)
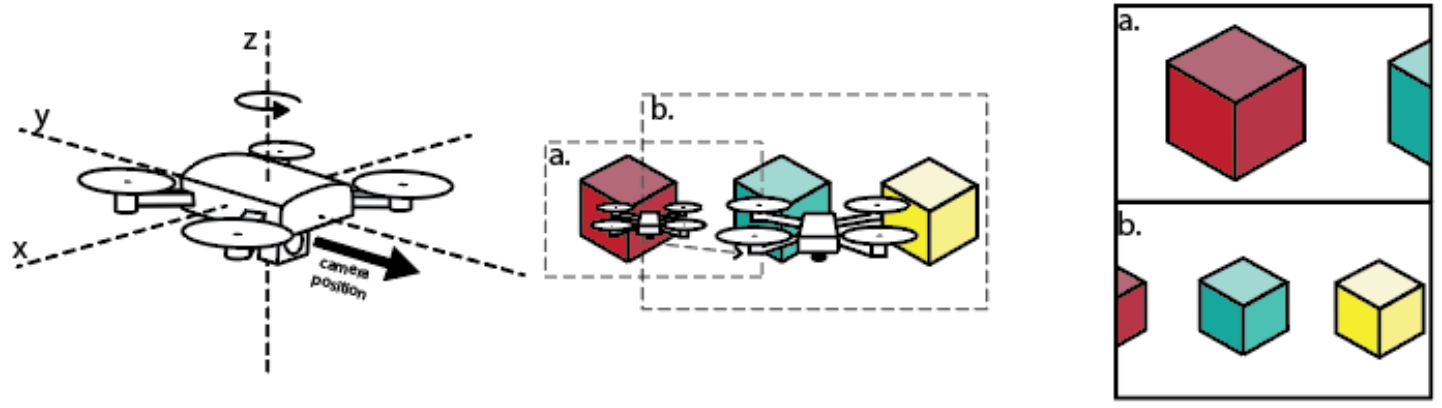

Pedestal (fixed XY position, UAV moves freely in Z with variable view direction)
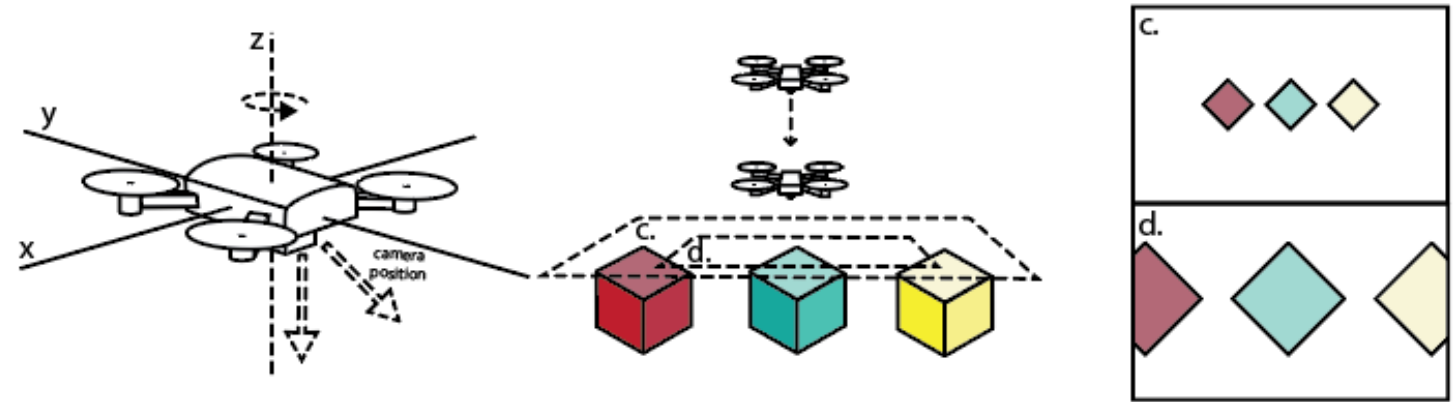

Sweeping (fixed XYZ position, UAV rotates and pans camera)
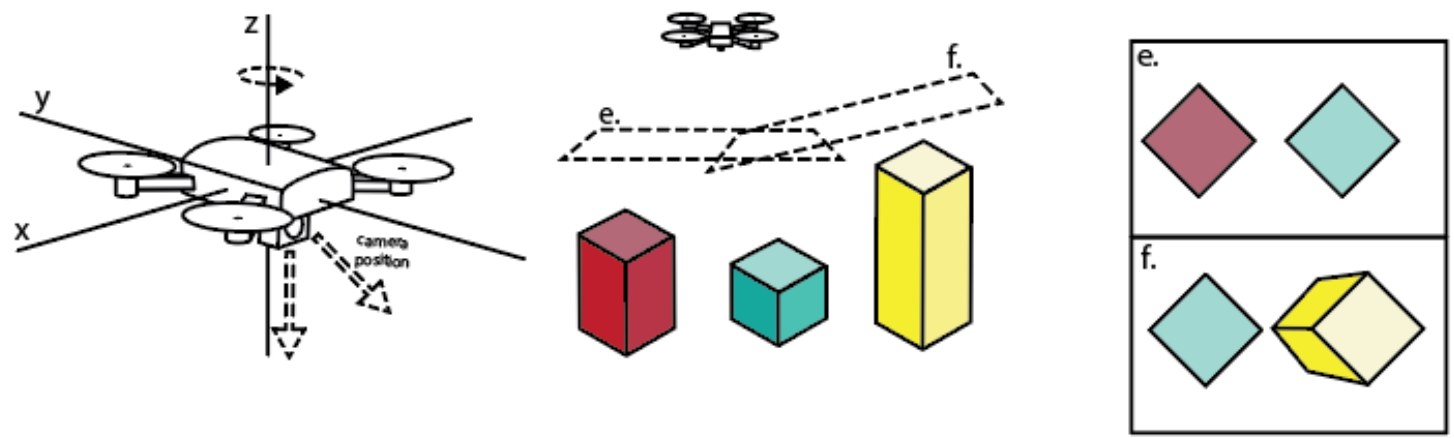

Figure 5. Possible flight orientations executed by adjusting the pitch or tilt (X), roll $(\mathrm{Y})$, and yaw or pan $(\mathrm{Z})$ axes. The camera orientation is constant during tracking and variable during pedestal and sweeping flights. The red, teal, and yellow boxes in a, $\mathrm{b}, \mathrm{c}, \mathrm{d}, \mathrm{e}$, and $\mathrm{f}$ show oblique and plan-view perspectives that each configuration allows. From Bateman et al., in prep. 


\subsection{Photomosaic Stratigraphy}

A 300 pixels per inch (PPI) photomosaic of the measured section was created in Adobe Photoshop via the Photomerge feature which stitched 47 drone images together. Then, the photomosaic was digitally scaled in ImageJ using a known distance provided by the 1-meter Jacob Staff placed along the cliff wall (Figure 6). A stratigraphic column was created using the measured bed thicknesses from ImageJ and descriptions of lithology and any resolvable sedimentary structures. Grain size was estimated based on images of the lithofacies taken in the field with grain size cards in the background.

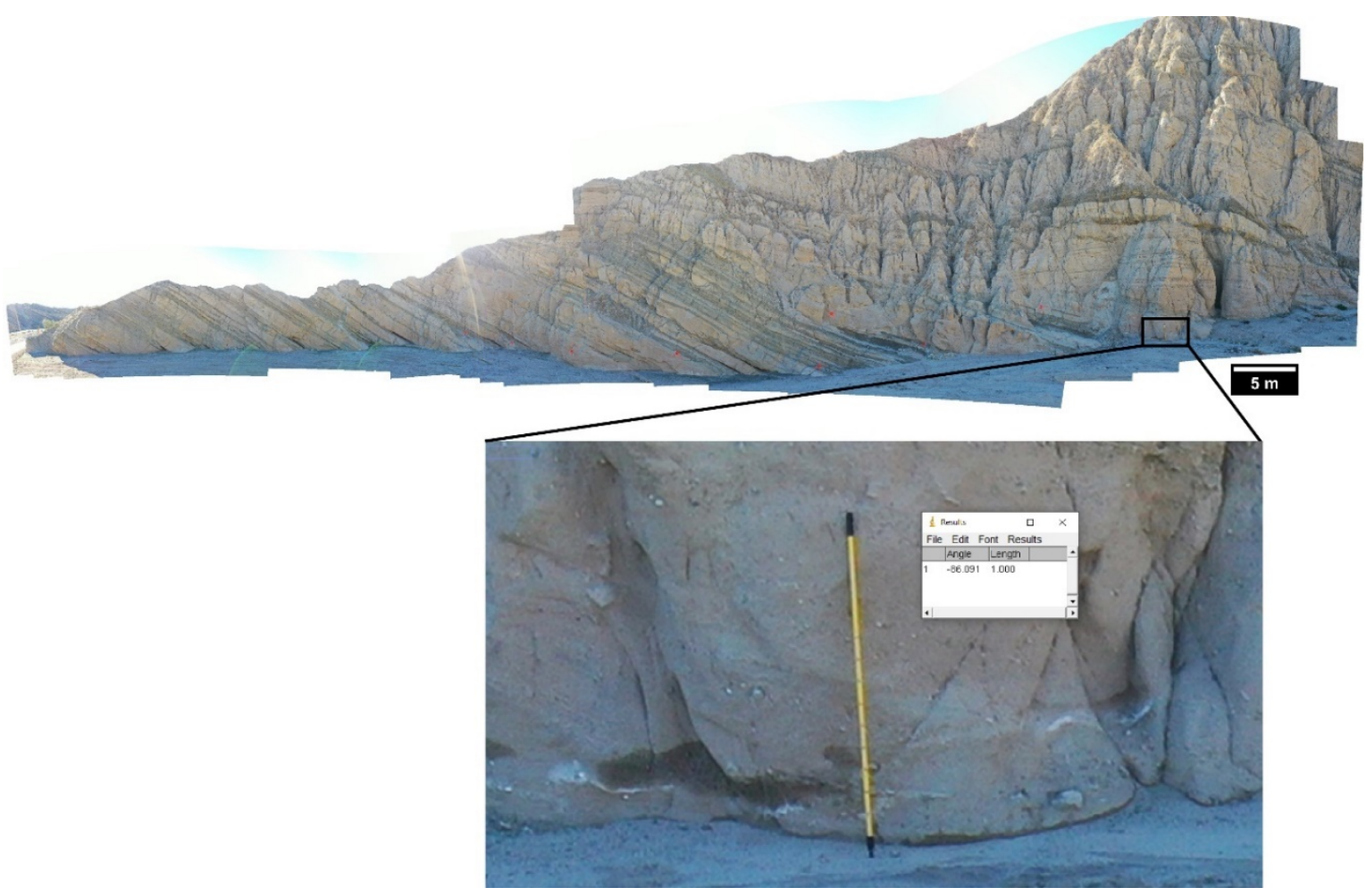

Figure 6. The photomosaic produced from drone flight images. Analysis in ImageJ utilized the 1-m Jacob Staff in the pop-out photo for scale. The pop-out image is a 200$\mathrm{x}$ magnification of the photomosaic showing the measurement of the Jacob Staff set as the photo scale. The photomosaic did not include the entire outcrop in the upper right section of the image. 


\subsection{Structure from Motion Photogrammetry and Stratigraphy}

The structure from motion (SfM) photogrammetric processing was performed in Pix4Dmapper (Figure 7) using an MSI GS66 Stealth laptop with an NVIDIA® GeForce RTX $^{\mathrm{TM}} 2070$ Max-Q Design graphics processing unit and an Intel ${ }^{\circledR}$ Core $^{\mathrm{TM}}$ i7-10750H central processing unit at $2.60 \mathrm{GHz}$ (six cores, 12 logical processors). A total of three DOMs using different data input criteria were processed as shown in Table 2. Two of the DOMs were created using 298 images, one at the low resolution (faster processing) setting, and one at the high resolution (slower processing) setting, and the third DOM was created using the same 298 images along with 452 images that were extracted every 20 frames from two drone videos: a total of 10 minutes and two seconds of video time. Only 117 out of the 298 images were geolocated and only 529 images in total were calibrated for this third DOM.

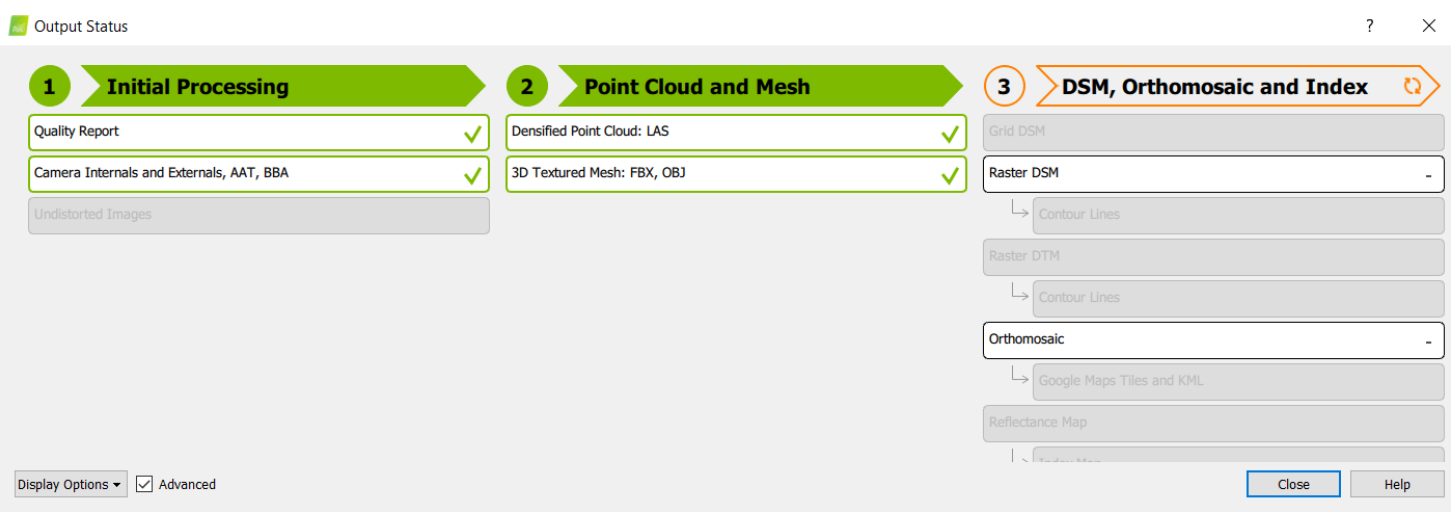

Figure 7. The workflow for Pix4Dmapper SfM processing separated into three main steps. The first two, initial processing and point cloud and mesh generation, are the most important. 
TABLE 2. QUALITY REPORT INFORMATION FOR EACH DOM PROCESSED IN PIX4DMAPPER.

\begin{tabular}{|c|c|c|c|}
\hline & Low Resolution Model & High Resolution Model & $\begin{array}{c}\text { High Resolution } \\
\text { Model with Drone } \\
\text { Video Frames + } \\
\text { Images }\end{array}$ \\
\hline $\begin{array}{l}\text { Processing } \\
\text { Speed }^{1}\end{array}$ & Fast & Slow & Slow \\
\hline $\begin{array}{c}\text { Outputs } \\
\text { Quality/Reliability² }\end{array}$ & Low & High & High \\
\hline $\begin{array}{l}\text { Average Ground } \\
\text { Sampling } \\
\text { Distance }\end{array}$ & $1.31 \mathrm{~cm} / 0.52 \mathrm{in}$ & $1.34 \mathrm{~cm} / 0.53 \mathrm{in}$ & $0.99 / 0.39$ in \\
\hline $\begin{array}{l}\text { Image Coordinate } \\
\text { System }\end{array}$ & $\begin{array}{c}\text { WGS } 84 \text { (EGM } 96 \\
\text { Geoid) }\end{array}$ & $\begin{array}{c}\text { WGS } 84 \text { (EGM } 96 \\
\text { Geoid) }\end{array}$ & $\begin{array}{c}\text { WGS } 84 \text { (EGM } 96 \\
\text { Geoid) }\end{array}$ \\
\hline $\begin{array}{l}\text { Total Number of } \\
\text { Calibrated and } \\
\text { Geolocated } \\
\text { Images }\end{array}$ & 298 & 298 & $529^{4}$ \\
\hline $\begin{array}{l}\text { Median Number } \\
\text { of Keypoints per } \\
\text { Image }\end{array}$ & 6232 & 61920 & 21130 \\
\hline $\begin{array}{l}\text { Number of 3D } \\
\text { Densified Points }\end{array}$ & 1528718 & 26803033 & 17912673 \\
\hline $\begin{array}{l}\text { Time for Point } \\
\text { Cloud } \\
\text { Densification }\end{array}$ & $12 \mathrm{~m}: 01 \mathrm{~s}$ & 02h:20m:53s & 01h:09m:21s \\
\hline $\begin{array}{l}\text { Time for 3D } \\
\text { Textured Mesh } \\
\text { Generation }\end{array}$ & $02 m: 46 s$ & $11 \mathrm{~m}: 39 \mathrm{~s}$ & $08 m: 42 s$ \\
\hline
\end{tabular}

${ }^{1}$ The processing speed and quality of outputs descriptions are automatically provided by Pix4DMapper in a quality report that is generated at the end of processing.

${ }^{2}$ Processing template descriptions given by Pix4DMapper. The templates included fast processing speed for a low-quality DOM and a slow processing speed for a high-quality DOM.

${ }^{3}$ The image coordinate system was the same for each DOM and that information was routinely imported from the metadata.

${ }^{4}$ The high resolution with video DOM used more images than the low-resolution and high-resolution DOMs since images were extracted from the videos. 
The latitude, longitude, and altitude of the orange GCPs were imported into each DOM project to increase the accuracy of the project. Stratigraphic measurements were completed in Pix4DMapper by creating polylines on the 3D textured mesh that was created from the dense point cloud. Bedding measurements from Pix4DMapper were used with the DOM image to make a stratigraphic column for each of the 3 models (low resolution, high resolution, and high resolution with video).

\subsection{Stratigraphic Logs}

Observations and measurements for all 5 techniques (field, photomosaic, and 3 DOMs) were recorded with SedLog, which is a free software written in Java that allows the user to create stratigraphic logs that can be exported as PDF, Scalable Vector Graphic (SVG), or JPEG files (Zervas et al., 2009). Data can either be added directly in the program or imported in a Comma Separated Values (CSV) format (Zervas et al., 2009). In this study, digital and field measurements were imported in the CSV format and exported as 1:100 scale graphic sedimentary logs to Adobe Illustrator. Logs resulting from all five techniques are aligned for comparative analysis, as well as interpretation of the resulting sequences.

\subsection{Bedding Measurements Using LIME}

LIME is a Norwegian-based high-performance software for visualizing and interpreting 3-D data sets (Buckley et al., 2019). Triangle meshes created in Pix4Dmapper were imported into LIME for visualization and measurement of bedding orientation. LIME requires three points to measure each plane in the DOM. The three points were distributed 
along well-defined bedding planes with care taken to position them as far along the bed as possible to define the plane with the least ambiguity that passed through each GCP marker on the cliff wall for a total of eight planes on each of the three DOMs. LIME allows for easy rotation of the DOM to ensure the chosen $x y z$-coordinates fit the DOM on both sides of the outcrop which results in less modification to the points after calculation. Additionally, any point can be modified if necessary. Once three points on the DOM are placed, a plane is calculated and plotted on the DOM (Figure 8). The dip, dip direction, and strike are calculated and exported for further analysis. Lastly, on the high-resolution DOM, 10 independent planes that were identified from well-defined bed contacts below the unconformity and 10 planes above the unconformity were placed to measure the dip, dip direction, and strike of these beds. 


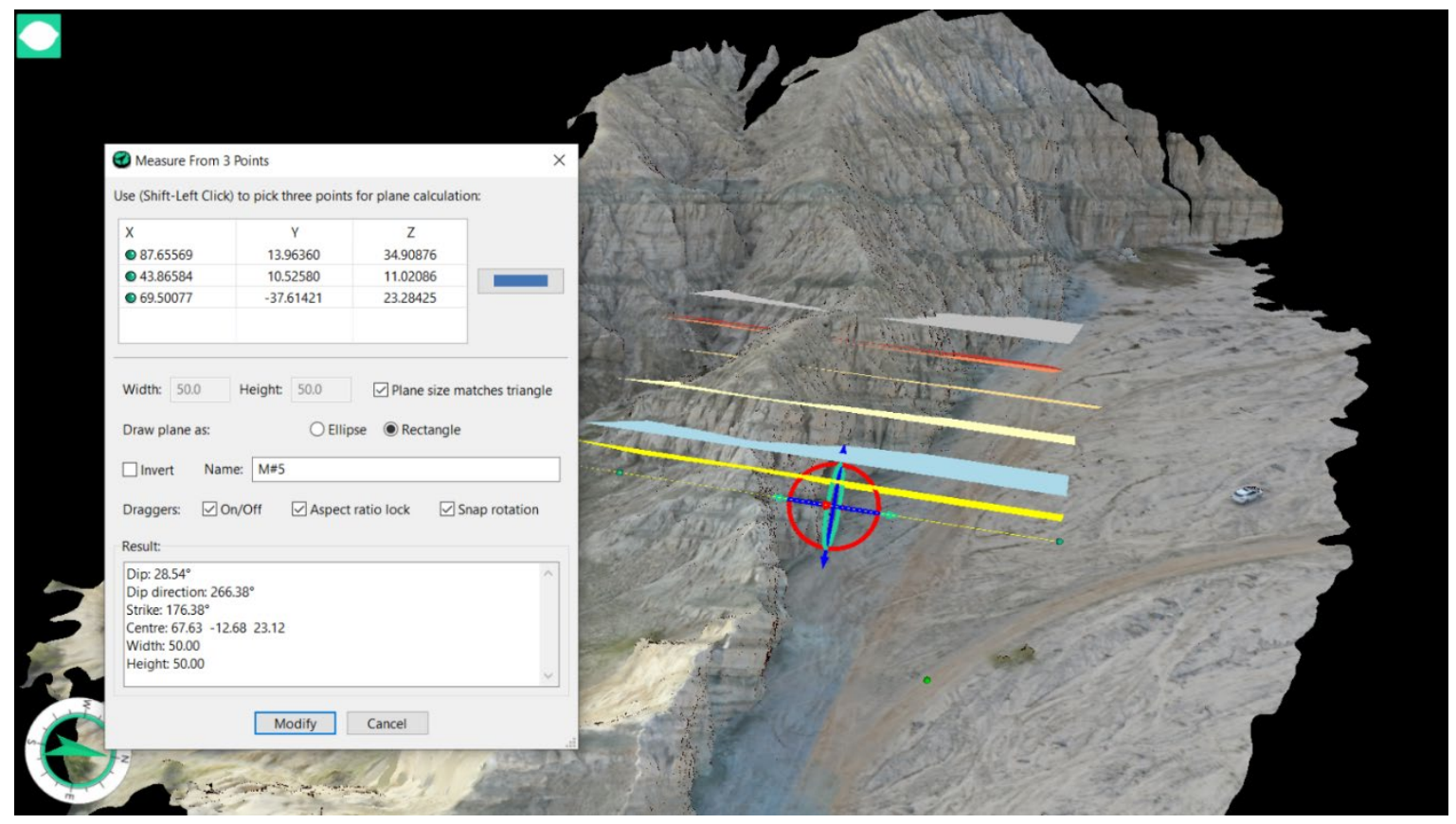

Figure 8. Example of the data output from three manually chosen points defining a plane in the LIME. The coordinates are "project coordinates" rather than "global coordinates". LIME automatically reduces the origin of the 3D textured mesh to coordinates that are close to $(0,0,0)$ using the following operation: Project $(\mathrm{XYZ})=$ Global $(\mathrm{XYZ})-$ offset $(\mathrm{XYZ})$.

\subsection{Spacing and Attitude of Planes from Survey Points}

A MATLAB workflow was created to calculate representative thicknesses between two planes (Appendix A). Successive bedding planes are each defined by three survey points obtained from the DOM and recorded in an Excel file. Subtracting the first point from the other two defines two vectors that describe their relative position in a common plane. The cross product of these two vectors results in the upward pointing normal vector, which is used to define the equation representing this plane and also to calculate the strike and dip. This procedure is repeated for the points representing each successive bedding plane (implemented within the subscript Appendix A: WORKFLOW_thickness.m). The planes were defined by three points and resulting strike and dip values for each of the 8 
planes that passed through each of the 8 GCPs. This procedure can be easily generalized to work with any number of survey points on a plane using least squares or maximum likelihood regression available within MATLAB (see Appendix A: WORKFLOW_3pt_calculation_simple.m).

Next, the distance between each adjacent pair of planes is obtained to determine the thickness of each sedimentary unit. Distances are calculated by projecting a line from each survey point to the adjacent plane in a specified direction; for each plane, three points are projected so that for every pair of planes, there are six estimates of "thickness." The direction of the projected line can be treated in two ways: (1) it is taken in the direction of the normal vector to the plane on which the point resides and then projected to the adjacent plane or (2) the direction is taken as the average of the normal vectors. Since most bedding planes are not perfectly parallel either for geological reasons or due to survey errors, the six estimates capture a reasonable range of thickness within the area spanned by the three survey points for each of the adjacent planes (this analysis is implemented within the subscript Appendix A: point2plane.m called within the script WORKFLOW_thickness.m). Again, this approach can be easily generalized by replacing the 3-point calculation with a least squares fit-plane, and thus increasing the data volume and adding redundancy to allow statistical characterization.

A third option that was considered, but abandoned for this workflow, would be to calculate the plane midway between the paired planes. The midplane has the average normal vector components of the two planes it is calculated from, and its position is determined as the centroid of the two sets of three survey points defining each plane. Once obtained, all of the data can then be translated to the origin by subtracting the centroid, then 
rotated by the dip angle around the line of strike; in this transformed reference frame, the new z-value of each survey point is half the thickness (i.e., distance between the two bedding planes).

The first two options retain the original attitudes of the planes and can be visualized alongside the DOM; the third option provides the simplest visualization of thickness in the local reference frame of the layer, much like how a Jacob staff is used by a field geologist. 


\section{CHAPTER 3}

\section{RESULTS}

In the Results, the findings from each of the five techniques are presented. Each section follows the same format beginning with a full lithofacies description and culminating in a detailed stratigraphic column. The traditional field measurements are presented first and the lithofacies observed in the field are taken as ground truths for comparison to the results from the other methods. In some cases, the other methods deviated from the categories defined in the field methods, most often due to the inability to make distinctions based on features such as fossils, bedforms, or thin layers which may not be visible due to limitations of a specific technique. Each technique was independently applied, with the starting assumption of the five major lithofacies types defined in the field. This is not unlike using a literature review of prior work as the starting point for a sedimentological study.

\subsection{Field Results}

\subsubsection{Lithofacies and Stratigraphy}

In the field, over 100 beds were grouped into five lithofacies. The beds span an angular unconformity towards the top of the measured section that separates the lower Palm Spring Fm. from the upper Palm Spring Fm. The lithofacies in the lower Palm Spring Fm. consist of grey-green shale (Figure 9A), interbedded sand and mud (Figure 9B), medium- 
grained sandstone (Figure 9C), coarse-grained sandstone (Figure 9D), and pebbly sandstone (Figure 9E).
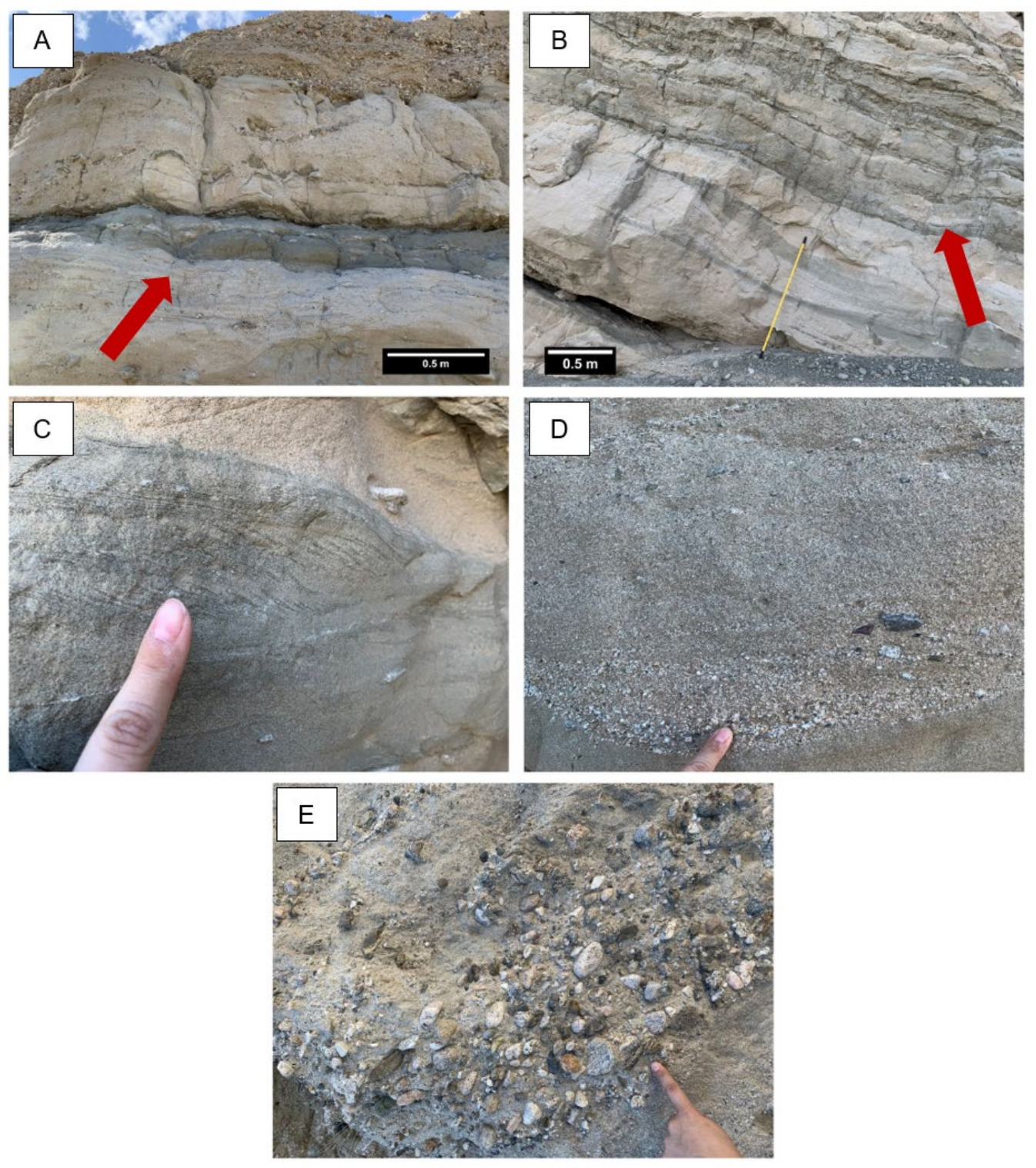

Figure 9. The five lithofacies identified in the field. (A) Red arrow pointing at shale facies (B) Red arrow pointing at the interbedded sand and mud facies (C) Medium-grained sandstone with a finger for scale (D) Coarse-grained sandstone with a finger pointing to a bed displaying pebble lag (E) Pebbly sandstone with a finger for scale. 


\section{Grey-green shale lithofacies}

The grey-green shale lithofacies include dark gray to green biotite-rich mudstone and siltstone. Individual beds may contain cross lamination, bioturbation, interbedded gypsum, and/or gastropod fossils. Several shale beds pinch in and out throughout the section, but typically have sharp bed contacts. In the uppermost part of the lower Palm Spring Fm., shale beds close to the unconformity were poorly preserved.

\section{Interbedded sand and mud lithofacies}

The interbedded sand and mud lithofacies consist of interbedded packages that range from coarse sandstone interbedded with siltstone to fine sandstone, to fine sandstone interbedded with mudstone. Sedimentary structures observed within the sand and mud include ripples, moderately graded bedding, wavy and parallel laminae in the mud, load structures, a few dropstones, flame structures, and bioturbation. Both discontinuous lenses of gypsum and conformable layers of gypsum are observed in some of the silty-mud layers. The sand is a neutral beige, and the silty mud is dark green to dark gray and is biotite-rich.

\section{Medium-grained sandstone lithofacies}

The medium-grained sandstone lithofacies consists of massive medium-grained sandstone and cross-stratified medium-grained sandstone with vertical burrows and ripples. The thick bedded medium crossbedded sandstone varies from neutral beige to beige with pink undertones near the base of the section and finer sediments with abundant biotite near to the top. The trough cross sets vary from small-scale to large-scale with sub- 
angular granitic, gneissic, and volcanic clasts that range from 10 to $20 \mathrm{~mm}$ in diameter. In normally graded beds there are commonly planar laminations, sandy drapes, low angle climbing ripples, and small-scale trough ripples. Vertical burrows filled with coarser sands from the overlying bed are present at the top. Low angle erosional scours, tabular cross stratification, and localized conglomerate concentrations are also noted in some beds.

\section{Coarse-grained sandstone lithofacies}

The coarse-grained sandstone lithofacies consists of cross-stratified coarse to very coarse-grained sandstone with pebble lag and a massive, coarse to very coarse-grained sandstone with rip-up clasts. The buff-colored coarse sandstone contains pebble-sized grains in pebble lag throughout the section. Several beds show trough cross-stratification where the stratification is evident due to coarsening in clast size. Clasts are dominated by angular to subangular felsic plutonic and gneissic clasts which range from 30 to $70 \mathrm{~mm}$ in diameter. Rip-up clasts are horizontally stratified and vary in size. Additionally, beds with slump and slide characteristics were seen above grayish-tan medium sandstones.

\section{Pebbly sandstone}

The pebbly sandstone lithofacies consists of horizontally stratified pebbly sandstone and massive pebbly sandstone. The horizontally stratified pebbly sandstone exhibits ripples and is poorly sorted with $10 \mathrm{~mm}$ to $1 \mathrm{~m}$-diameter clasts. The horizontally stratified strands of coarser clasts are chiefly composed of Orocopia schist, but also contain felsic plutonic and gneissic clasts. Several beds contain tan, medium-sized discontinuous sand lenses. Large clast-supported bases form sharp contacts with the silty mud from the 
interbedded layer. The massive pebbly sandstone is clast supported and poorly sorted with a sandy matrix. The pebbles include Orocopia schist, felsic plutonic, and gneissic clasts.

The measured section from the field includes 73.35 meters of lower Palm Spring Fm and 27.10 meters of upper Palm Spring Fm. (Figure 10A). Based on the relative thickness of the different lithofacies, this section consists of 3.6\% biotite shale, $11.6 \%$ interbedded sand and mud, $36.6 \%$ medium-grained sandstone, $21.8 \%$ coarse-grained sandstone, and $26.4 \%$ pebbly sandstone. 


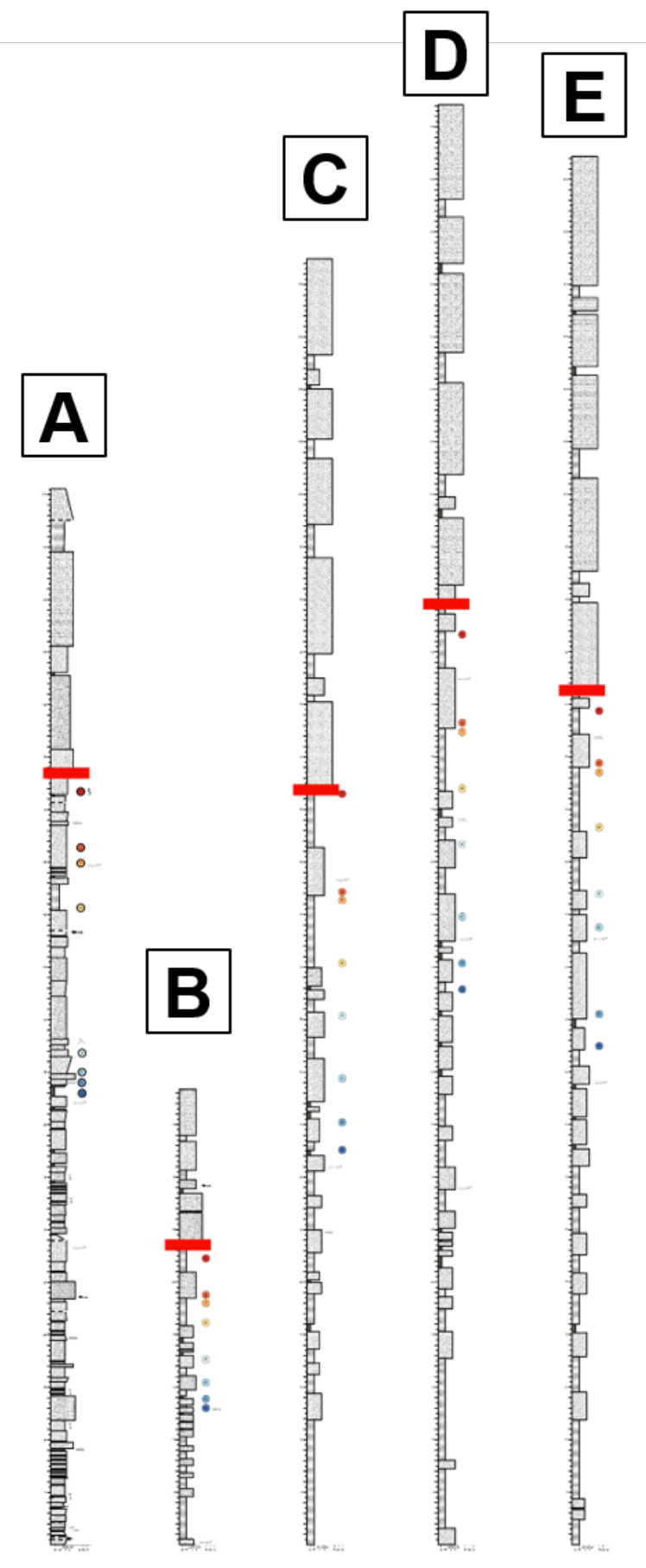

Figure 10. Five different stratigraphic sections of independently measured sections. From left to right, these are: (A) field measurements, (B) photomosaic, (C) low-resolution DOM, (D) high-resolution DOM, and (E) high-resolution with video DOM. The red line in each section is the angular unconformity. All stratigraphic sections start with the same basal unit. 
The section between the lowermost GPS marker (Marker a) and uppermost marker (Marker h), all within the lower Palm Spring Fm., consisted of 4\% biotite shale, 11\% interbedded sand and mud, 15\% medium-grained sandstone, 68\% coarse-grained sandstone, and 2\% pebbly sandstone (Figure 11A). Marker a was located on a shale bed, markers $\mathrm{b}, \mathrm{d}, \mathrm{f}, \mathrm{g}$, and $\mathrm{h}$ were located on coarse-grained sandstone beds, and marker $\mathrm{c}$ was located on a pebbly sandstone bed as identified in the field. Primary and secondary sedimentary structures are seen throughout the section, though most are classified as primary, with cross stratification as the most common. Internal stratification was evident due to grain size and color differences within beds. Secondary sedimentary structures include possible bioturbation. Contacts commonly noted between beds include both gradational and abrupt with sharp erosive bases. 

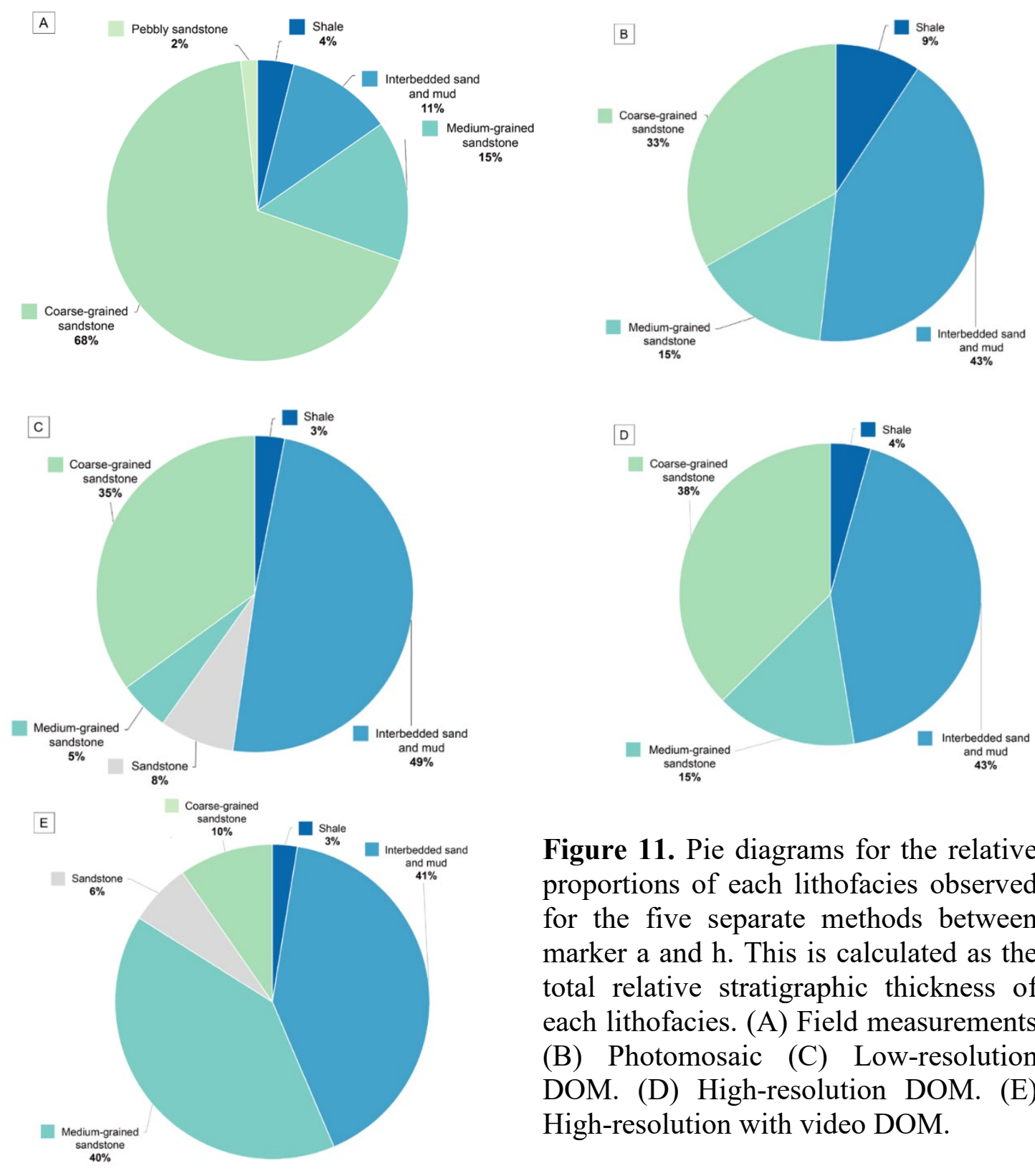

Figure 11. Pie diagrams for the relative proportions of each lithofacies observed for the five separate methods between marker a and $\mathrm{h}$. This is calculated as the total relative stratigraphic thickness of each lithofacies. (A) Field measurements (B) Photomosaic (C) Low-resolution DOM. (D) High-resolution DOM. (E) High-resolution with video DOM. 


\subsection{Photomosaic Results}

\subsubsection{Lithofacies and Stratigraphy}

The same five lithofacies described above are observed in the photomosaic, although not all bedforms, textures, and fossils recorded in the field are visible (Figure 10B).

\section{Grey-green shale lithofacies}

The grey-green shale lithofacies includes dark gray to green biotite-rich mudstone - the resolution of the image does not show differences between silty and muddy beds easily. Some of the beds have interbedded gypsum, but they are very thin and difficult interpret. Some of the shale beds near the unconformity look like they pinch in and out due to debris that has fallen from sandy layers above.

\section{Interbedded sand and mud lithofacies}

The interbedded sand and mud lithofacies consist of sandstone interbedded with mudstone. The interbedded sand and mud layer is medium to thick bedded and dominated by sandy layers. Some of the mud-rich layers contain conformable gypsum layers.

\section{Medium-grained sandstone lithofacies}

The medium-grained sandstone lithofacies consists of massive medium-grained sandstone and cross-stratified medium-grained sandstone with ripples and plane bed laminations towards the tops of beds that grade into the interbedded sand and mudstone. Only large-scale trough cross sets are distinguishable. 


\section{Coarse-grained sandstone lithofacies}

The coarse-grained sandstone lithofacies consists coarse to very coarse-grained sandstone with pebble lag and rip-up clasts. The lithology, color, and shape of the clasts are not resolvable. Rip-up clasts are horizontally oriented and vary in size.

\section{Pebbly sandstone lithofacies}

The pebbly sandstone lithofacies consists of horizontally stratified pebbly sandstone and massive pebbly sandstone. Though the boundaries of the pebbles compared to the matrix were discernable, the lithology of the pebbles could not be identified - only the colors of cobble to boulder sized clasts were identifiable.

The photomosaic shows inclined beds with an angular unconformity. The total measured section is approximately 48.38 meters, with 28.63 meters measured below the unconformity and 14.74 meters above the unconformity (Figure 10B). The section consists of $4.8 \%$ grey-green shale, $36.4 \%$ interbedded sand and mud, $19.5 \%$ medium-grained sandstone, $28.4 \%$ coarse-grained sandstone, and $10.9 \%$ pebbly sandstone. The measured section between Marker a and Marker $\mathrm{h}$ is approximately 15.61 meters and consists of $9 \%$ grey-green shale, $42 \%$ interbedded sand and mud, 15\% medium-grained sandstone, and $33 \%$ coarse-grained sandstone (Figure 11B). Marker a was located on a shale bed, markers $\mathrm{e}, \mathrm{f}$, and $\mathrm{h}$ were located on the interbedded sand and mud layers, marker $\mathrm{b}$ was located on the medium crossbedded sandstone, and markers $\mathrm{c}, \mathrm{d}$, and $\mathrm{g}$ were located on the coarsegrained sandstone beds as identified in the photomosaic. Trough and planar stratification were commonly seen in the medium-grained sandstone beds. There were more sharp contacts between beds identified than gradational contacts. 


\subsection{Digital Outcrop Models}

Three SfM models were created using different resolution templates in Pix4DMapper. The details of the quality reports for each DOM are listed below in Table 2. The "processing speed and quality of outputs" descriptions are the descriptions provided by Pix4DMapper. The image coordinate system, WGS 84 (EGM 96 Geoid), was the same for each DOM. The output coordinate system, WGS 84/UTM Zone 11N (EGM 96 Geoid), was also the same for each DOM. The high resolution with video DOM included more images than the low resolution and high-resolution DOMs since images were extracted from the videos. Run times are listed in Table 2. The high-resolution DOM required the most time for point cloud densification and 3D textured mesh generation with a time of 02hrs:20min: $53 \mathrm{sec}$ for the point cloud densification and $11 \mathrm{~min}: 39 \mathrm{sec}$ for the $3 \mathrm{D}$ textured mesh generation while the low-resolution DOM only took approximately 15 minutes in total to generate both a dense point cloud and a 3D textured mesh.

\subsubsection{Low Resolution Digital Outcrop Model}

The low-resolution DOM (Figure 12) showed some gaps in the model, particularly around the back side of the outcrop, and difficulty aligning the lower and upper part of the outcrop, but overall provided a complete section in a short amount of time. 


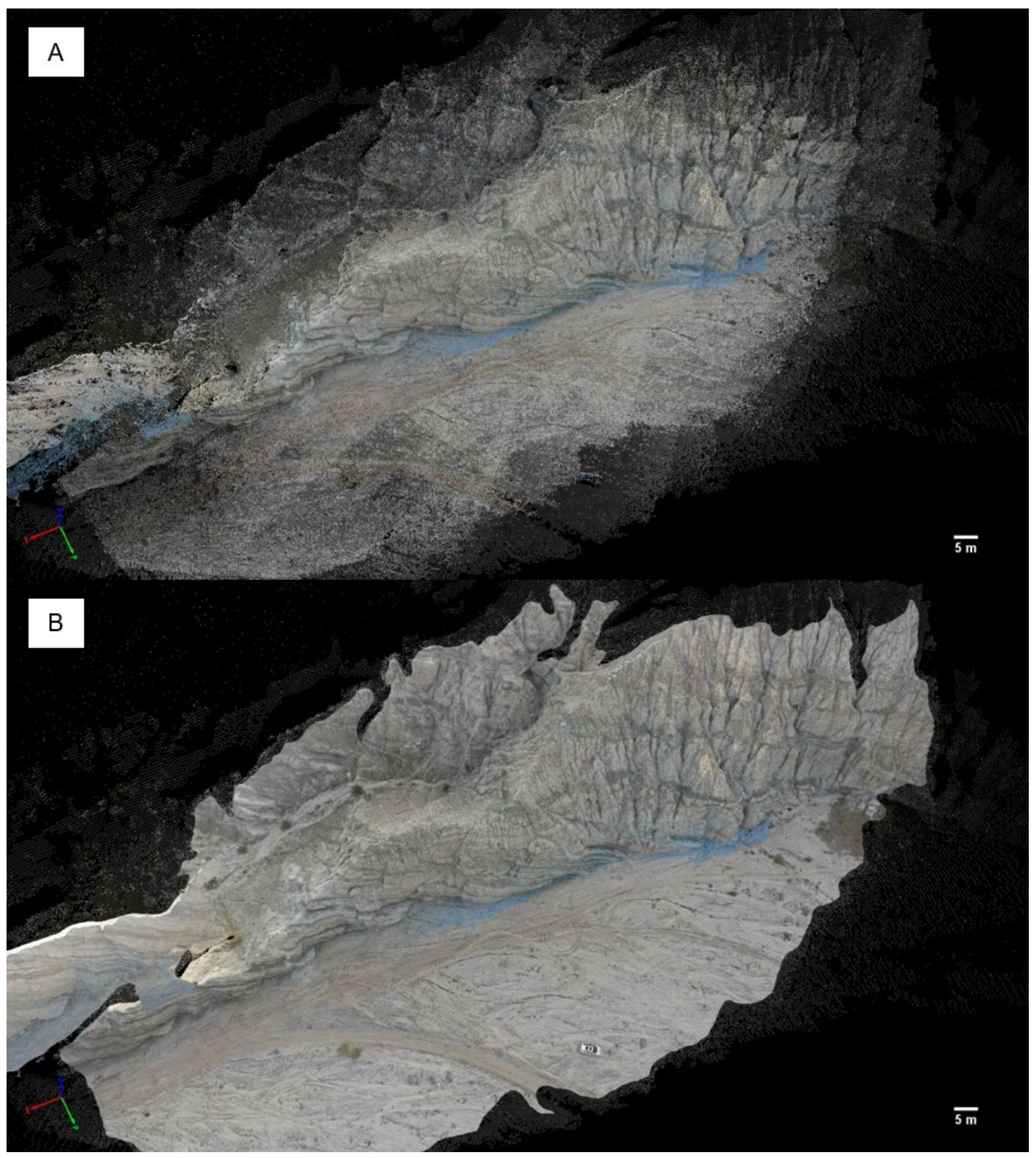

Figure 12. Oblique views of the low-resolution DOM. Note the car in the bottom center area in B. The orientation is shown in the lower left where $\mathrm{x}$ (easting) is red, y (northing) is green, and $\mathrm{z}$ (elevation) is blue. (A) Shows the densified point cloud and (B) shows the 3D textured mesh. 


\subsubsection{Lithofacies and Stratigraphy}

There were six lithofacies recorded in analysis of the low-resolution DOM. These included the same five as observed in the field, as well as a sandstone where grain size cannot be determined.

\section{Grey-green shale lithofacies}

The grey-green shale beds were dark grey and thin-bedded throughout the entire section. Additionally, interbedded gypsum was not resolvable in any of the shale beds. Some thin and white blurry lines were interpreted as the interbedded gypsum that had been observed in the field.

\section{Interbedded sand and mud lithofacies}

Interbedded sand and mud layers were mainly determined based on color differences in rhythmic bedding. In some beds, the DOM could be rotated to show differential weathering of the mud layers compared to the sandy layers.

\section{Medium-grained sandstone lithofacies}

The medium-grained sandstone was consistently beige in color throughout the section. There are no individual pebbles resolvable within the beds. Some trough crossbedding was noticeable due to differences in sediment colors as well as the trough pattern. 


\section{Coarse-grained sandstone lithofacies}

Individual grains are distinguishable in coarse-grained sandstone beds. The units are also identified based on the presence of coarse pebble lag. The types of clasts were not discernable. Imbricated mud rip-up clasts were easily seen in a few beds.

\section{Pebbly sandstone lithofacies}

Pebbly sandstone is identified by the horizontal stratification of large pebble to cobble sized clasts that range in color from light pink to predominantly white. The lithology of the pebbles could not be determined.

\section{$\underline{\text { Sandstone - no associated grain size }}$}

The last type of lithofacies observed in the low-resolution DOM was just interpreted as a sandstone based on the beige color. These beds were blurry and no grain size or bedform could be identified. Thus, it did not fit with the medium-grained or the coarse-grained sandstones.

A total of 71.8 meters of lower Palm Spring Fm. and 56.05 meters of upper Palm Spring Fm. was measured (Figure 10C). The entire measured section contained 8.7\% sandstone with no associated grain size, $2.8 \%$ grey-green shale, $39.0 \%$ interbedded sand and mud, $8.5 \%$ medium-grained sandstone, $11.7 \%$ coarse-grained sandstone, and 29.2\% pebbly sandstone. The section between GCP Marker a and GCP Marker h consisted of 8\% sandstone with no discernable grain size, 3\% grey-green shale, 49\% interbedded sand and mud, 5\% medium-grained sandstone, and 35\% coarse-grained sandstone (Figure 11C). Markers a, e, f, and $\mathrm{h}$ were located on interbedded sand and mud beds, Marker $\mathrm{b}$ was 
located on a bed of sandstone with no associated grainsize, and Markers c, d, and g were located on beds of coarse-grained sandstone as determined in the low-resolution DOM. Most bedding contacts were distinguished from each other based on grain size differences and color.

\subsubsection{High Resolution Digital Outcrop Model}

The high-resolution DOM (Figure 13) is complete, with a clear continuous section, and the slot canyon behind the outcrop is also fully resolved. 


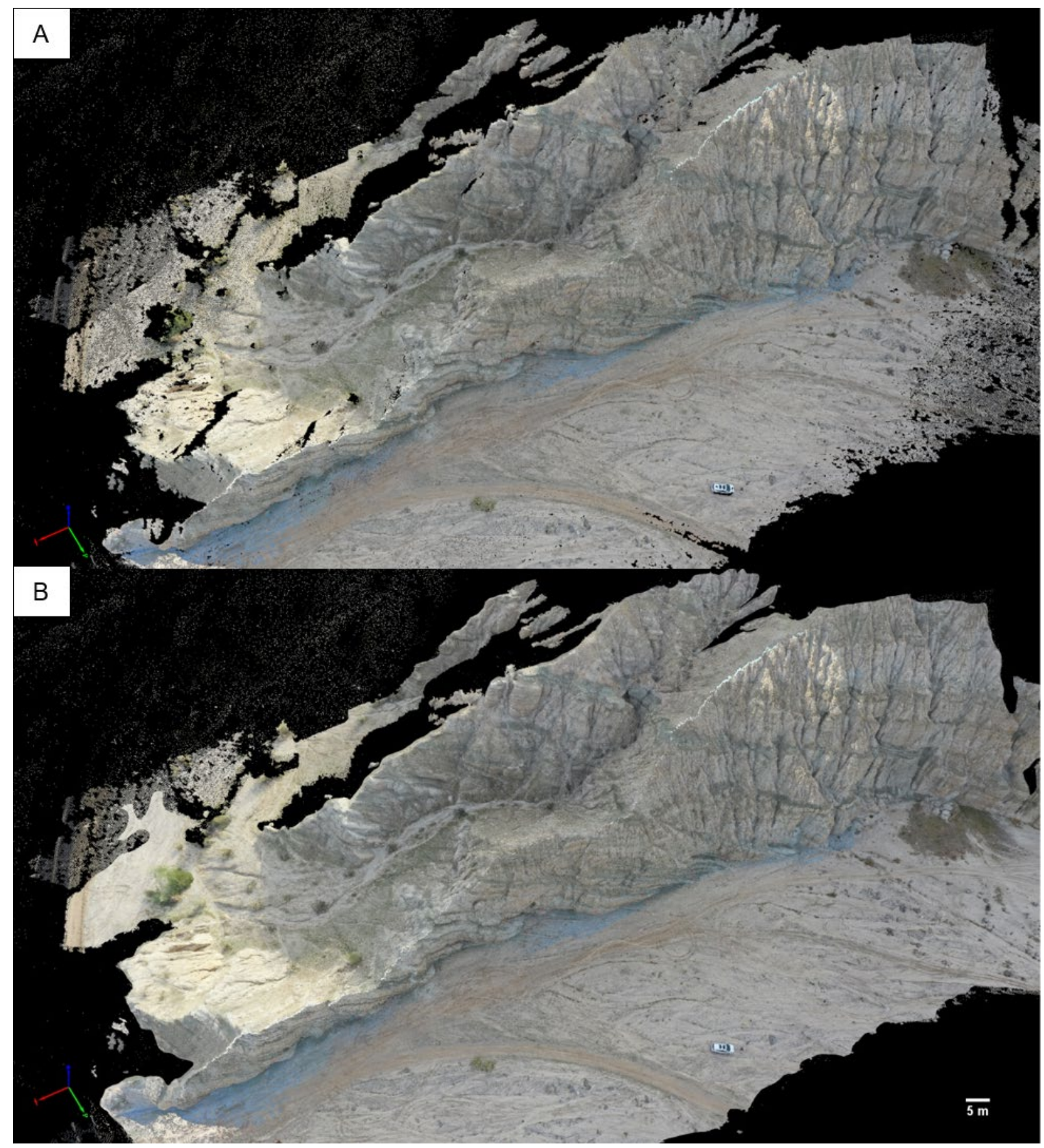

Figure 13. Oblique views of the high-resolution DOM. The orientation is shown in the lower left where $\mathrm{x}$ (easting) is red, y (northing) is green, and z (elevation) is blue. (A) Shows the densified point cloud and (B) shows the $3 \mathrm{D}$ textured mesh. Note the textured mesh fills in a lot of the missing data in the dense point cloud. 


\subsubsection{Lithofacies and Stratigraphy}

There are five lithofacies identified in the high-resolution DOM. All units from the field are identified in the high-resolution DOM.

\section{Grey-green Shale}

The shale layers were dark grey, thin bedded, and sparse throughout the entire section. There were no resolvable features or fossils or distinguishable types of bedding. The shale layers were identified mainly due to color and weathering compared to surrounding competent sandstone.

\section{Interbedded sand and mud}

Interbedded sand and mud layers are mainly determined based on color differences in rhythmic bedding. In some beds, the DOM could be rotated to show differential weathering of the mud layers compared to the sandy layers. Overall, most beds were dominated by sand which was determined based on the beige color compared to the dark grey muddy interbeds.

\section{Medium-grained sandstone}

The medium-grained sandstone is beige in color with both planar laminations and trough crossbedding. Clasts that slightly stand out compared to the finer-grained lithofacies are resolvable, but not as large as clasts seen in the coarse-grained sandstone or pebbly sandstone beds. Some medium-grained sandstone beds did not contain sedimentary structures. 


\section{Coarse-grained sandstone}

The coarse-grained sandstone beds include pebble lag deposits. Individual clasts are resolvable, but colors other than white are not distinguishable. In addition to pebble lag deposits, there are also mud-rip up clasts that are resolvable.

\section{Pebbly sandstone}

Pebbly sandstone is identified by the horizontal stratification of large pebble to cobble sized clasts. The colors of the pebbles appear primarily white and grey. The lithology of the pebbles could not be determined.

The full measured section includes 89.58 meters of the lower Palm Spring Fm. and 47.47 meters of the upper Palm Spring Fm. (Figure 10D). The entire measured section consists of $5.0 \%$ shale, $35.4 \%$ interbedded sand and mud, $16.2 \%$ medium-grained sandstone, $17.1 \%$ coarse-grained sandstone, and $26.3 \%$ pebbly sandstone. The section between the markers consists of $4 \%$ shale, $43 \%$ interbedded sand and mud, $15 \%$ mediumgrained sandstone, and 37\% coarse-grained sandstone (Figure 11D). Markers a, e, f, and h were located on beds of interbedded sand and mud, Marker b was located on a bed of medium-grained sandstone, and Markers c, d, and g were located on beds of coarse-grained sandstone.

\subsubsection{High Resolution with Video Digital Outcrop Model}

The high resolution with video DOM (Figure 14) is incomplete with gaps near the base of the section and in the slot canyon behind the main section wall. In addition, a 
blue tinge throughout many images is present from incorporation of the sky coloration into the model.

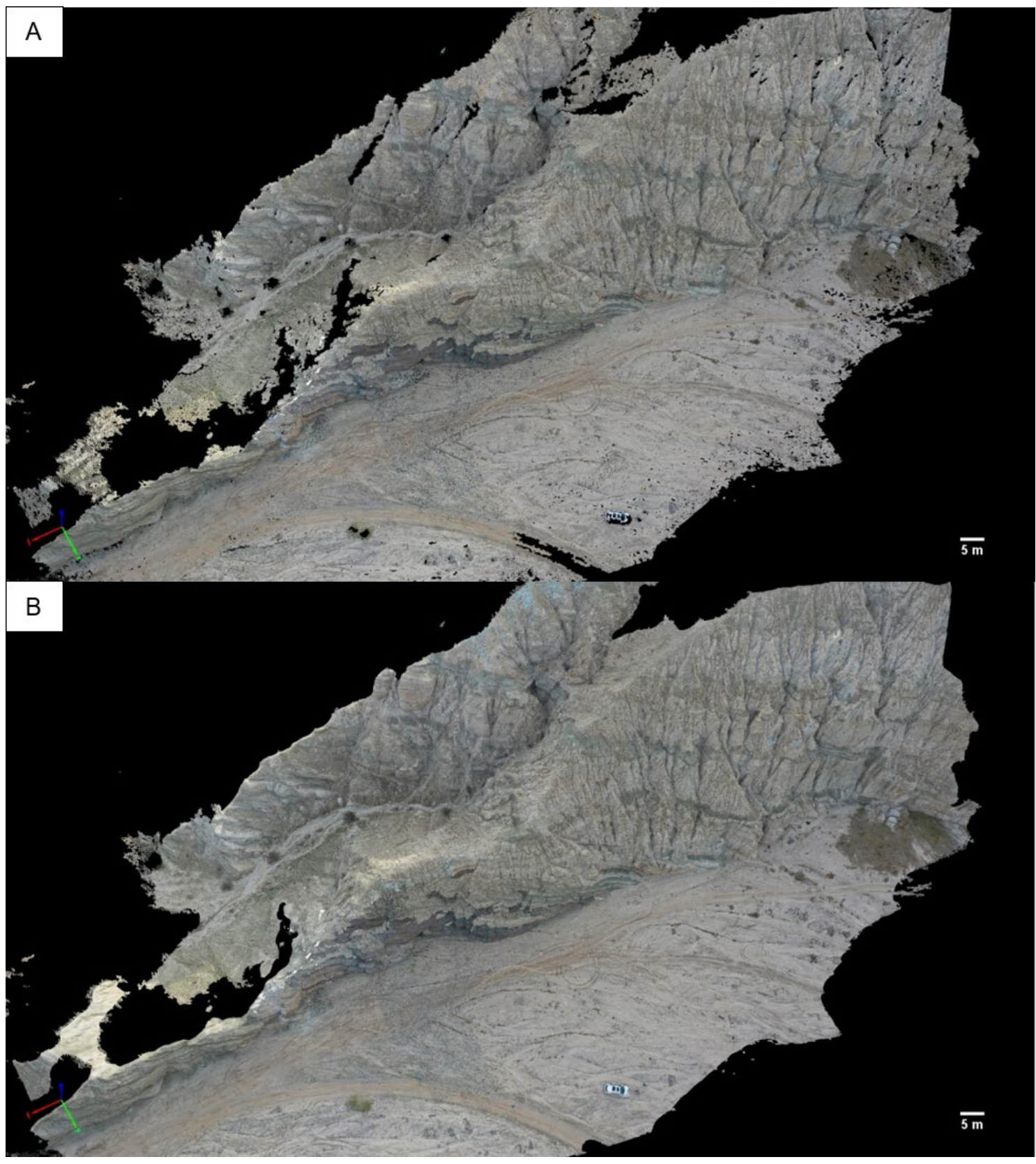

Figure 14. Oblique views of the high-resolution with video DOM. The orientation is shown in the lower left where $x$ (easting) is red, $y$ (northing) is green, and $z$ (elevation) is blue. (A) Shows the densified point cloud and (B) shows the 3D textured mesh. 


\subsubsection{Lithofacies and Stratigraphy}

The six lithofacies identified in the high resolution with video DOM are the same as those observed in the low-resolution DOM.

\section{Grey-green shale lithofacies}

The shale layers are dark grey and are difficult to distinguish. Shale layers do not appear continuous and are commonly blurred into interbedded sand and mud layers or sandstone.

\section{Interbedded sand and mud lithofacies}

Interbedded sand and mud layers are identified based on color differences in rhythmic bedding compared to thicker beds of different grain sized sandstones. The mud is a dark grey and the sandstone was a light grey to beige.

\section{Medium-grained sandstone lithofacies}

The medium-grained sandstone shows more grain detail than the sandstone without any grain size associated. There are no individual pebbles seen within the beds. Trough crossbedding is only observed in one bed, otherwise, the medium-grained beds were described as massive.

\section{Coarse-grained sandstone lithofacies}

Individual grains are distinguishable in coarse-grained sandstone beds. These beds are also identified based on the presence of coarse pebble lag. The types of clasts are not 
discernable and appear white in color. Imbricated mud rip-up clasts are observable in a few beds.

\section{Pebbly sandstone lithofacies}

Pebbly sandstone is identified by the horizontal stratification of large pebble to cobble sized clasts. The colors of the pebbles appear light pink to predominantly white. The lithology of the pebbles could not be determined.

\section{$\underline{\text { Sandstone lithofacies - no associated grain size }}$}

The general sandstone lithofacies observed in the low-resolution DOM is interpreted as a sandstone based on the beige color. These beds are blurry and no bedforms could be identified. Thus, it did not fit with the medium-grained or the coarse-grained sandstones.

The full stratigraphic column measured using this technique includes 81.42 meters of the lower Palm Spring Fm. and 50.80 meters of the upper Palm Spring Fm. (Figure 10E). The entire section consists of $3.0 \%$ grey-green shale, $33.6 \%$ interbedded sand and mud, $21.5 \%$ medium-grained sandstone, $6.6 \%$ coarse-grained sandstone, $32.3 \%$ pebbly sandstone, and 3.0\% sandstone with no associated grain size. The measured section between Markers a through $\mathrm{h}$ consisted of $3 \%$ grey-green shale, $41 \%$ interbedded sand and mud, $40 \%$ medium-grained sandstone, $10 \%$ coarse-grained sandstone, $0 \%$ pebbly sandstone, and 6\% sandstone with no distinguishable grain size (Figure 11E). Marker a was located on a sandstone bed, markers b, c, and d were located on medium-grained sandstone layers, markers e, $\mathrm{f}$, and $\mathrm{h}$ were located on an interbedded sand and mud layer, 
and marker $\mathrm{g}$ was located on a coarse-grained sandstone layer as identified using the high resolution with video DOM.

\subsubsection{LIME Results}

The planes created based on three user-defined points per plane through the GCP markers are fairly similar in the low-resolution DOM, the high-resolution DOM, and the high resolution with video DOM (Figures 15 and 16). Each color corresponds to a unique plane through a GCP marker with blue representing the lowermost marker a, and the grey representing the uppermost marker $\mathrm{h}$. 

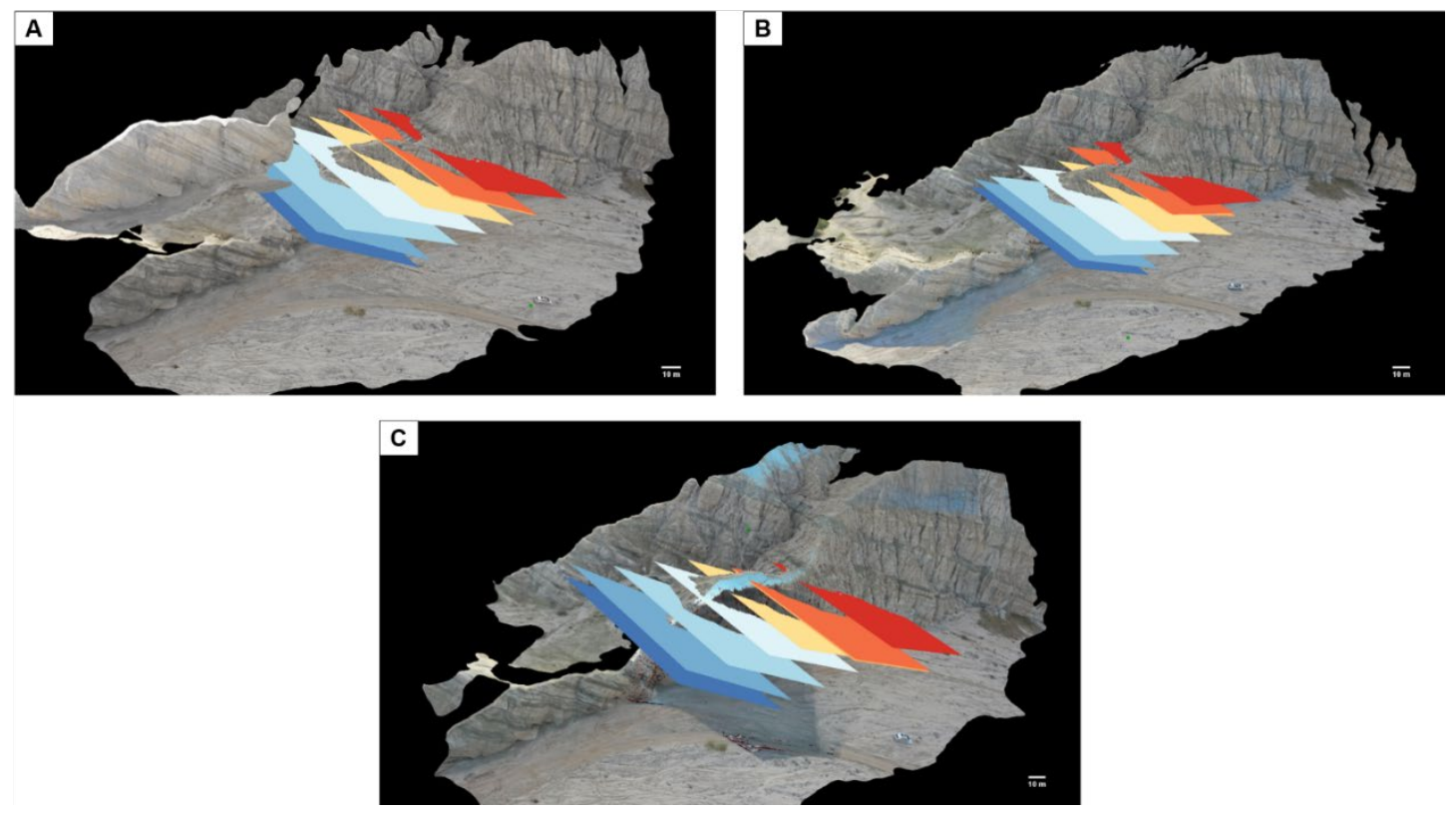

Figure 15. Planes created in LIME that were used for the true thickness measurements. (A) Planes for low resolution DOM. (B) Planes for high resolution DOM. (C) Planes for high resolution with video DOM. 


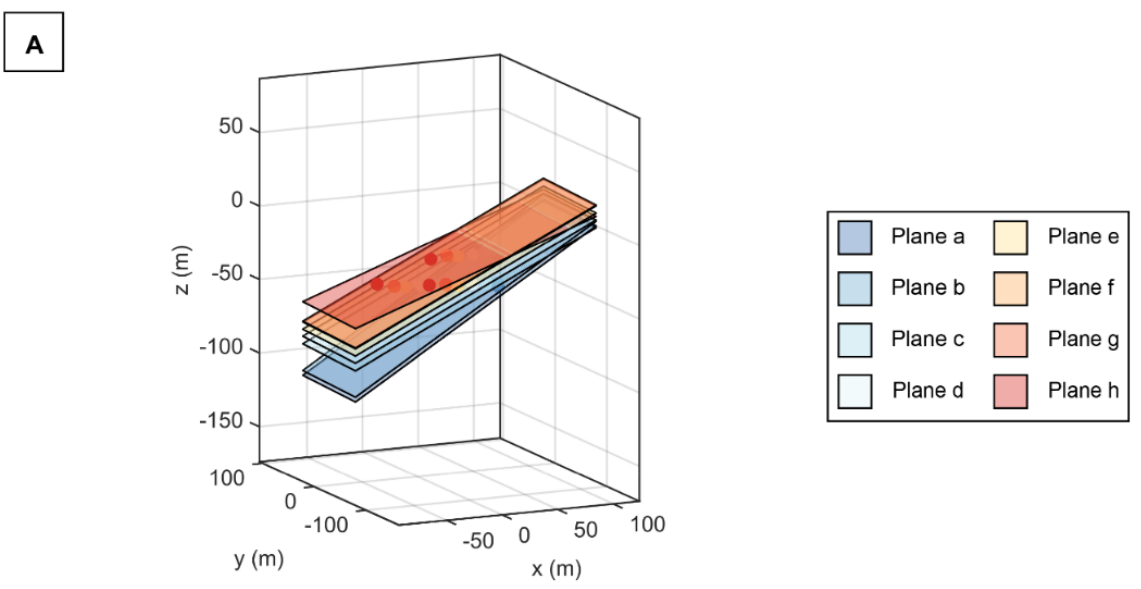

B

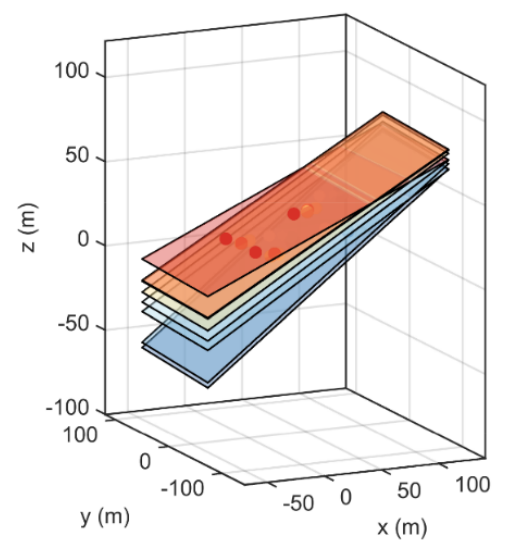

C

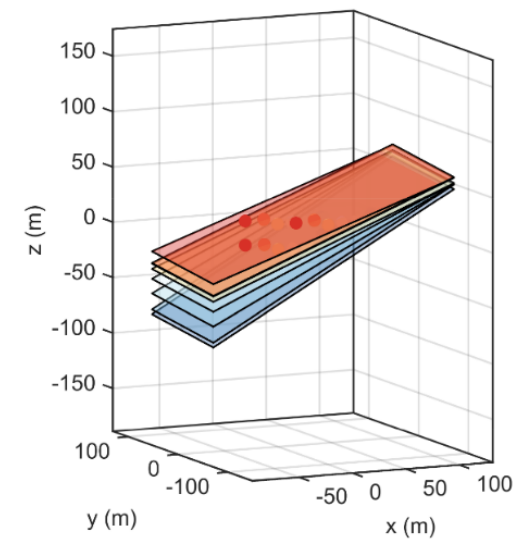

Figure 16. Visualization of planes and points from the MATLAB workflow that calculated true thicknesses based on the three points that created each plane in LIME. The planes were placed so that they intersected each bed with a GCP. The points seen on the planes are the three upper and three lower points for each plane. (A) Low resolution DOM. (B) High resolution DOM. (C) High resolution with video DOM.

The strike values for the low-resolution DOM (Table 3), high-resolution DOM (Table 4), and high-resolution with video DOM (Table 5) are approximately 177.0 and the dip values for planes a-f are all between 20 and 30 degrees, while the dip values for planes g and h slightly decrease to below 20, but not less than 15 degrees. 
TABLE 3. THE THREE POINTS (X, Y, Z), STRIKE, AND DIP VALUES THAT DEFINED THE EIGHT PLANES USED IN THE TRUE THICKNESS CALCULATIONS FOR THE LOW-RESOLUTION DOM.

\begin{tabular}{|c|c|c|c|c|c|}
\hline Plane & $x$ & $Y$ & Z & $\begin{array}{c}\text { Strike } \\
\left({ }^{\circ}\right)\end{array}$ & $\begin{array}{c}\text { Dip } \\
\left(\left(^{\circ}\right)\right.\end{array}$ \\
\hline \multicolumn{6}{|l|}{ Plane a } \\
\hline Point 1 & 66.54 & -12.50 & -26.12 & 177.8 & 25.55 \\
\hline Point 2 & 21.43 & -11.61 & -47.66 & 177.8 & 25.55 \\
\hline Point 3 & 43.54 & -62.04 & -38.04 & 177.8 & 25.55 \\
\hline \multicolumn{6}{|l|}{ Plane b } \\
\hline Point 1 & 65.10 & -12.55 & -23.60 & 177.8 & 25.55 \\
\hline Point 2 & 19.99 & -11.65 & -45.14 & 177.8 & 25.55 \\
\hline Point 3 & 42.10 & -62.09 & -35.51 & 177.8 & 25.55 \\
\hline \multicolumn{6}{|l|}{ Plane C } \\
\hline$\overline{\text { Point } 1}$ & 56.46 & -12.43 & -25.15 & 177.0 & 20.56 \\
\hline Point 2 & 9.638 & -11.62 & -42.68 & 177.0 & 20.56 \\
\hline Point 3 & 32.60 & -62.01 & -35.06 & 177.0 & 20.56 \\
\hline \multicolumn{6}{|l|}{ Plane d } \\
\hline$\overline{\text { Point } 1}$ & 44.11 & -12.34 & -24.58 & 177.0 & 20.56 \\
\hline Point 2 & -2.709 & -11.52 & -42.10 & 177.0 & 20.56 \\
\hline Point 3 & 20.25 & -61.91 & -34.48 & 177.0 & 20.56 \\
\hline \multicolumn{6}{|l|}{ Plane e } \\
\hline$\overline{\text { Point } 1}$ & 30.97 & -12.22 & -24.76 & 177.0 & 20.56 \\
\hline Point 2 & -15.85 & -11.40 & -42.28 & 177.0 & 20.56 \\
\hline Point 3 & 7.111 & -61.79 & -34.66 & 177.0 & 20.56 \\
\hline \multicolumn{6}{|l|}{ Plane $\mathrm{f}$} \\
\hline$\overline{\text { Point } 1}$ & 20.67 & -12.15 & -23.68 & 177.0 & 20.56 \\
\hline Point 2 & -26.16 & -11.33 & -41.21 & 177.0 & 20.56 \\
\hline Point 3 & -3.193 & -61.72 & -33.59 & 177.0 & 20.56 \\
\hline \multicolumn{6}{|l|}{ Plane $\mathrm{g}$} \\
\hline $\overrightarrow{\text { Point } 1}$ & 20.50 & -12.16 & -23.25 & 177.0 & 20.56 \\
\hline Point 2 & -26.32 & -11.34 & -40.78 & 177.0 & 20.56 \\
\hline Point 3 & -3.355 & -61.73 & -33.16 & 177.0 & 20.56 \\
\hline \multicolumn{6}{|l|}{ Plane h } \\
\hline$\overline{\text { Point } 1}$ & 6.393 & -11.99 & -24.84 & 175.8 & 15.58 \\
\hline Point 2 & -41.78 & -11.26 & -38.22 & 175.8 & 15.58 \\
\hline Point 3 & -18.14 & -61.61 & -32.67 & 175.8 & 15.58 \\
\hline
\end{tabular}


TABLE 4. THE THREE POINTS (X, Y, Z), STRIKE, AND DIP VALUES THAT DEFINED THE EIGHT PLANES USED IN THE TRUE THICKNESS CALCULATIONS FOR THE HIGH-RESOLUTION DOM.

\begin{tabular}{|c|c|c|c|c|c|}
\hline Plane & $x$ & Y & Z & $\begin{array}{c}\text { Strike } \\
\left({ }^{\circ}\right)\end{array}$ & $\begin{array}{l}\text { Dip } \\
\left({ }^{\circ}\right)\end{array}$ \\
\hline \multicolumn{6}{|l|}{ Plane a } \\
\hline Point 1 & 87.66 & 13.96 & 34.91 & 176.4 & 28.54 \\
\hline Point 2 & 43.87 & 10.53 & 11.02 & 176.4 & 28.54 \\
\hline Point 3 & 69.50 & -37.61 & 23.28 & 176.4 & 28.54 \\
\hline \multicolumn{6}{|l|}{ Plane b } \\
\hline Point 1 & 86.36 & 13.88 & 37.29 & 176.4 & 28.54 \\
\hline Point 2 & 42.57 & 10.44 & 13.40 & 176.4 & 28.54 \\
\hline Point 3 & 68.20 & -37.70 & 25.66 & 176.4 & 28.54 \\
\hline \multicolumn{6}{|l|}{ Plane c } \\
\hline$\overline{\text { Point } 1}$ & 79.72 & 13.38 & 36.02 & 176.6 & 23.54 \\
\hline Point 2 & 34.02 & 9.820 & 16.06 & 176.6 & 23.54 \\
\hline Point 3 & 60.61 & -38.26 & 26.34 & 176.6 & 23.54 \\
\hline \multicolumn{6}{|l|}{ Plane d } \\
\hline$\overline{\text { Point } 1}$ & 68.01 & 12.50 & 36.54 & 176.6 & 23.54 \\
\hline Point 2 & 22.31 & 8.944 & 16.57 & 176.6 & 23.54 \\
\hline Point 3 & 48.90 & -39.14 & 26.87 & 176.6 & 23.54 \\
\hline \multicolumn{6}{|l|}{ Plane e } \\
\hline$\overline{\text { Point } 1}$ & 5.948 & 10.87 & 14.71 & 176.7 & 23.06 \\
\hline Point 2 & 8.341 & -39.07 & 14.49 & 176.7 & 23.06 \\
\hline Point 3 & 53.10 & -11.98 & 34.18 & 176.7 & 23.06 \\
\hline \multicolumn{6}{|l|}{ Plane f } \\
\hline$\overline{\text { Point } 1}$ & -5.008 & 3.690 & 15.00 & 177.0 & 21.88 \\
\hline Point 2 & -1.974 & -46.22 & 15.17 & 177.0 & 21.88 \\
\hline Point 3 & 42.82 & -18.38 & 33.72 & 177.0 & 21.88 \\
\hline \multicolumn{6}{|l|}{ Plane $\mathrm{g}$} \\
\hline Point 1 & -5.237 & 1.915 & 15.38 & 177.0 & 21.88 \\
\hline Point 2 & 0.612 & -47.72 & 16.69 & 177.0 & 21.88 \\
\hline Point 3 & 43.73 & -16.99 & 34.63 & 177.0 & 21.88 \\
\hline \multicolumn{6}{|l|}{ Plane $\mathrm{h}$} \\
\hline Point 1 & -17.65 & 4.544 & 18.50 & 176.2 & 17.34 \\
\hline Point 2 & -14.99 & -45.39 & 18.31 & 176.2 & 17.34 \\
\hline Point 3 & 31.35 & -17.95 & 33.30 & 176.2 & 17.34 \\
\hline
\end{tabular}


TABLE 5. THE THREE POINTS (X, Y, Z), STRIKE, AND DIP VALUES THAT DEFINED THE EIGHT PLANES USED IN THE TRUE THICKNESS CALCULATIONS FOR THE HIGH-RESOLUTION WITH VIDEO DOM.

\begin{tabular}{lccccc}
\hline Plane & $\mathrm{X}$ & $\mathrm{Y}$ & $\mathrm{Z}$ & $\begin{array}{c}\text { Strike } \\
\left({ }^{\circ}\right)\end{array}$ & $\begin{array}{c}\text { Dip } \\
\left({ }^{\circ}\right)\end{array}$ \\
\hline Plane a & & & & & \\
Point 1 & 30.97 & -30.00 & -7.712 & 171.6 & 29.53 \\
Point 2 & 74.63 & -31.34 & 16.63 & 171.6 & 29.53 \\
Point 3 & 52.21 & 19.18 & 8.274 & 171.6 & 29.53 \\
& & & & & \\
Plane b & & & & & \\
Point 1 & 29.16 & -30.27 & -4.469 & 171.6 & 29.53 \\
Point 2 & 72.81 & -31.61 & 19.88 & 171.6 & 29.53 \\
Point 3 & 50.39 & 18.91 & 11.52 & 171.6 & 29.53 \\
& & & & & \\
Plane c & & & & & \\
Point 1 & 14.60 & -30.39 & -5.077 & 170.6 & 26.71 \\
Point 2 & 59.41 & -31.55 & 17.07 & 170.6 & 26.71 \\
Point 3 & 36.41 & 18.88 & 9.811 & 170.6 & 26.71 \\
& & & & & \\
Plane d & & & & & \\
Point 1 & -0.737 & -30.62 & -4.444 & 169.5 & 24.23 \\
Point 2 & 45.01 & -31.62 & 15.72 & 169.5 & 24.23 \\
Point 3 & 21.54 & 18.73 & 9.451 & 169.5 & 24.23 \\
Plane e & & & & & \\
\hline Point 1 & -14.19 & -30.77 & -4.638 & 168.6 & 22.32 \\
Point 2 & 32.21 & -31.64 & 13.97 & 168.6 & 22.32 \\
Point 3 & 8.414 & 18.65 & 8.478 & 168.6 & 22.32 \\
& & & & & \\
Plane f & & & & & \\
Point 1 & -21.75 & -19.44 & -1.912 & 168.6 & 22.32 \\
Point 2 & 24.65 & -20.32 & 16.69 & 168.6 & 22.32 \\
Point 3 & 0.854 & 29.97 & 11.20 & 168.6 & 22.32 \\
Plane g & & & & & \\
Point 1 & -21.93 & -19.48 & -1.469 & 168.6 & 22.32 \\
Point 2 & 24.47 & -20.35 & 17.14 & 168.6 & 22.32 \\
Point 3 & 0.676 & 29.94 & 11.65 & 168.6 & 22.32 \\
Plane h & & & & & \\
Point 1 & -39.81 & -19.75 & -0.781 & 167.1 & 19.92 \\
Point 2 & 7.349 & -20.45 & 15.82 & 167.1 & 19.92 \\
Point 3 & -16.82 & 29.75 & 11.33 & 167.1 & 19.92 \\
\hline & & & & &
\end{tabular}


In addition to the 8 planes through GCP markers, 10 bedding plane measurements below the unconformity and 10 bedding plane measurements taken from above the unconformity on the high-resolution model show that the dip angles change from below the unconformity to above the unconformity (Figure 17). There is a larger decrease in the dip angle for the planes that are measured immediately above the plane placed at marker $h$ which is at the base of the bed that directly abuts the unconformity.

\section{A}

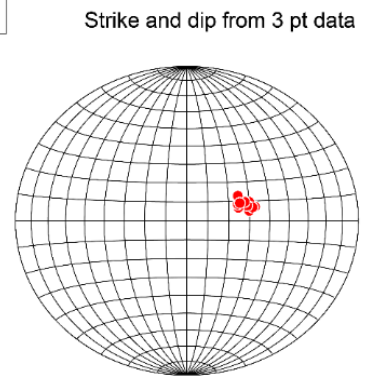

B

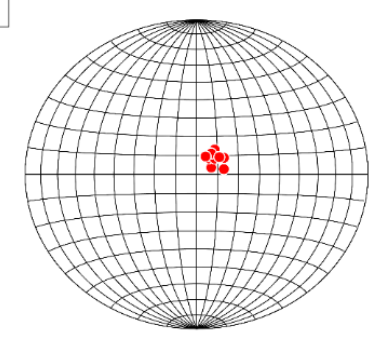

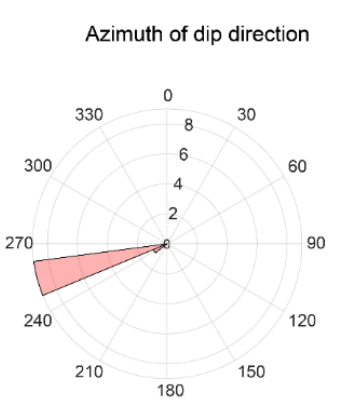

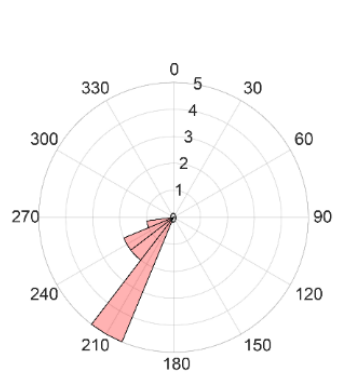

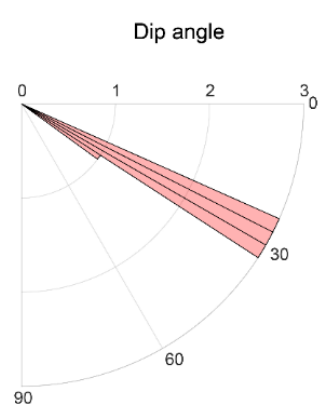

90

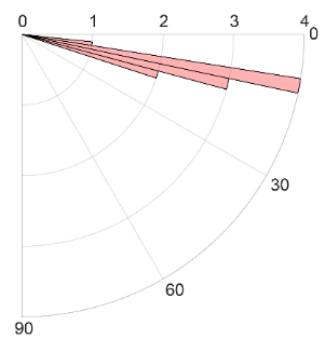

Figure 17. The strike, azimuth of dip direction, and the dip angle values measured using the high-resolution DOM for (A) ten planes below the unconformity and (B) ten planes above the unconformity.

\subsection{GPS Points}

The GPS coordinates for markers a through $\mathrm{h}$ are shown in Table 6 . The $\mathrm{x}$ value is the easting (m), the y value is the northing (m), and the $\mathrm{z}$ value is the elevation in meters 
within UTM zone 11. Although these GPS coordinates are put into each of the DOMs, when the DOM is created, positions may shift slightly. To confirm these positions, the GPS coordinates of the GCP markers and the different DOMs are compared (Figure 18A). The largest variance between the DOMs and the GCP markers is seen in the northing values (Figure 18B). Table 7 shows the residuals between the DOMs and the GPS coordinates of the GCPs. The GPS Coordinates for the markers on each of the DOMs are located in Appendix B.

TABLE 6. UTM COORDINATES FOR ORANGE GCPS A-H AND ASSOCIATED HORIZONTAL AND VERTICAL PRECISION FROM PROCESSED DIFFERENTIAL GPS DATA.

\begin{tabular}{cccccc}
\hline Marker & Easting & Northing & Elevation & $\begin{array}{c}\text { Horizontal } \\
\text { Precision }\end{array}$ & $\begin{array}{c}\text { Vertical } \\
\text { Precision }\end{array}$ \\
\hline a & 594675.2 & 3716930 & 53.772 & 0.032 & 0.042 \\
b & 594665.2 & 3716930 & 52.100 & 0.007 & 0.007 \\
c & 594653.6 & 3716937 & 53.409 & 0.013 & 0.014 \\
d & 594640.7 & 3716939 & 53.879 & 0.019 & 0.022 \\
e & 594625.9 & 3716940 & 52.778 & 0.003 & 0.005 \\
f & 594614.7 & 3716939 & 53.546 & 0.090 & 0.081 \\
g & 594624.5 & 3716935 & 57.436 & 0.022 & 0.025 \\
h & 594601.1 & 3716942 & 56.445 & 0.003 & 0.005 \\
\hline
\end{tabular}



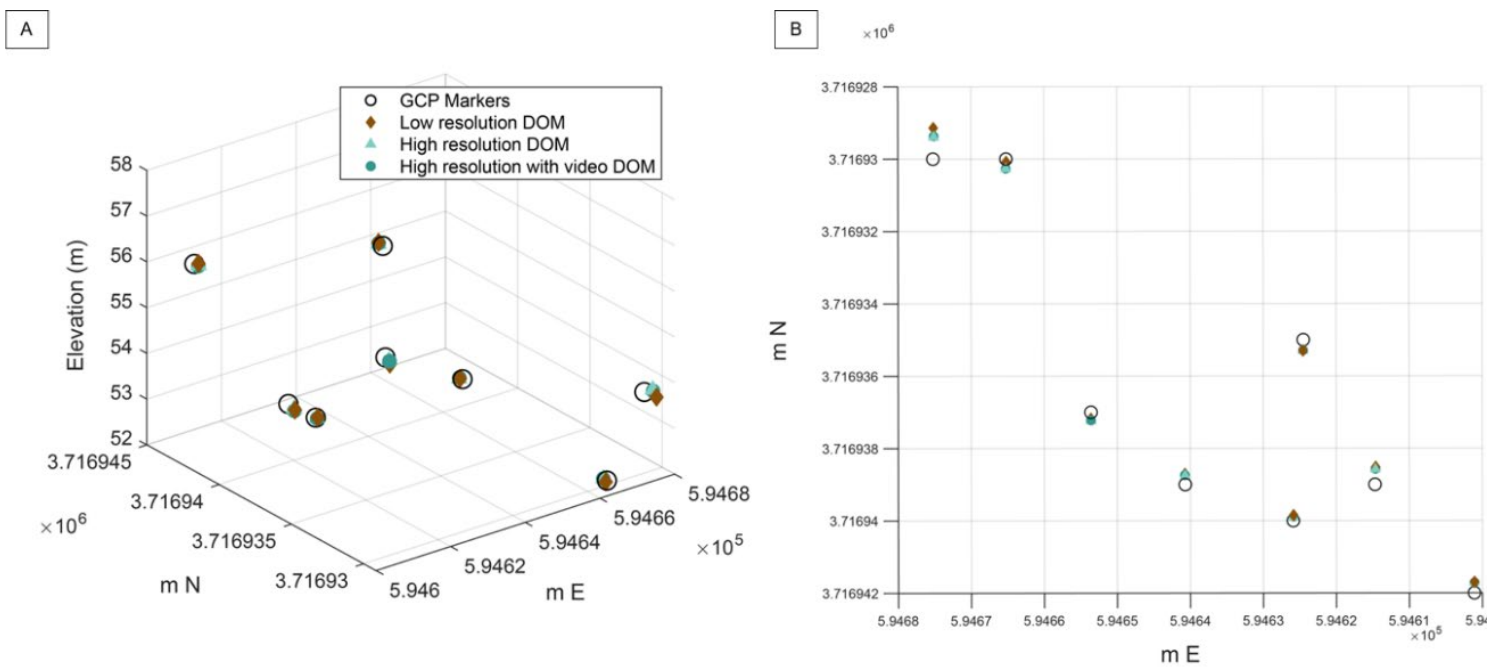

Figure 18. Comparisons of the original UTM coordinates of the GCP markers (a-h) and the coordinates of the markers after the SfM process. Most of the variations from the locations of the DOMs compared to the locations of the GCPs are shown in the northing direction. (A) Shows the (XYZ) coordinates and (B) shows the easting (m) on the $\mathrm{x}$-axis and the northing $(\mathrm{m})$ on the $y$-axis.

TABLE 7. NORTHING RESIDUALS FROM EACH DOM TO THE MARKER GPS COORDINATES.

\begin{tabular}{cccc}
\hline \hline Markers & $\begin{array}{c}\text { Low Resolution DOM } \\
\text { Northing }\end{array}$ & $\begin{array}{c}\text { High Resolution } \\
\text { DOM Northing }\end{array}$ & $\begin{array}{c}\text { High Resolution Video } \\
\text { DOM Northing }\end{array}$ \\
\hline a & -0.860 & -0.606 & -0.630 \\
b & 0.080 & 0.268 & 0.267 \\
c & 0.180 & 0.231 & 0.223 \\
d & -0.290 & -0.239 & -0.262 \\
e & -0.150 & -0.082 & -0.109 \\
$\mathrm{f}$ & -0.480 & -0.420 & -0.427 \\
$\mathrm{~g}$ & 0.300 & 0.302 & 0.289 \\
$\mathrm{~h}$ & -0.300 & -0.297 & -0.285 \\
\hline
\end{tabular}




\section{CHAPTER 4}

\section{DISCUSSION}

\subsection{Comparison of Stratigraphic Sections Between Markers}

The stratigraphic columns resulting from the five different techniques differ in several significant ways between the basal unit and the unconformity (Figure 10), and between the GCP markers (Figure 19), with the field measurements showing the greatest inconsistencies compared to the other techniques. First, sedimentary structures such as cross-beds are observed in each of the five methods; but fossils, bioturbation, and soft sediment deformation are only available from field measurements (Table 8). Similarly, constraints on grain size differed between techniques. The percentages of the different lithofacies are similar between the three DOMs, however, grain size for sandstone was not always distinguishable using the low resolution and the high resolution with video DOM, which is similar to the level of detail that Bistacchi et al. (2015) were able to determine from their DOM created via LiDAR. In detail, the smallest resolvable structures vary by position in the photomosaic and DOMs due to variable pixel smearing, image quality, and distance between the camera and the outcrop surface photographed. 


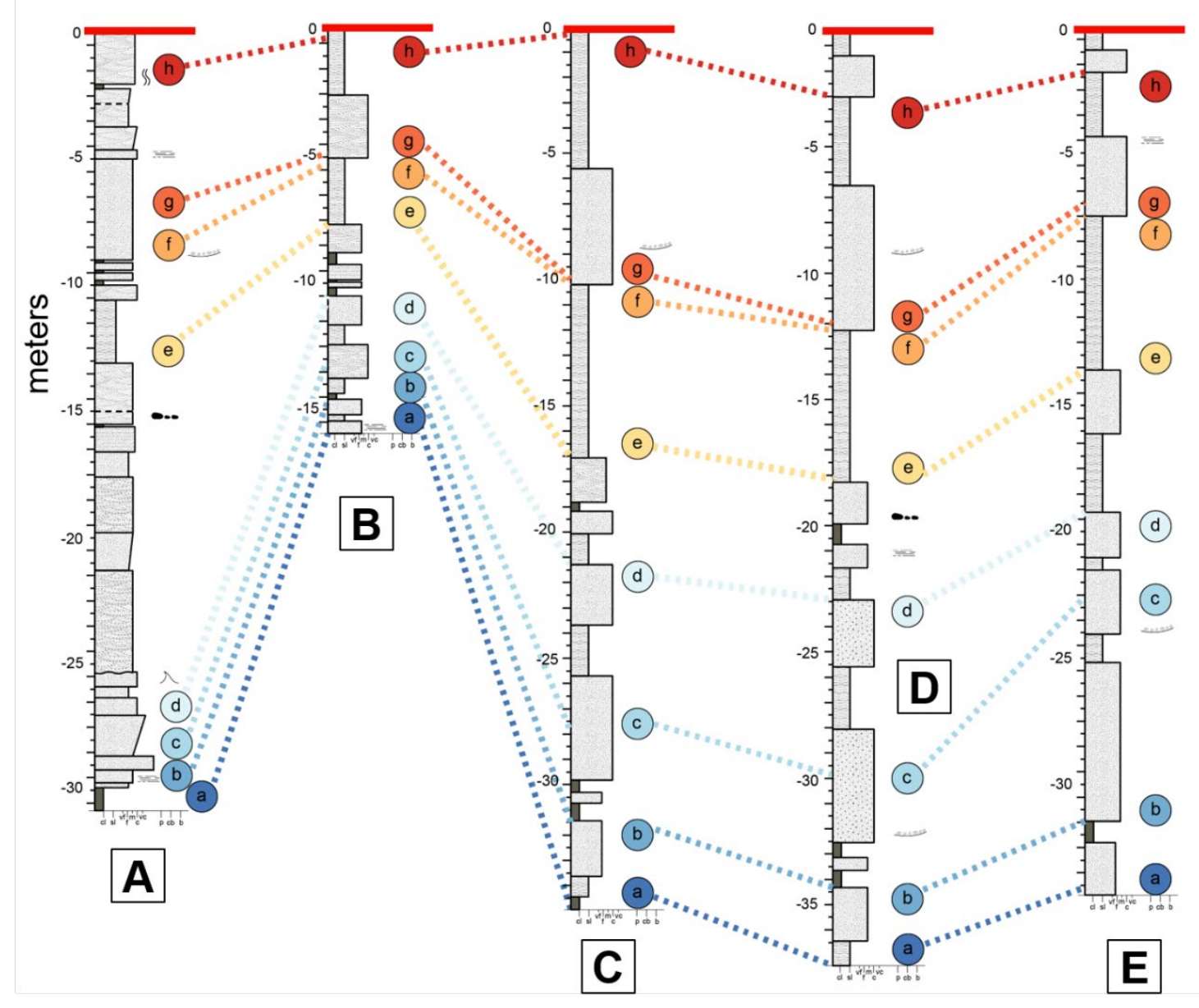

Figure 19. The five stratigraphic columns between the orange GCPs. They are labeled as markers a-h and represent meters below the unconformity. (A) Field measurements, (B) Photomosaic, (C) Low-resolution DOM, (D) High-resolution DOM, and (E) Highresolution with video DOM.

Second, the techniques produced different patterns in bed thickness. Field methods report the largest number of beds, the thinnest beds, and a wide range of bed thickness. Digital-based techniques tend to result in fewer and thicker beds. As a result, the number of beds decrease and the thickness increases (Table 8). 
TABLE 8. COMPARISONS OF OUTCROP CHARACTERISTICS BETWEEN THE FIVE TECHNIQUES.

\begin{tabular}{|c|c|c|c|c|c|}
\hline $\begin{array}{c}\text { Outcrop } \\
\text { characteristics }\end{array}$ & Field & Photomosaic & $\begin{array}{l}\text { Low- } \\
\text { Resolution } \\
\text { DOM }\end{array}$ & $\begin{array}{l}\text { High- } \\
\text { Resolution } \\
\text { DOM }\end{array}$ & $\begin{array}{c}\text { High- } \\
\text { Resolution + } \\
\text { Video DOM }\end{array}$ \\
\hline Grain size ${ }^{5}$ & $\begin{array}{l}\text { Sub-mm } \\
\text { (Sh to SIt) }\end{array}$ & $\begin{array}{l}\mathrm{mm} \\
(\mathrm{Sh})\end{array}$ & $\begin{array}{l}\mathrm{mm} \\
(\mathrm{Sh})\end{array}$ & $\begin{array}{l}\mathrm{mm} \\
\text { (Sh) }\end{array}$ & $\begin{array}{l}\mathrm{mm} \\
(\mathrm{Sh})\end{array}$ \\
\hline Fossils & $x$ & & & & \\
\hline Sed Structure & $x$ & $x$ & $x$ & $x$ & $x$ \\
\hline Bioturbation & $x$ & & & & \\
\hline Soft-sed. Def. ${ }^{6}$ & $x$ & & & & \\
\hline $\begin{array}{l}\text { Minimum Bed } \\
\text { Thickness }\end{array}$ & $0.10 \mathrm{~m}$ & $0.09 \mathrm{~m}$ & $0.24 \mathrm{~m}$ & $0.17 \mathrm{~m}$ & $0.12 \mathrm{~m}$ \\
\hline $\begin{array}{l}\text { Maximum Bed } \\
\text { Thickness }\end{array}$ & $9.00 \mathrm{~m}$ & $4.33 \mathrm{~m}$ & $11.91 \mathrm{~m}$ & $9.72 \mathrm{~m}$ & $12.29 \mathrm{~m}$ \\
\hline Number of beds & 129 & 42 & 46 & 58 & 51 \\
\hline $\begin{array}{l}\text { Relative Length }{ }^{7} \\
\text { of cumulative } \\
\text { thickness }\end{array}$ & 1.00 & 0.71 & 0.82 & 0.79 & 0.78 \\
\hline $\begin{array}{l}\text { Reproduce GCP } \\
\text { spacing }\end{array}$ & & & $x$ & $x$ & $x$ \\
\hline
\end{tabular}

${ }^{5} \mathrm{Sh}=$ shale, $\mathrm{Slt}=$ siltstone, $\mathrm{SSf}=$ fine sandstone, $\mathrm{SSm}=$ medium sandstone, $\mathrm{SSc}=$ coarse sandstone, Cong $=$ conglomerate.

${ }^{6}$ Soft sediment deformation

${ }^{7}$ Relative length is compared for the interval measured in the field and is defined as the ratio of this distance to the field measurement (Figure 10). 
Third, the estimated stratigraphic thickness varies by technique with the field measurements indicating the largest cumulative thickness and the photomosaic indicating the smallest. Each of the DOMs indicate similar thickness regardless of resolution (Figure 10). This thickness appears to directly correlate with image resolution in the photomosaic and DOMs so that lower resolution models result in thinner sedimentary thickness and only the highest resolution data approaches the thickness estimated from the field measurements.

Fourth, the distance between GCPs can be calculated from their GPS coordinates and then compared to the stratigraphic columns. In the case of the field measurements, these two estimations of distance are independent. The same is true for the 2D photomosaic. However, for the DOMs, the GPS coordinates of the markers is used to support DOM construction during the SfM processing; nevertheless, this process optimizes the full set of information including all the imagery and so a comparison to the GCP distances still provides an estimation of how well real distances in the physical space are replicated in the digital outcrop models.

\subsection{Bedding Thickness Variability}

Identification of true bed thickness is critical for determination of sedimentation rates, as well as for studies of sequence stratigraphy or cyclostratigraphy (Drummond and Bruce, 1996). In order to get accurate measurements of bed thickness, the true thickness perpendicular to the strike and dip of the bed must be measured. Alluvial systems such as the Palm Spring Formation contain channelized deposits that make direct measurements of 
bedding surfaces difficult in the field. DOMs provide a much more accurately defined bedding orientation since the user can manipulate the placement of the planes and measure orientations across a larger region and over the crest of the ridge for better 3D exposure. True thickness and bedding orientations can therefore be more accurate than field measurements, and an overview of the outcrop in the DOM can help elucidate small changes in bed orientation, similar to results achieved with LiDAR-based DOMs by Bellian et al. (2005). For example, in the LIME measurements of the 8 planes (Figure 16), even below the unconformity, there are small changes in bed orientation, with steeper bedding towards the base, and decreasing as you go up section. This therefore allows for more accurate determination of changes in bed orientation as you move up through a section, as well as adjustment of bed thickness. In addition, when the orientation of the bed changes slightly, variability in bed thickness may result from the location in which the measurement was taken.

Identification of "true" thickness, or determination of what technique provides the most accurate representation of true thickness is difficult. Due to the $\mathrm{mm}$ precision in the $\mathrm{x}, \mathrm{y}$, and $\mathrm{z}$ coordinate directions of the GPS measurements, these points are taken to be "true", and because the bedding planes can be identified with certainty through these points, particularly in the high-resolution DOM, the thicknesses of these layers are the basis for comparison of the 5 techniques. There is no significant distortion of the DOMs from the GPS points (Figure 18). The true thickness measurements taken from the perpendicular to the LIME planes are similar for each DOM, with variation of only about a degree in strike and 3 degrees in dip between the low-resolution and high-resolution DOM. There are only two planes with highly variable results for the low- and high-resolution DOMs 
while the high-resolution with video DOM shows variability in planes two, three, four, and seven (Figure 20). However, because it had already previously been noted that textural properties and grain sizes were best determined with the high-resolution DOM, this made for the most accurate determination of bedding planes.
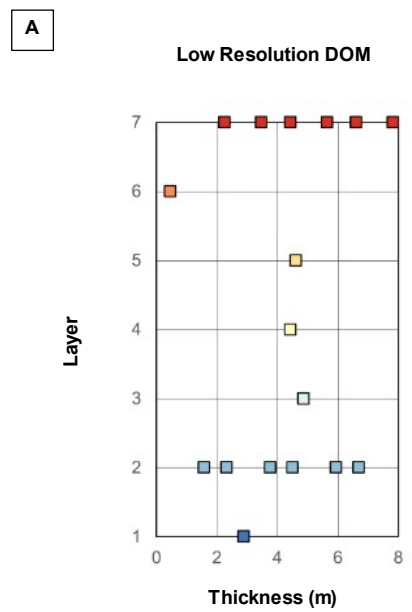
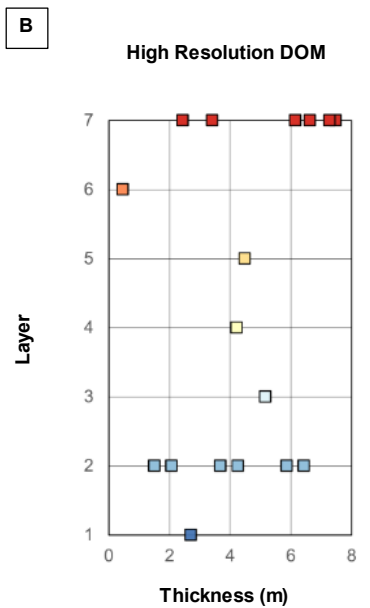

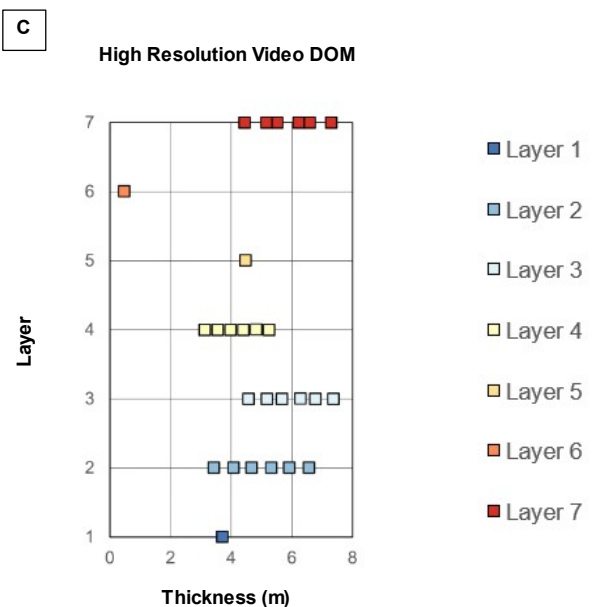

Figure 20. True thickness measurements from MATLAB for each DOM. The layers represent the thicknesses between two planes generated in LIME. Layer 1 is the thickness between planes a-b, layer 2 is the thickness between planes b-c, layer 3 is the thickness between planes c-d, layer 4 is the thickness between planes d-e, layer 5 is the thickness between planes e-f, layer 6 is the thickness between planes $\mathrm{f}-\mathrm{g}$, and layer 7 is the thickness between planes $g$-h, The six data points for each layer represent the distance from the 3 points on the lower bed to the upper bed and the three points from the upper bed down to the lower bed. The single points observed in layers 1, 3, 4, 5, and 6 indicate that the thickness measurements were similar because the planes were parallel and the multiple points in layers 2 and 7 for the low-resolution and high-resolution as well as layer 2, 3, 4, and 7 in the high-resolution with video DOM indicate large ranges in the six calculated thickness measurements due to sub-parallel bedding planes.

Several factors should be considered when conducting this analysis. First is the size of the features and associated strike and dip that needs to be measured. Strike and dip derived from a set of three (or more) points by fitting a plane implicitly assumes a uniform attitude over that distance. Longer distances between the set of points help minimize the 
impact of uncertainty in the point locations, but also assumes a constant strike and dip of the structure spanning that distance which may be a poor assumption in deformed regions or if the depositional setting includes variation in bed thickness. The optimal length should be similar to the size of the structure being measured and the length should also be large compared to the uncertainty in the position of survey points.

Separation in all three directions must be considered; if we consider a set of three points, the best case is that they define an equilateral triangle whose edges are similar in length to the features being represented and that the uncertainty in the vertex locations is much smaller than the edge length. As the triangular patch becomes flatter, and the ratio between the height and base-length of the triangle tends toward zero, the estimated attitude of the triangular patch becomes unreliable. If a larger number of points is used to define a plane, the goal should still be that the points tend to define a roughly circular patch. These limitations also apply to estimating bed thickness since thickness is taken to be measured in the direction normal to the bed, and where beds are not in a parallel position along each bed surface will influence the estimated thickness. Thus, the points used to define attitude and from which to measure thickness must be scaled to the sedimentary structures they are intended to represent.

Measurements of thickness on the stratigraphic columns from the field, photomosaic, and DOMs between markers demonstrate significant differences between the techniques (Figure 21), as is seen in the comparison of the stratigraphic columns (Figure 19). The thicknesses between markers on the stratigraphy from the photomosaic, low resolution, high-resolution, and high-resolution with video mostly cluster together. A larger range of variability between methods is seen for layers two and seven, but this is 
expected given the slight change in bed orientation so that the bounding planes are not exactly parallel. However, the field measurements are appreciably different than the four other methods and are not systematic. Some layers are thicker, and some are thinner. For the most part, the digital methods match closely with the "true" thickness measurements from LIME since they reproduce the spacing between the GCPs, but the field method does not. This may be due to a number of factors: (1) error in the determination of strike and dip in the field, (2) over- or under- estimation of individual beds due to scours, channels, and otherwise uneven bedding planes, (3) additive errors in bed estimation, which is also concluded by Calvo et al. (2014). This is demonstrated in layer 4 where the field measurement is very thick in comparison to the other techniques (Figure 21). In this case, many small beds were identified and measured, and small errors in each likely resulted in the overestimation of total thickness. 


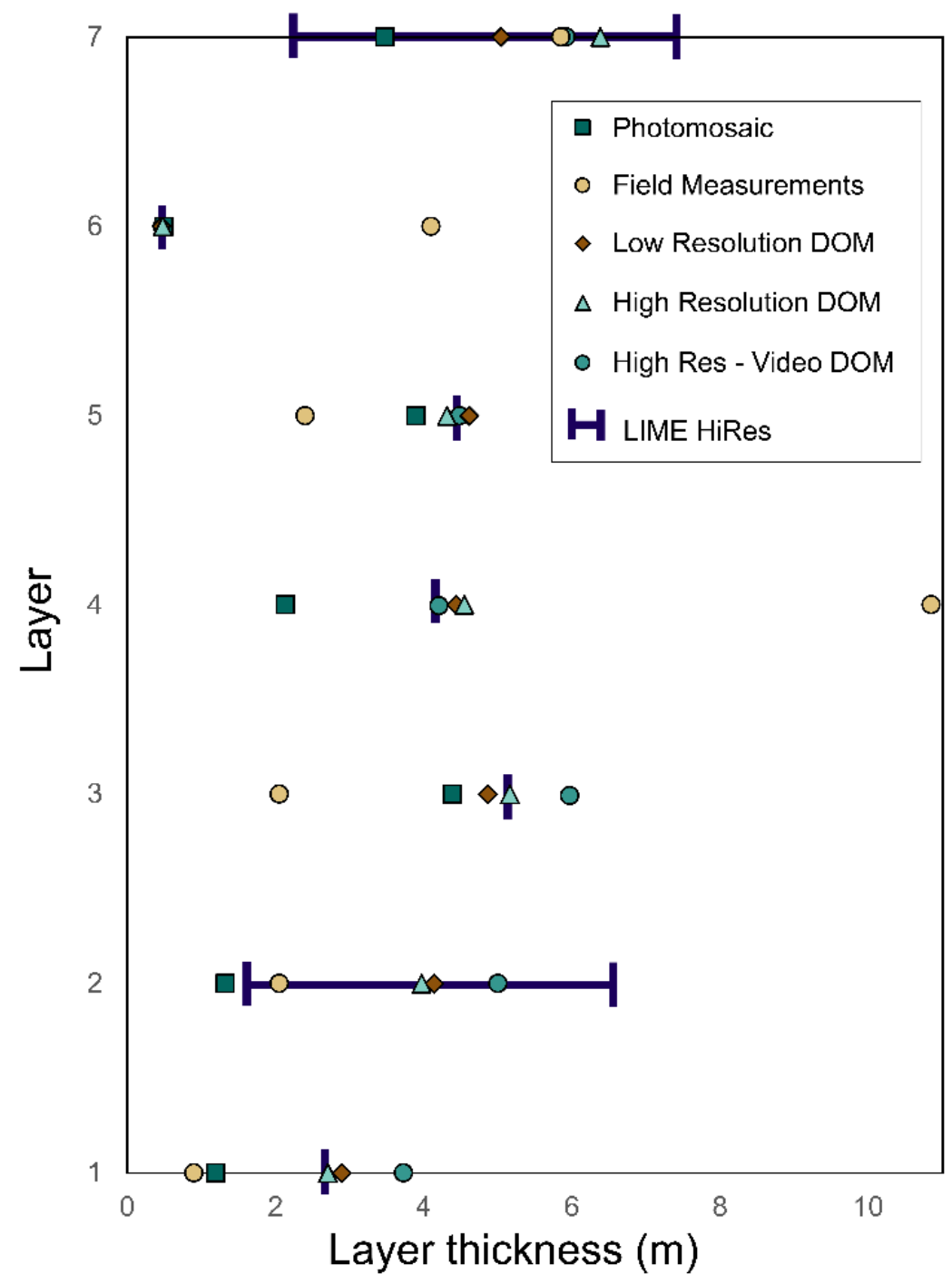

Figure 21. Calculated thicknesses from the stratigraphic measurements for the DOMs, the photomosaic, and the field, along with the thickness calculated between bedding planes in the high-resolution DOM using the LIME planes technique. The solid lines for the LIME measurements represent the range of thickness measurements due to the bedding planes being subparallel. 


\subsection{Lithology Comparison}

Overall sedimentological observations were much more detailed using the fieldwork method. The lithologic observations closely match the observations by Sylvester and O'Black-Gans (2016) and McNabb et al. (2017). Grain size, sedimentary structures, presence or absence of fossils, the nature of bedding contacts, and composition (even of large pebbles) were not easily determined using the four digital methods. As a result, there is heterogeneity in lithology depending on the stratigraphic analysis method used, even when grouped into 5 overarching lithofacies with grain sizes ranging from mud to pebble conglomerates.

Grain sizes in the field were determined using grain size charts. Some photos were taken with grain size cards to assist in digital techniques but were not available as embedded in the drone imagery, and therefore the DOMs. However, color and texture, along with the prior field experience, allowed for much of the stratigraphy to be classified. Though, in some beds, grain size and texture could not be distinguished using the lowresolution DOM or the high resolution with video DOM (Figure 22). In these cases, a general sandstone lithofacies with no associated grain size was added to the lithofacies types. Using this method avoids contaminating the stratigraphic columns with highly uncertain data. An alternative approach, which should be considered in the future, is to include two separate designations: one for rock type and a second for the quality or uncertainty in the rock type definition. Accordingly, a complete stratigraphic column can be recorded, but the relative reliability of information it records will also be available to ensure that it is reasonably interpreted. A result of this approach will not only be the 
derivation of stratigraphic columns, but also an aggregate estimation of the uncertainty derived from each method by comparing the relative frequency of high to low quality data generated by the five different methods.

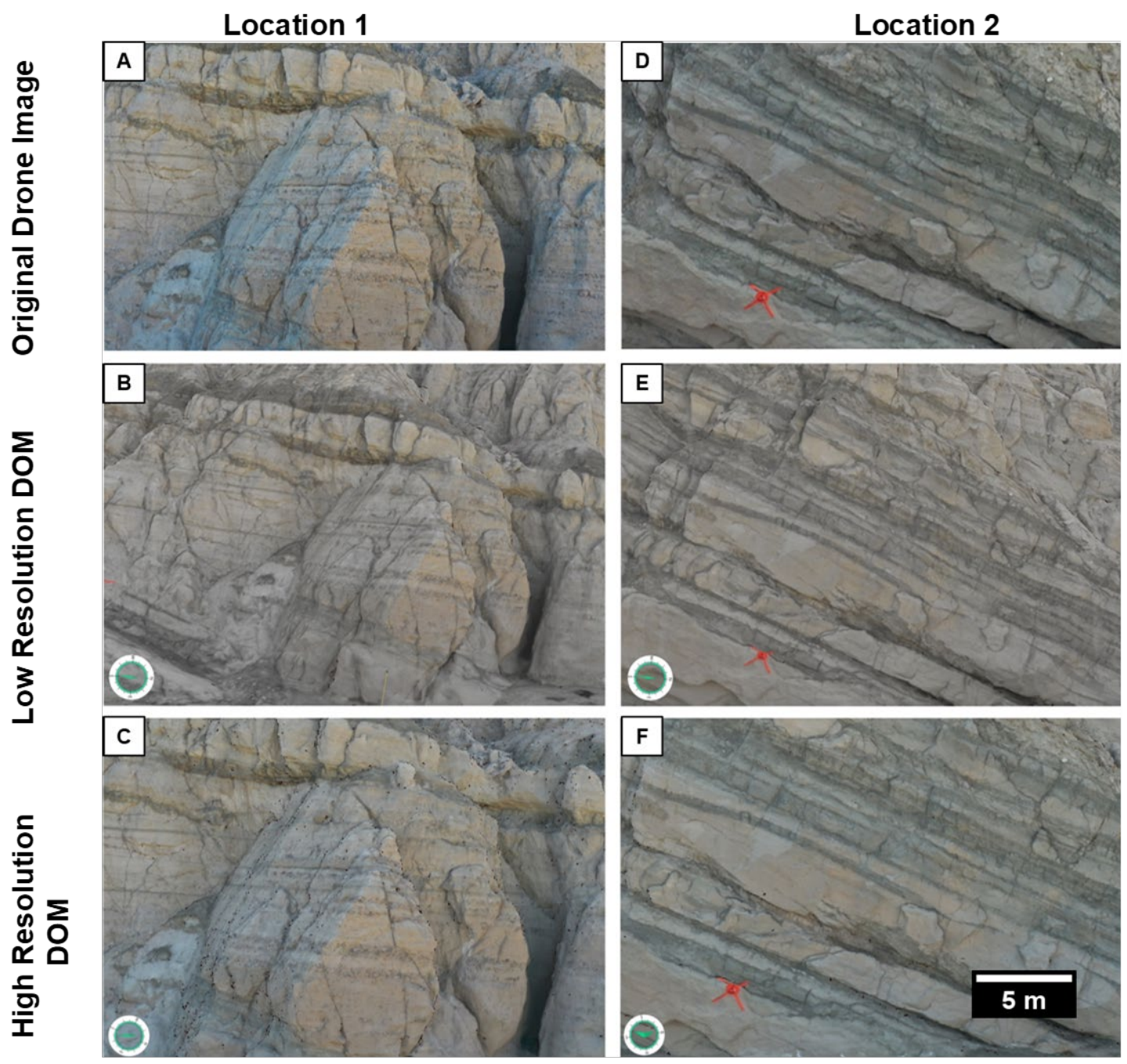

Figure 22. Comparisons of the quality and colors of the drone images and the 3D textured meshes for the low-resolution DOM and the high-resolution DOM. (A) and (D) are drone images used in the SfM processing. (B) and (E) are images of the same areas seen in the low-resolution DOM and (C) and (F) are images of the same areas seen in the high-resolution DOM. The triangle meshes smooth out the surfaces reducing the detail that is observable in original photos or in the field. 
In addition to the uncertainty in grain size determination while completing the digital techniques, color is inaccurately represented in the low-resolution DOM compared to the high-resolution DOM and the actual images (Figure 22). The end result is that the observations in the field were very different from the digital methods, much like the bedding thickness measurement. One key finding for understanding sediment transport and environments, is the significant difference in the abundance of mudstone vs coarse sandstone. In the field, only $15 \%$ of the stratigraphic column between marker a and $\mathrm{h}$ are composed of mud or interbedded mud and sand, whereas in the digital techniques, over $44 \%$ is estimated (Figure 23). Over a large area, this has significant ramifications for estimations of flow velocity, depositional systems, and basin analysis.

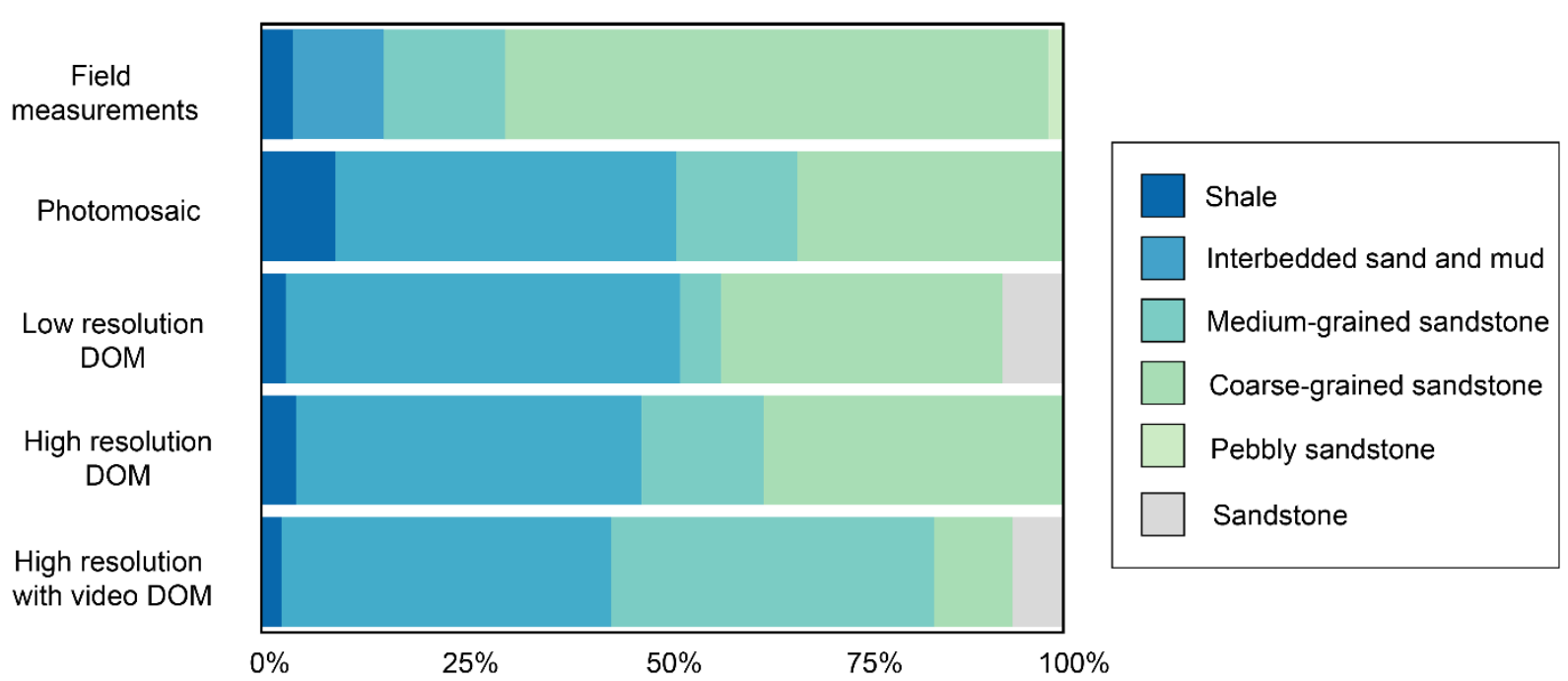

Figure 23. Comparisons of the lithology between markers a-h for each method. Note the pebbly sandstone was only seen in the field observation and the general sandstone with no associated grain size was seen in the low-resolution DOM and high-resolution with video DOM. 
The high resolution with video DOM were particularly problematic because the photos and video were collected on 2 separate days with different lighting conditions. Because of this, although there were more images used, each image experienced greater smearing to combine the files. The indicated situation implies the DOMs methodology may be subject to reproducibility problems resulting from environmental factors; alternatively, for larger field areas that must be mapped over several days this sensitivity may limit the size of the region for which a DOM can be created (above and beyond limitations due to computing power as the number of images increases to resolve larger regions). It is clear that the addition of more data was disadvantageous. The photos alone provided sufficient data and minimized the volume of data collected (and storage needed) Moreover, the photos contained the embedded metadata, which was lost during extraction of photos from the video.

In reality, some of the variation in the volumetric estimation of the lithologies is likely due to differences in thickness measurements. However, comparison of the stratigraphic columns (Figure 19), suggests that this is not the only reason for the variance. Alignment of beds between the sections demonstrates that significantly more detail in individual small beds is noted in the field.

Because of the smearing of beds and the limited resolution of grain size due to the textured mesh of the DOM, as well as the inability to identify fossils, some bedforms, and other sedimentary structures, the DOMs cannot fully replace field-based stratigraphic analyses. 


\subsection{Suggested Workflow}

By utilizing the strengths of the different techniques, we may be able to improve on a traditional geologic workflow by using this new technology (Table 9). In order to maximize time in the field, a simple flight plan should be developed for reconnaissance of the desired outcrop(s). During the first day, markers should be placed, spread out around the outcrop, and drone photos should be taken to cover the outcrop(s), with care taken to try to fully blanket the outcrop from different angles. GPS coordinates of all markers, preferably dGPS (or hand-held in the case of a very large areas with spaced-out markers to reduce relative error), should be collected for SfM since they are used as automatic tie points between all the images, and provide the ground truth control points for the models for accurate bedding measurements. Those photos can be used to create a low-resolution DOM, which does not take much time, as a quality check, as well as a way to determine bed orientations quickly and immediately, either in the field that day or that evening. The low-resolution model will then help the user decide the best orientations and lighting for the desired final DOM. If the images from the first day are sufficient, these can be used to make a high-resolution DOM, but if new images are needed, care should be taken to collect all new images within a single day in as short a time frame as possible to minimize changes in lighting, and the DOM should be developed from this new set of photos only. This will allow for optimal coloration of the final 3D textured mesh and keypoint matching during the SfM processing. 
TABLE 9. A SUMMARY OF THE FINDINGS BETWEEN THE FIVE TECHNIQUES AND BRIEF REVIEW OF SFM.

\begin{tabular}{|c|c|c|c|c|c|}
\hline Method & Outcomes & Benefits & Limitations & Time & Best Application \\
\hline Field & $\begin{array}{c}S / D^{8} \\
\text { Bed thickness } \\
\text { Facies interpretation } \\
\text { Paleocurrent } \\
\text { Transport direction }\end{array}$ & $\begin{array}{c}\text { Multiple lines of data (e.g., } \\
\text { texture, mineralogy, } \\
\text { sedimentary structures }+ \\
\text { geometry) }\end{array}$ & $\begin{array}{c}\text { Low data volume } \\
\text { Access to high/precarious } \\
\text { outcrops } \\
\text { Land access }\end{array}$ & $\begin{array}{l}\text { 1-2 days/ strat } \\
\text { section }\end{array}$ & $\begin{array}{c}\text { Facies identification } \\
\text { Geolocated training data such as S/D at } \\
\text { known survey points } \\
\text { Bed thickness distribution } \\
\text { Fine-scale lithologic details }\end{array}$ \\
\hline Photomosaic & Facies interpretation & $\begin{array}{c}\text { Examine large outcrop } \\
\text { expanse } \\
\text { Low cost }\end{array}$ & $\begin{array}{l}\text { Need minimum geometric } \\
\text { perspective distortions } \\
\text { Sensitive to light conditions } \\
\text { (e.g., shadows) } \\
\text { Low data volume }\end{array}$ & $\begin{array}{l}\text { Photomosaic: } 10 \\
\text { minutes in Adobe } \\
\text { Photoshop }\end{array}$ & $\begin{array}{l}\text { Quick method to examine large continuous } \\
\text { outcrops }\end{array}$ \\
\hline $\begin{array}{l}\text { Low-resolution } \\
\text { DOM }\end{array}$ & $\begin{array}{c}\text { S/D } \\
\text { Bed thickness } \\
\text { Facies interpretation }\end{array}$ & $\begin{array}{c}\text { Examine large outcrop } \\
\text { expanse } \\
\text { Quality check }\end{array}$ & $\begin{array}{l}\text { Smearing of grain scale } \\
\text { features } \\
\text { High data volume }\end{array}$ & DOM: 15 minutes & $\begin{array}{c}\text { Maximize time in field } \\
\text { Determine best orientations and lighting }\end{array}$ \\
\hline $\begin{array}{l}\text { High-resolution } \\
\text { DOM }\end{array}$ & $\begin{array}{c}\text { S/D } \\
\text { Bed thickness } \\
\text { Facies interpretation }\end{array}$ & $\begin{array}{l}\text { Examine large outcrop } \\
\text { expanse } \\
\text { High potential data volume } \\
\text { (S/D, thickness) }\end{array}$ & $\begin{array}{l}\text { Storage and computing } \\
\text { requirements } \\
\text { Interpretation limited to color } \\
\text { and weathering } \\
\text { characteristics. }\end{array}$ & DOM: 02h: 30m & $\begin{array}{c}\text { Independent field measurements to test and } \\
\text { validate early modeling }\end{array}$ \\
\hline $\begin{array}{l}\text { High-resolution } \\
\text { +Video DOM }\end{array}$ & $\begin{array}{c}\text { S/D } \\
\text { Bed thickness } \\
\text { Facies interpretation }\end{array}$ & $\begin{array}{l}\text { Examine large outcrop } \\
\text { expanse } \\
\text { High potential data volume } \\
\text { (S/D, thickness) }\end{array}$ & $\begin{array}{l}\text { Lacks full EXIF information } \\
\text { Extracted frames at best } \sim 8.8 \\
\text { megapixels from } 4 \mathrm{~K} \text { video } \\
\text { Sensitive to light conditions }\end{array}$ & DOM: 01h: $20 \mathrm{~m}$ & $\begin{array}{l}\text { In general, without EXIF information, video is } \\
\text { not recommended for SfM }\end{array}$ \\
\hline SfM from sUAVs & $\begin{array}{l}\text { Digital outcrop, } \\
\text { elevation, and terrain } \\
\text { models }\end{array}$ & $\begin{array}{l}\text { Meso- and large-scale } \\
\text { structural boundaries in } \\
\text { images } \\
\text { High data volume }\end{array}$ & $\begin{array}{c}\text { Smearing of grain-scale } \\
\text { features during DOM creation } \\
\text { Land access } \\
\text { Adherence to FAA }{ }^{9} \\
\text { regulations } \\
\text { Environmental conditions }\end{array}$ & $\begin{array}{l}\text { Depends on DOM } \\
\text { template and } \\
\text { program used }\end{array}$ & $\begin{array}{l}\text { Representative S/D and bed thickness at } \\
\text { length-scale from } \mathrm{cm} \text { to } \mathrm{m} \\
\text { Define control points with precision surveys }\end{array}$ \\
\hline
\end{tabular}

\footnotetext{
${ }^{8} \mathrm{~S} / \mathrm{D}=$ Strike and dip

${ }^{9} \mathrm{FAA}=$ Federal Aviation Administration
} 
After the initial DOM is created and bedding measurements are completed, traditional stratigraphic analysis with the DOM as a guide should be completed in the field. The bedding, grain size, lithology, sedimentary structures, and fossil observations may be mapped directly on the DOM and bed thickness measurements collected concurrently. Care should be taken to record placement of markers in the stratigraphic section for later analysis and correlation with the DOM as needed. The DOMs also provide an independent means of recording the position of detailed measurements, samples, and photos as well as a real-time check between distances between features represented in the model and the distances measured in the field by tape measure or Jacob staff. Early detection of incompatibilities could thus be detected, and actions could be taken to identify and resolve their source leading to higher quality data overall. In addition, if samples are collected, by marking sampling locations on the DOM, any later confusion or communication difficulty between different researchers may be reduced. 


\section{CHAPTER 5}

\section{CONCLUSION}

Each of the techniques have strengths as well as weaknesses - even the traditional field methods. The high-resolution DOM produced with a single flight of photographic data was the ideal DOM to extract sedimentologic data. The dense point cloud and 3D textured mesh comparisons in the high-resolution DOM produced a field replica with minimal stretching, and resolvable lithologic units. Though high-resolution DOMs require a longer processing time than low-resolution DOMs, the time required is not substantially more than that for low-resolution DOMs. The high-resolution with video DOM was difficult to generate since metadata was not included with the videos and the videos were taken from a separate flight, resulting in a change in the lighting conditions of the outcrop. Furthermore, the high-resolution with video DOM covered approximately the same amount of outcrop, but it was not uniform in color due to differences in image lighting. While the photomosaic showed more sedimentary structures, correct coloration of the outcrop, and boundaries between beds, the lack of 3-dimensional exposures results in inaccurate bedding plane measurements and consequently the stratigraphic log is compressed, and bedding thickness measurements are inaccurate. The drone-related techniques can be used to replicate stratigraphic sections measured traditionally in the field, but not without limitations concerning consistent and accurate lithological identification or the compositional and textural data with the level of detail that is possible with field analysis. Ultimately, although fieldwork cannot be replaced, drone technology may change the way in which we can do this work by providing more accurate bedding measurements and augmenting field data and allowing a researcher to collect large amounts of geologic data that can be revisited at any time. 


\section{REFERENCES}

Allmendinger, R.W., Cardozo, N.C. and Fisher, D., 2012. Structural Geology Algorithms: Vectors \& Tensors. Cambridge University Press, Cambridge, 289 p.

Anderson, K. and Segall, P., 2013. Bayesian inversion of data from effusive volcanic eruptions using physics-based models: Application to Mount St. Helens 2004-2008. Journal of Geophysical Research: Solid Earth, 118(5), pp.2017-2037.

Axen, G.J., Fletcher, J.M., 1998. Late Miocene-Pleistocene extensional faulting, northern Gulf of California, Mexico and Salton Trough, California. Int. Geol. Rev. 40, pp.217-244.

Babcock, E.A., 1974. Geology of the Northeast Margin of the Salton Trough, Salton Sea, California. GSA Bull. 85, pp.321-332.

Bellian, J.A., Kerans, C. and Jennette, D.C., 2005. Digital outcrop models: applications of terrestrial scanning lidar technology in stratigraphic modeling. Journal of sedimentary research, 75(2), pp.166-176.

Bemis S.P., Micklethwaite S., Turner D., et al., 2014. Ground-based and UAV-Based photogrammetry: A multi-scale, high-resolution mapping tool for structural geology and paleoseismology. J. Struct. Geol. 69, pp.163-178

Bergh, S.G., Sylvester, A.G., Damte, A., Indrevær, K., 2019. Polyphase kinematic history of transpression along the Mecca Hills segment of the San Andreas fault, southern California. Geosphere 15, pp.901-934. 
Bilmes A., D’Elia L., Lopez L., et al., 2019. Digital outcrop modelling using “structure-frommotion" photogrammetry: Acquisition strategies, validation, and interpretations to different sedimentary environments. J South Am Earth Sci 96: 102325.

Bistacchi A., Balsamo F., Storti F., et al., 2015. Photogrammetric digital outcrop reconstruction, visualization with textured surfaces, and three-dimensional structural analysis and modeling: Innovative methodologies applied to fault-related dolomitization (Vajont Limestone, Southern Alps, Italy). Geosphere 11 pp.2031-2048.

Boley, J.L., Stimac, J.P., Weldon, R.J., Rymer, M.J., 1994. Stratigraphy and paleomagnetism of the Mecca and Indio Hills, southern California. In: McGill, S.F., Ross, T.M. (Eds.), Geological Investigations of an Active Margin: Geological Society of America. Cordilleran Section Guidebook, Trip 15, pp. 336-344.

Bond C.E., Shipton Z.K., Jones R.R., et al., 2007. Knowledge transfer in a digital world: Field data acquisition, uncertainty, visualization, and data management. Geosphere 3 pp.568576.

Boufama, B., Weinshall, D. and Werman, M., 1994, May. Shape from motion algorithms: a comparative analysis of scaled orthography and perspective. In European Conference on Computer Vision (pp. 197-204). Springer, Berlin, Heidelberg.

Bubniak, I.M., Bubniak, A.M., Gavrilenko, O.D., Nikulishyn, V.I. and Golubinka, I.I., 2019, May. Using laser scanning and digital photogrammetry for creation of virtual geological outcrops: Case studies from the west of Ukraine. In 18th International Conference on 
Geoinformatics-Theoretical and Applied Aspects, 2019 (1), pp. 1-5. European Association of Geoscientists \& Engineers.

Burnham, B.S. and Hodgetts, D., 2019. Quantifying spatial and architectural relationships from fluvial outcrops. Geosphere, 15(1), pp.236-253.

Buckley S.J., Ringdal K., Naumann N., et al., 2019. LIME: Software for 3-D visualization, interpretation, and communication of virtual geoscience models. Geosphere 15, pp.222235.

Calvo R., Ramos E., 2015. Unlocking the correlation in fluvial outcrops by using a DOMderived virtual datum: Method description and field tests in the Huesca fluvial fan, Ebro Basin (Spain). Geosphere 11, pp.1507-1529.

Caravaca, G., Le Mouélic, S., Mangold, N., L’Haridon, J., Le Deit, L. and Massé, M., 2020. 3D digital outcrop model reconstruction of the Kimberley outcrop (Gale crater, Mars) and its integration into Virtual Reality for simulated geological analysis. Planetary and Space Science, 182, p.104808.

Cawood A.J., Bond C.E., Howell J.A., et al., 2017. LiDAR, UAV, or compass-clinometer? Accuracy, coverage and the effects on structural models. $J$ Struct Geol 98, pp.67-82.

Chang, S.-B.R., Allen, C.R., Kirschvink, J.L., 1987. Magnetic stratigraphy and a test for block rotation of sedimentary rocks within the San Andreas fault zone, Mecca Hills, southeastern California. Quat. Res. 27, pp.30-40. 
Chesley J.T., Leier A.L., White S., Torres R., 2017. Using unmanned aerial vehicles and structure-from-motion photogrammetry to characterize sedimentary outcrops: An example from the Morrison Formation, Utah, USA. Sediment Geol. 354, pp.1-8.

Cirillo, D., 2020. Digital Field Mapping and Drone-Aided Survey for Structural Geological Data Collection and Seismic Hazard Assessment: Case of the 2016 Central Italy Earthquakes. Applied Sciences, 10(15), p.5233.

De Paor, D.G., 2016. Virtual rocks. GSA Today, 26(8), pp.4-11.

Dewez, T.J., Girardeau-Montaut, D., Allanic, C. and Rohmer, J., 2016. Facets: a cloudcompare plugin to extract geological planes from unstructured $3 \mathrm{~d}$ point clouds. International Archives of the Photogrammetry, Remote Sensing \& Spatial Information Sciences, 41.

Dibblee, T.W., 1954. Geology of the Imperial Valley region, California. Geology of southern California, California Division of Mines Bulletin vol. 170, pp.21-28.

Dickinson, W.R., Suczek, C.A., 1979. Plate tectonics and sandstone compositions. Am. Assoc. Pet. Geol. Bull. 63, pp.2164-2182.

Dorsey, R.J., Umhoefer, P.J., 2011. Influence of sediment input and plate-motion obliquity on basin development along an active oblique-divergent plate boundary: Gulf of California and Salton Trough. Tectonics Sediment. Basins, Wiley Online Books.

Durkin P.R., Boyd R.L., Hubbard S.M., et al., 2017. Three-Dimensional Reconstruction of Meander-Belt Evolution, Cretaceous McMurray Formation, Alberta Foreland Basin, Canada. J Sediment Res 87, pp.1075-1099. 
Drummond, C.N., and Bruce H.W. , 1996. Stratal Thickness Frequencies and the Prevalence of Orderedness in Stratigraphic Sequences. The Journal of Geology, 104(1), pp.1-18.

Fabuel-Perez, I., Hodgetts, D. and Redfern, J., 2010. Integration of digital outcrop models (DOMs) and high resolution sedimentology-workflow and implications for geological modelling: Oukaimeden Sandstone Formation, High Atlas (Morocco). Petroleum Geoscience, 16(2), pp.133-154.

Favalli, M., Fornaciai, A., Isola, I., Tarquini, S. and Nannipieri, L., 2012. Multiview 3D reconstruction in geosciences. Computers \& Geosciences, 44, pp.168-176.

Fedo, C.M., Sircombe, K.N., Rainbird, R.H., 2003. Detrital zircon analysis of the sedimentary record. Rev. Mineral. Geochemistry 53, pp.277-303.

Fuis, G.S. and Mooney, W.D., 1990. Lithospheric structure and tectonics from seismic-refraction and other data. The San Andreas Fault System, California, United States Geol. Surv. Prof. Pap. 1515, pp.206-236.

Groshong Jr, R.H., 2006. 3-D structural geology (pp. 305-371). Springer-Verlag Berlin Heidelberg.

Han, L., Hole, J.A., Stock, J.M., Fuis, G.S., Kell, A., Driscoll, N.W., Kent, G.M., Harding, A.J., Rymer, M.J., González-Fernández, A., Lázaro-Mancilla, O., 2016. Continental rupture and the creation of new crust in the Salton Trough rift, southern California and northern Mexico: Results from the Salton Seismic Imaging Project. J. Geophys. Res. Solid Earth 121, pp.7469-7489. 
Hansman, R.J. and Ring, U., 2019. Workflow: From photo-based 3-D reconstruction of remotely piloted aircraft images to a 3-D geological model. Geosphere, 15(4), pp.1393-1408.

Hilley, G.E., Mynatt, I. and Pollard, D.D., 2010. Structural geometry of Raplee Ridge monocline and thrust fault imaged using inverse Boundary Element Modeling and ALSM data. Journal of Structural Geology, 32(1), pp.45-58.

Jänecke, S.U., Markowski, D.K., Evans, J.P., Persaud, P., Kenney, M., 2018. Durmid ladder structure and its implications for the nucleation sites of the next $\mathrm{M}>7.5$ earthquake on the San Andreas fault or Brawley seismic zone in southern California. Lithosphere 10, pp.602-631.

Johnson K., Nissen E., Saripalli S., et al., 2014. Rapid mapping of ultrafine fault zone topography with structure from motion. Geosphere 10, pp.969-986.

Jordan B.R., 2019. Collecting field data in volcanic landscapes using small UAS (sUAS)/drones. J Volcanol Geotherm Res 385, pp.231-241.

Labourdette R., Jones R.R., 2007. Characterization of fluvial architectural elements using a three-dimensional outcrop data set: Escanilla braided system, South-Central Pyrenees, Spain. Geosphere 3, pp.422-434.

Lowe, D.G., 1999, September. Object recognition from local scale-invariant features. In Proceedings of the seventh IEEE international conference on computer vision 2, pp. $1150-1157$.

Lowe, G., 2004. Sift-the scale invariant feature transform. Int. J, 2(91-110), p.2. 
Maerten L., Pollard D.D., Maerten F., 2001. Digital mapping of three-dimensional structures of the Chimney Rock fault system, central Utah. J Struct Geol 23, pp.585-592.

McCaffrey, K.J.W., Feely, M., Hennessy, R. and Thompson, J., 2008. Visualization of folding in marble outcrops, Connemara, western Ireland: An application of virtual outcrop technology. Geosphere, 4(3), pp.588-599.

McNabb, J.C., Dorsey, R.J., Housen, B.A., Dimitroff, C.W., Messé, G.T., 2017. Stratigraphic record of Pliocene-Pleistocene basin evolution and deformation within the Southern San Andreas fault zone, Mecca Hills, California. Tectonophysics 719-720, pp.66-85.

Mezghani, M.M., Fallatah, M.I. and AbuBshait, A.A., 2018. From drone-based remote sensing to digital outcrop modeling: integrated workflow for quantitative outcrop interpretation. Journal of Remote Sensing \& GIS, 7(2).

Nesbit P.R., Durkin P.R., Hugenholtz C.H., et al., 2018. 3-D stratigraphic mapping using a digital outcrop model derived from UAV images and structure-from-motion photogrammetry. Geosphere 14, pp.2469-2486.

Nieminski N.M., Graham S.A., 2017. Modeling Stratigraphic Architecture Using Small Unmanned Aerial Vehicles and Photogrammetry: Examples from the Miocene East Coast Basin, New Zealand. J Sediment Res 87, pp.126-132.

Ouédraogo, M.M., Degré, A., Debouche, C. and Lisein, J., 2014. The evaluation of unmanned aerial system-based photogrammetry and terrestrial laser scanning to generate DEMs of agricultural watersheds. Geomorphology, 214, pp.339-355. 
Pavlis, T.L. and Mason, K.A., 2017. The new world of 3D geologic mapping. Gsa Today, 27(9), pp.4-10.

Rarity, F., Van Lanen, X.M.T., Hodgetts, D., Gawthorpe, R.L., Wilson, P., Fabuel-Perez, I. and Redfern, J., 2014. LiDAR-based digital outcrops for sedimentological analysis: workflows and techniques. Geological Society, London, Special Publications, 387(1), pp.153-183.

Senger, K., Betlem, P., Birchall, T., Buckley, S.J., Coakley, B., Eide, C.H., Flaig, P.P., Forien, M., Galland, O., Gonzaga Jr, L. and Jensen, M., 2020. Using digital outcrops to make the high Arctic more accessible through the Svalbox database. Journal of Geoscience Education, pp.1-15.

Spetsakis, M. and Aloimonos, J.Y., 1991. A multi-frame approach to visual motion perception. International Journal of Computer Vision, 6(3), pp.245-255.

Strecha, C., Küng, O. and Fua, P., 2012. Automatic mapping from ultra-light UAV imagery (No. CONF).

Sunkara, J.K., Purnima, K., Muchakala, S., Y, R., 2011., Super-resolution based image reconstruction, IJCST 2(3), pp.273-281.

Sylvester, A.G., O’Black-Gans, E., 2016. Roadside Geology of Southern California, Illustrated. ed. Mountain Press Publishing Company. 
Sylvester, A.G., Smith, R.R., 1976. Tectonic transpression and basement-controlled deformation in San Andreas fault zone, Salton Trough, California. Am. Assoc. Pet. Geol. Bull. 60, pp.2081-2102.

Sylvester, A.G., Smith, R.R., 1987. Structure section in Painted Canyon, Mecca Hills, southern California. Cordilleran Sect. Geol. Soc. Am.

Szeliski, R. and Kang, S.B., 1994. Recovering 3D shape and motion from image streams using nonlinear least squares. Journal of Visual Communication and Image

Triantafyllou, A., Watlet, A., Le Mouélic, S., Camelbeeck, T., Civet, F., Kaufmann, O., Quinif, Y. and Vandycke, S., 2019. 3-D digital outcrop model for analysis of brittle deformation and lithological mapping (Lorette cave, Belgium). Journal of Structural Geology, 120, pp.55-66.

Trinks, I., Clegg, P., McCaffrey, K., Jones, R., Hobbs, R., Holdsworth, B., Holliman, N., Imber, J., Waggott, S. and Wilson, R., 2005. Mapping and analysing virtual outcrops. Visual Geosciences, 10(1), pp.13-19.

Vázquez-Tarrío D., Borgniet L., Liébault F., Recking A., 2017. Using UAS optical imagery and SfM photogrammetry to characterize the surface grain size of gravel bars in a braided river (Vénéon River, French Alps). Geomorphology 285, pp.94-105.

Vollgger S.A., Cruden A.R., 2016. Mapping folds and fractures in basement and cover rocks using UAV photogrammetry, Cape Liptrap and Cape Paterson, Victoria, Australia. $J$ Struct Geol 85, pp.168-187. 
Wallace, R.E. (Ed.), 1990. The San Andreas fault system, California, Professional Paper.

Westoby M.J., Brasington J., Glasser N.F., et al., 2012. "Structure-from-Motion" photogrammetry: A low-cost, effective tool for geoscience applications. Geomorphology 179, pp.300-314.

Westoby M.J., Dunning S.A., Woodward J., et al., 2015. Instruments and methods:

Sedimentological characterization of Antarctic moraines using uavs and Structure-fromMotion photogrammetry. J Glaciol 61, pp.1088-1102.

Whitmeyer, S.J., Nicoletti, J. and De Paor, D.G., 2010. The digital revolution in geologic mapping. Gsa Today, 20(4/5), pp.4-10.

Zahm, C., Lambert, J. and Kerans, C., 2016. Use of unmanned aerial vehicles (UAVs) to create digital outcrop models: An example from the Cretaceous Cow Creek Formation, Central Texas. GCAGS Journal, 5, pp.180-188.

Zervas, D., Nichols, G.J., Hall, R., Smyth, H.R., Lüthje, C. and Murtagh, F., 2009. SedLog: A shareware program for drawing graphic logs and log data manipulation. Computers \& Geosciences, 35(10), pp.2151-2159. 


\section{APPENDIX A}

\section{MATLAB SCRIPTS AND FUNCTIONS}

The analysis of bedding attitude and associated thickness of layers between bedding planes is obtained via workflow scripts with associated subroutine scripts and functions implemented in MATLAB (Table A.1). These custom scripts are provided in this Appendix; a subset of these scripts was obtained from the book Structural Geology Algorithms by Allmendinger (2012). These scripts can be downloaded from the Cambridge University Press' web portal at https://www.cambridge.org/us/academic/subjects/earth-and-environmentalscience/structural-geology-tectonics-and-geodynamics/structural-geology-algorithms-vectorsand-tensors? format=PB?format=PB.

Table A1. LIST OF CUSTOM SCRIPTS USED TO EXTRACT ATTITUDE AND THICKNESS DATA FROM DOM.

\begin{tabular}{|c|c|c|c|c|}
\hline Hierarchy & Filename & Type & Purpose & Source \\
\hline 1 & $\begin{array}{c}\text { WORKFLOW_3pt_ } \\
\text { calculation_simple. } \\
\text { m }\end{array}$ & $\mathrm{S}$ & $\begin{array}{c}\text { Calculate Strike and Dip from } \\
\text { three points }\end{array}$ & JM, NCD \\
\hline 1 & $\begin{array}{c}\text { WORKFLOW_thick } \\
\text { ness.m }\end{array}$ & $\mathrm{S}$ & $\begin{array}{c}\text { Calculate Strike, Dip, Normal } \\
\text { Vector and apparent distances } \\
\text { between adjacent planes. }\end{array}$ & JM, NCD \\
\hline 1 & $\begin{array}{c}\text { WORKFLOW_vis_s } \\
\text { d.m }\end{array}$ & $\mathrm{S}$ & $\begin{array}{c}\text { Visualize strike and dip } \\
\text { measurements via stereograms and } \\
\text { rose diagrams }\end{array}$ & JM, NCD \\
\hline 2 & IMPORT_sd & $\mathrm{S}$ & $\begin{array}{c}\text { Import strike and dip values from } \\
\text { Excel file }\end{array}$ & $\mathrm{JM}, \mathrm{NCD}$ \\
\hline 2 & IMPORT_stations & $\mathrm{S}$ & $\begin{array}{c}\text { Import survey points defining a } \\
\text { bedding play from Excel file }\end{array}$ & $\mathrm{JM}, \mathrm{NCD}$ \\
\hline 2 & IMPORT_thickness & $\mathrm{S}$ & $\begin{array}{c}\text { Import points and field } \\
\text { measurements from Excel File }\end{array}$ & $\mathrm{JM}, \mathrm{NCD}$ \\
\hline
\end{tabular}




\begin{tabular}{|c|c|c|c|c|}
\hline 3 & point2plane.m & F & $\begin{array}{c}\text { Distance between planes based on } \\
\text { input starting point on one plane } \\
\text { and direction toward second plane }\end{array}$ & JM, NCD \\
\hline 3 & sdv2eqnplane.m & F & $\begin{array}{c}\text { Strike and dip to equation of the } \\
\text { plane }\end{array}$ & JM, NCD \\
\hline 4 & PlotLineStereonet.m & F & Plot points on a stereogram & JM, NCD \\
\hline 4 & PLOT_vis_layers.m & F & $\begin{array}{c}\text { Visualize equations of plane and } \\
\text { survey stations }\end{array}$ & JM, NCD \\
\hline 5 & affine_fit & F & least squares fit plane to points & AD \\
\hline 5 & n2sd.m & F & Normal vector to strike and dip & NCD \\
\hline 5 & v2tp.m & F & Vector to trend and plunge & NCD \\
\hline 6 & $\begin{array}{c}\text { Download } \\
\text { supporting scripts }\end{array}$ & Stereonet.m & F & A_SA \\
\hline 7 & GreatCircle.m & F & $\begin{array}{c}\text { Plot steregram } \\
\text { stereogram }\end{array}$ & \\
\hline 7 & GeogrToView.m & F & Convert geographic to projected & \\
\hline 7 & Pole.m & F & $\begin{array}{c}\text { Pole vector to plane from trend and } \\
\text { plunge }\end{array}$ & \\
\hline 7 & SmallCircle.m & F & Calculate small circles on \\
stereogram & \\
\hline 7 & STCoordLine.m & F & $\begin{array}{c}\text { Project line onto local x, y of } \\
\text { stereogram from trend an dplunge }\end{array}$ & \\
\hline 7 & ZeroTwoPi.m & F & Convert azimuth to radiam & \\
\hline
\end{tabular}

$\mathrm{JM}=$ JoAnna Marlow, NCD = Nicholas Davatzes, A_SA = Allmendinger (2012), AD = Adrien Leygue (2013) (Matlab Exchange)

$\mathrm{S}=$ script, $\mathrm{F}=$ function

Note that as written, the level 1 WORKFLOW scripts assume a directory structure; these scripts call scripts AddDataDirs or AddFunctionDirs which are simply scripts that use the ADDPATH function to temporarily add the subdirectories to the MATLAB search path. It is possible to put all scripts in the same directory instead, then simply remove the calls to these helper scripts. 


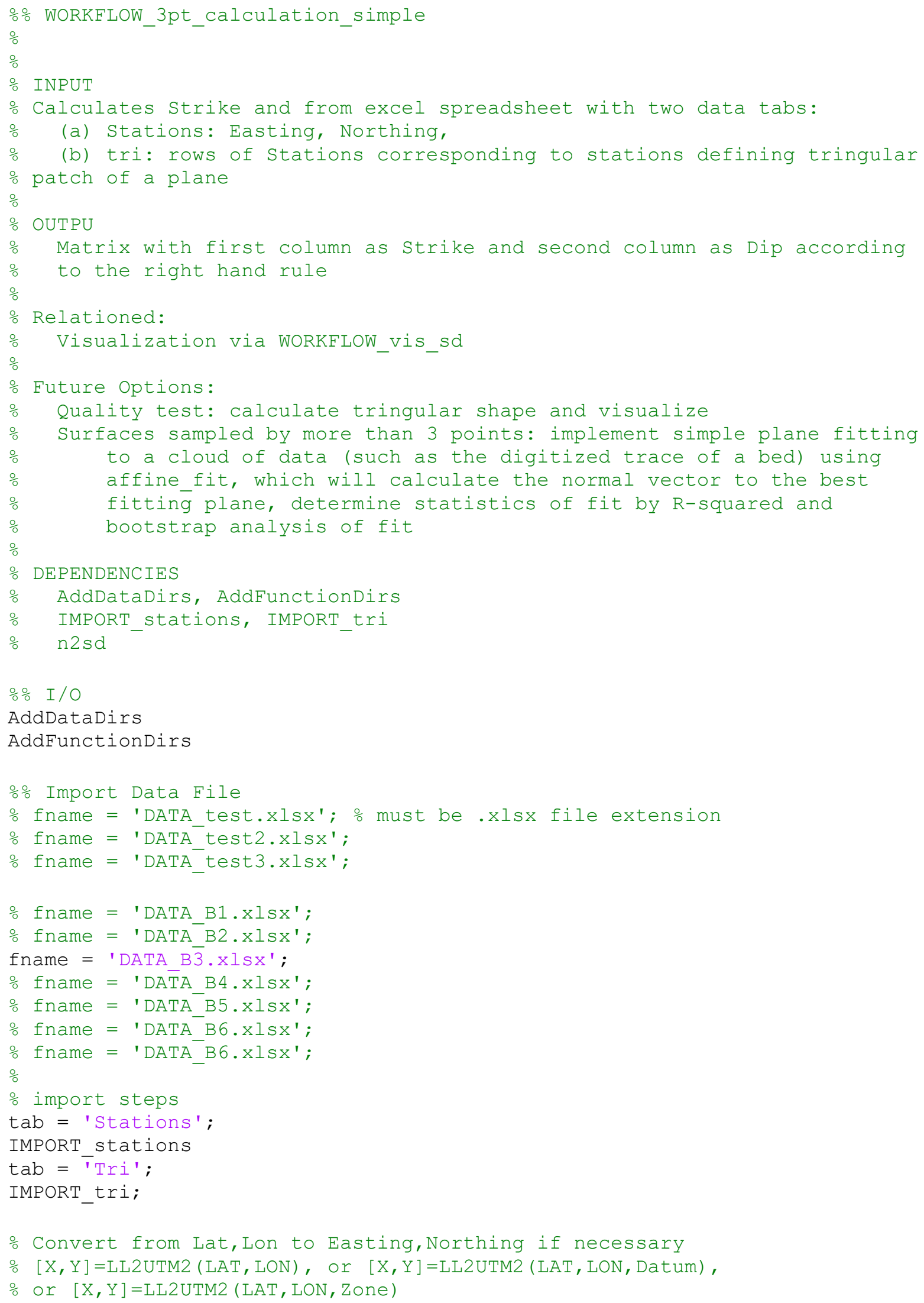




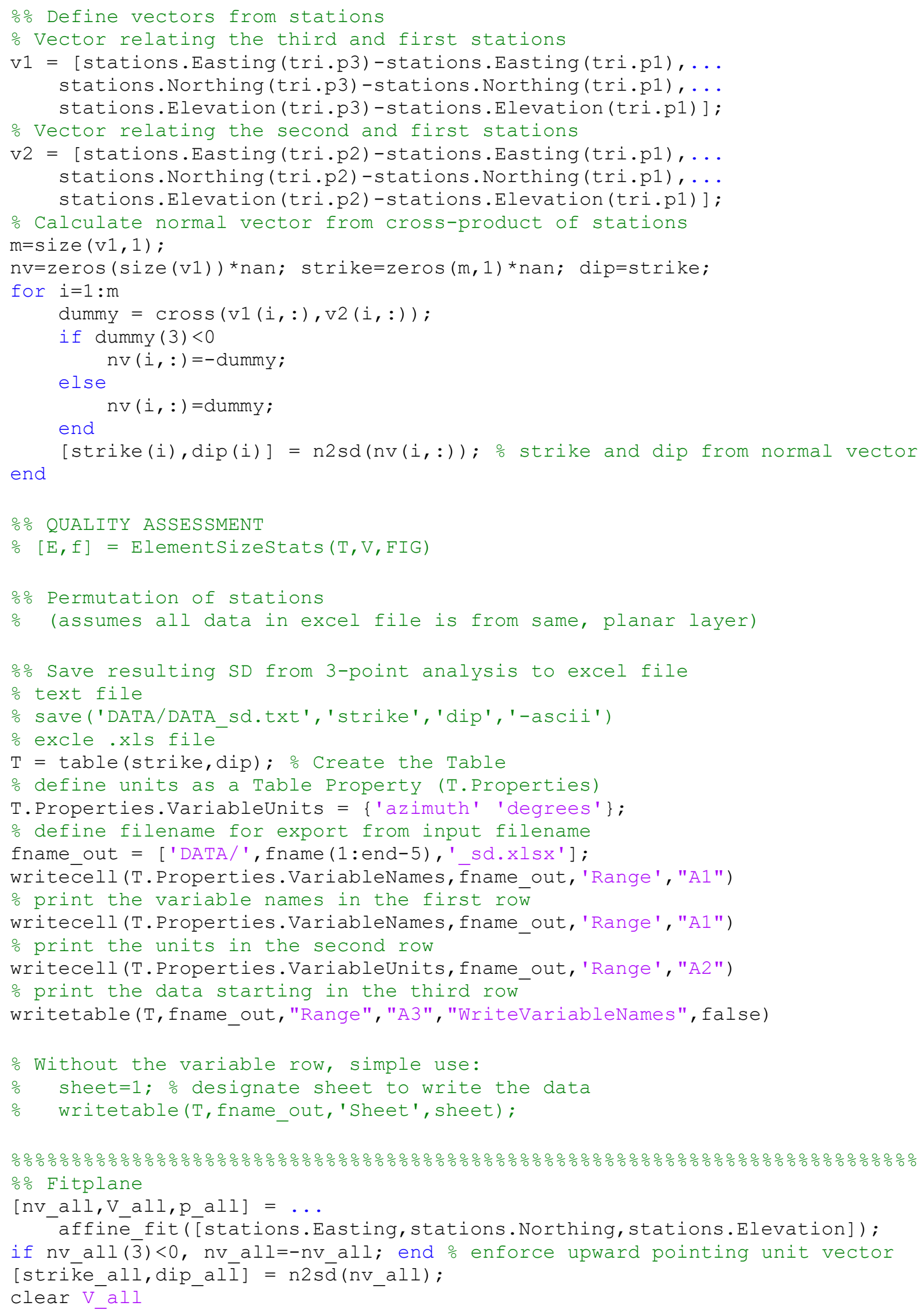




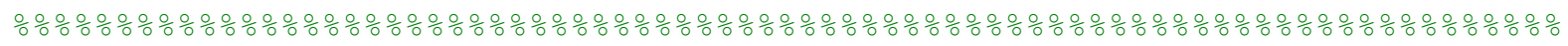

응 TEST - Visualize Set of Points

$\mathrm{fl}=\mathrm{figure}$;

ax1 = subplot $(2,1,1)$;

\% plot conntecting lines between sequential rows of stations

plot3 (stations.Easting, stations. Northing, stations.Elevation, '-k') ;

hold on

o plot station locations, color-coded by elevation

$\mathrm{S}=8^{\wedge} 2 ;$ \% size of plotted symbols

hs = scatter3 (stations.Easting, stations.Northing, stations.Elevation,...

S, stations.Elevation, 'filled');

xlabel('Easting [m]'); ylabel('Northing [m]'); zlabel('Elevation [m]')

grid on, box on, axis equal

hc = colorbar; ylabel (hc, 'Elevation (m)');

\% plot fitplane to scattered points

\% define corner points for patch plot

$\mathrm{xlp}=[\min ($ stations.Easting) $\max$ (stations.Easting) ...

max (stations.Easting) min(stations.Easting) min(stations.Easting)];

$\mathrm{x} 2 \mathrm{p}=[\mathrm{min}$ (stations.Northing) min(stations.Northing) ...

max (stations.Northing) max(stations.Northing) min(stations.Northing)];

\% use normal form of equation of plane:

\% $\mathrm{n} * \mathrm{p} 0 \mathrm{p}=0,(\mathrm{n} 1)(\mathrm{x} 1-\mathrm{p} 1)+(\mathrm{n} 2)(\mathrm{x} 2-\mathrm{p} 2)+(\mathrm{n} 3)(\mathrm{x} 3-\mathrm{p} 3)=0$,

응 $(\mathrm{n} 1)(\mathrm{x} 1)+(\mathrm{n} 2)(\mathrm{x} 2)+(\mathrm{n} 3)(\mathrm{x} 3)-((\mathrm{n} 1)(\mathrm{p} 1)+(\mathrm{n} 2)(\mathrm{p} 2)+(\mathrm{n} 3)(\mathrm{p} 3))=0$

응 $\quad(\mathrm{n} 1)(\mathrm{x} 1)+(\mathrm{n} 2)(\mathrm{x} 2)+(\mathrm{n} 3)(\mathrm{x} 3)=((\mathrm{n} 1)(\mathrm{p} 1)+(\mathrm{n} 2)(\mathrm{p} 2)+(\mathrm{n} 3)(\mathrm{p} 3))$

응 $(\mathrm{n} 1)(\mathrm{x} 1)+(\mathrm{n} 2)(\mathrm{x} 2)+(\mathrm{n} 3)(\mathrm{x} 3)=\operatorname{dot}(\mathrm{n}, \mathrm{p})$

을 $(\mathrm{x} 3)=(\operatorname{dot}(\mathrm{n}, \mathrm{p})-(\mathrm{n} 1)(\mathrm{x} 1)-(\mathrm{n} 2)(\mathrm{x} 2))(1 / \mathrm{n} 3)$

$x 3 p=\left(\operatorname{dot}\left(n v \_a l l, p \_a l l\right)-n v \_a l l(1) * x l p-n v \_a l l(2) * x 2 p\right) *\left(1 / n v \_a l l(3)\right) ;$

patch (x1p, x2p, x3p, '采', 'FaceAlpha', 0.4, 'EdgeCō̄or', 'r')

o calculate residuals

$x 3$ model $=\left(\operatorname{dot}\left(n v \_a l l, p \_a l l\right)-n v \_a l l(1) *\right.$ stations.Easting - nv_all(2)*...

stations. Northing) * $(1 / \mathrm{nv}$ all $(\overline{3}))$;

res = stations.Elevation-x3model; $\%$ residual

\% plot lines connecting data points to the fit plane

plot3 ([stations.Easting, stations.Easting] ', ... [stations.Northing, stations.Northing] ', ...

[stations.Elevation, x3model] ', 'k-', 'Color', [0.6 0.60 .6$]$ )

plot3 (stations.Easting, ...

stations. Northing, ...

x3model', 'o', 'Color', [ 0.60 .60 .6$]$ )

\% reference horizontal plane through the centroid

patch $\left(x 1 p, x 2 p, p \_a l l(3)\right.$ *ones ( $\left.\operatorname{size}(x 1 p)\right), \ldots$

'b- ', 'FaceAlpha', 0.2 , 'FaceColor', [ $\left.\begin{array}{lll}0 & 0 & 1\end{array}\right]$, 'EdgeColor', 'b' )

o reference Vertical Plane through the centroid

$\mathrm{L}=\max \left(\operatorname{sqrt}\left(\left(\mathrm{p}_{-}\right.\right.\right.$all $(1)$-stations.Easting) $.^{\wedge} 2+\ldots$ (p_all(2)-stations.Northing).^2));

o defiñe corners of vertical plane

$\mathrm{xlvert}=\mathrm{p}$ all $(1)+\mathrm{L}^{*}[\operatorname{cosd}(90-($ strike all+90) $) \operatorname{cosd}(90-(\mathrm{strike}$ all-90)) ... cosd $\left(9 \overline{0}-\left(\right.\right.$ strike_all-90) ) cosd $\left(90-\left(\bar{s} t r i k e \_a l l+90\right)\right) \ldots$

cosd $(90-($ strike all+90)) ];

$\mathrm{x} 2 \mathrm{vert}=\mathrm{p}$ _all $(2)+\mathrm{L}^{*}[\mathrm{sind}(90-($ strike_all+90) $)$ sind $(90-($ strike_all-90) $) \ldots$ sind $\left(9 \overline{0}-\left(\right.\right.$ strike_all-90) ) sind $\left(90-\left(\bar{s} t r i k e \_a l l+90\right)\right) \ldots$

sind $(90-($ strike all +90$))]$;

dummyx3 = [stations.Elevation; $\left.\times 3 \mathrm{p}^{\prime}\right]$;

$\mathrm{x} 3$ vert $=\ldots$ 
[min (dummyx3) min (dummyx3) max (dummyx3) max (dummyx3) min (dummyx3) ]; patch (x1vert, $x 2$ vert, $x 3$ vert, ...

'k-', 'FaceAlpha', 0.3 , 'FaceColor', [ $\left.\begin{array}{lll}0.7 & 0.7 & 0.7\end{array}\right]$, 'EdgeColor', 'k' )

\% Reference footprint of fit plane

ax2 = subplot $(2,1,2)$;

stem3 (stations.Easting, stations. Northing, res, 'filled')

hold on

patch $(\mathrm{x} 1 \mathrm{p}, \mathrm{x} 2 \mathrm{p}$, zeros (size $(\mathrm{x} 1 \mathrm{p}))$, 'r-' ' 'FaceAlpha', 0.2, 'EdgeColor' , 'r') xlabel('Easting [m]'); ylabel('Northing [m]'); zlabel('Residual [m]') grid on, box on, axis equal

\% view(90-strike all, 15)

axl. View $=[90-$ strīke_all $1+15,15]$;

ax2. View $=[90-$ strike all+15, 15];

linkprop ([ax1 ax2], \{'Cameraposition', 'CameraUpVector', 'Xlim', 'Ylim'\});

\% simple camparison of Strike/Dip to FitPlane Strike/Dip

f2 = figure;

subplot $(2,1,1) \div$ compare strike

hl=plot (strike, 'ro', 'MarkerFaceColor', 'r'); grid on, box on, hold on

h2=plot ( [ l length (strike)], [strike all strike all], 'k-') ;

을 forting

ylim([0 360]); xlabel('station'), ylabel('strike (RHR, azimuth)');

set (gca, 'XTick', [])

legend([h1 h2],'3-point','lsq fit plane')

subplot $(2,1,2) \div$ compare dip

plot (dip, 'ro', 'MarkerfaceColor', 'r'), grid on, box on, hold on

plot([1 length(dip)], [dip_all dip_all],'k-')

ylim([0 90]), set (gca,' 'YTick', [0:10:90])

xlabel('station'), ylabel('dip (degrees)')

set (gca, 'XTick', 1:1:length (dip))

응 Save resulting fit plane to excel file

o text file

응 save('DATA/DATA sd.txt','strike', 'dip','-ascii')

o excle.xls file

strike_fp = strike_all(ones(size(strike)));

dip_fp $=$ dip_all (ones (size(dip)));

$\mathrm{T}=$ table (strike, dip, strike_fp, dip_fp); $\%$ Create the Table

o define units as a Table Property (T.Properties)

T.Properties.VariableUnits $=$ \{'azimuth' 'degrees','azimuth', 'degrees'\};

\% define filename for export from input filename

fname_out $=[$ 'DATA/', fname (1:end-5),'_sd_fitplane.xlsx'];

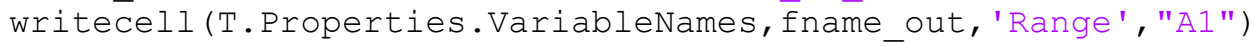

o print the variable names in the first row

writecell (T.Properties.VariableNames, fname_out, 'Range', "A1")

o print the units in the second row

writecell (T.Properties.VariableUnits, fname_out, 'Range ', "A2")

o print the data starting in the third row

writetable (T, fname_out, "Range", "A3" , "WriteVariableNames", false)

응 Save Figures

savefig(f1, ['Figures/', fname (1:end-4), '3D.fig']) ;

saveas (f1, ['Figures/', fname (1:end-4), '_- 3D.eps'], 'epsc') ;

savefig(f2, ['Figures/', fname(1:end-4), '_compare.fig']) ; 


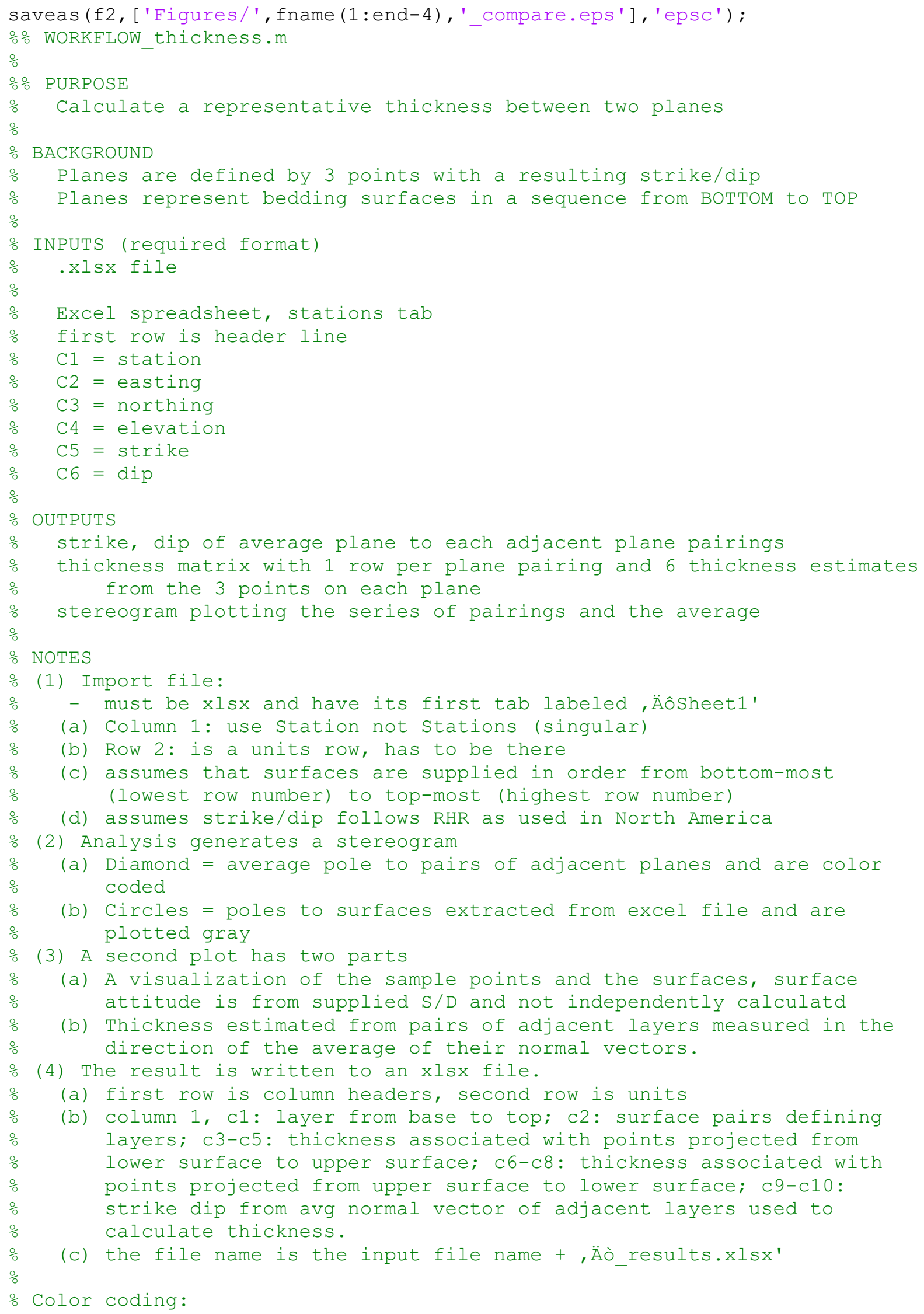




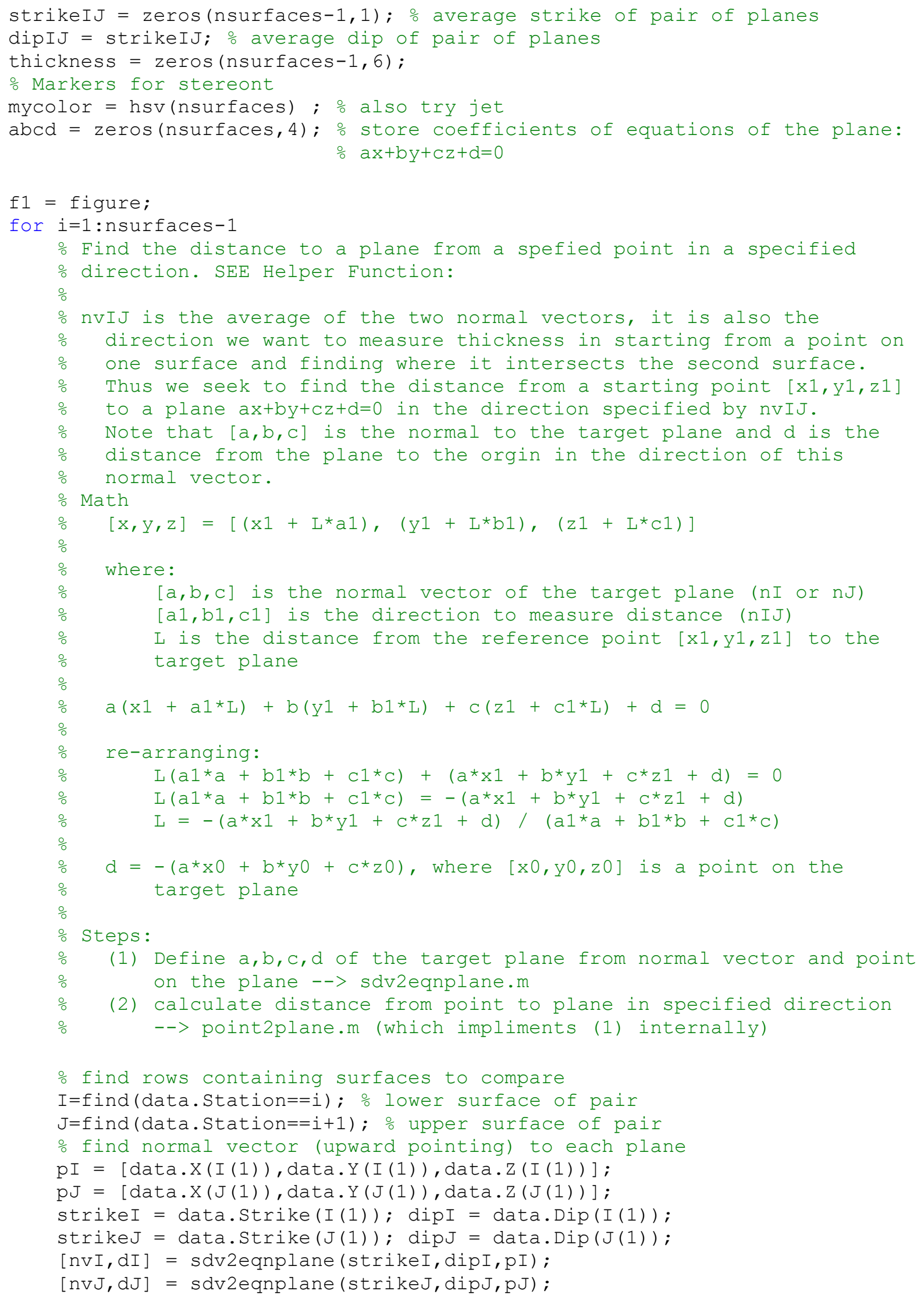




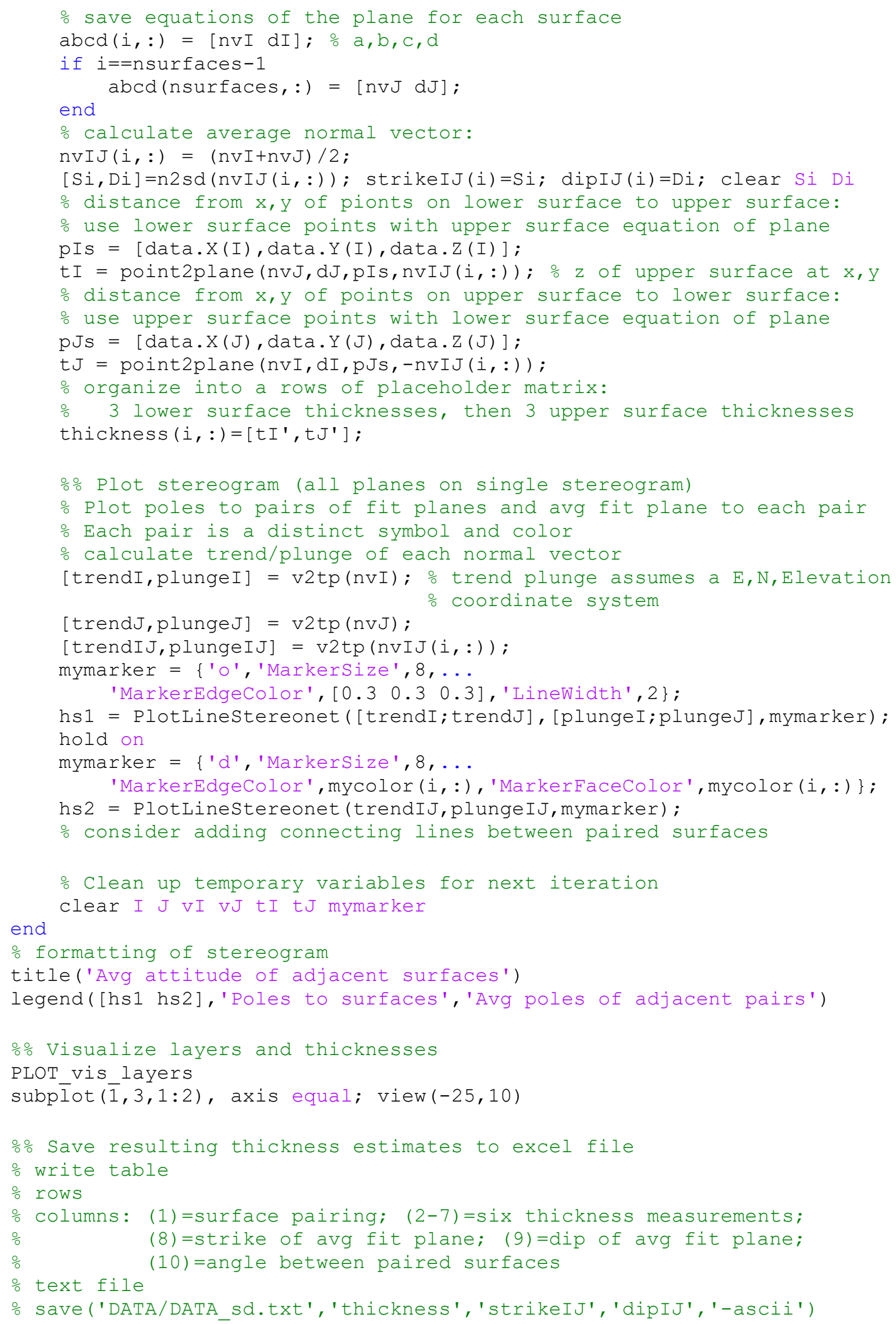




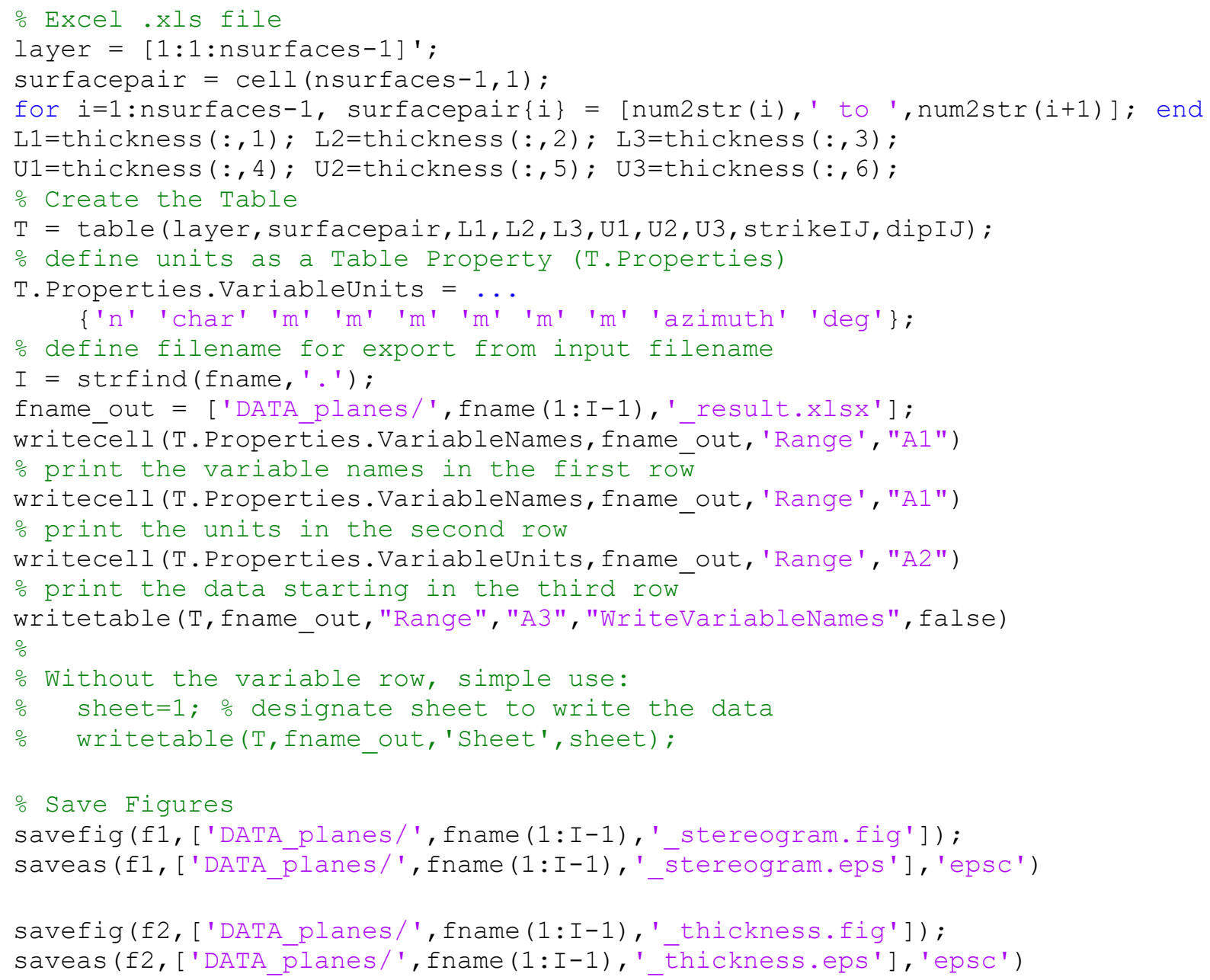




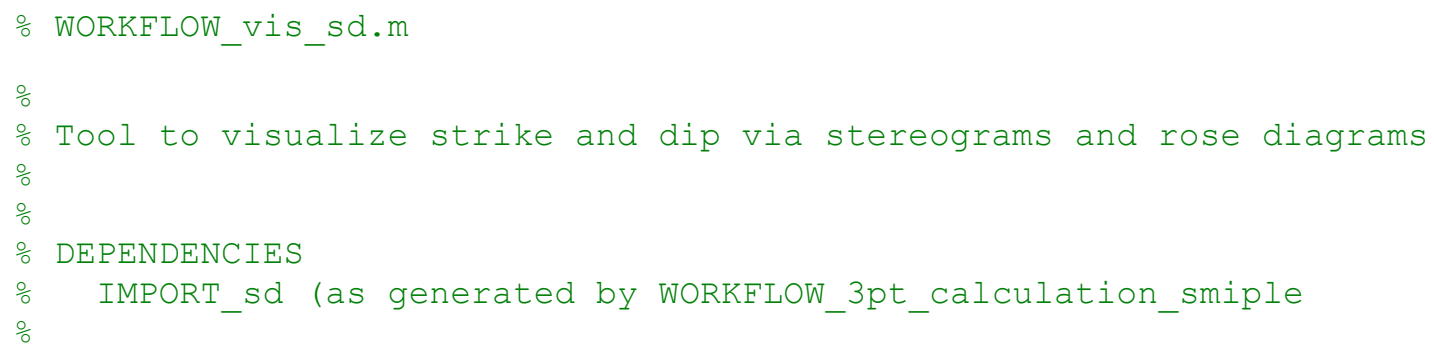




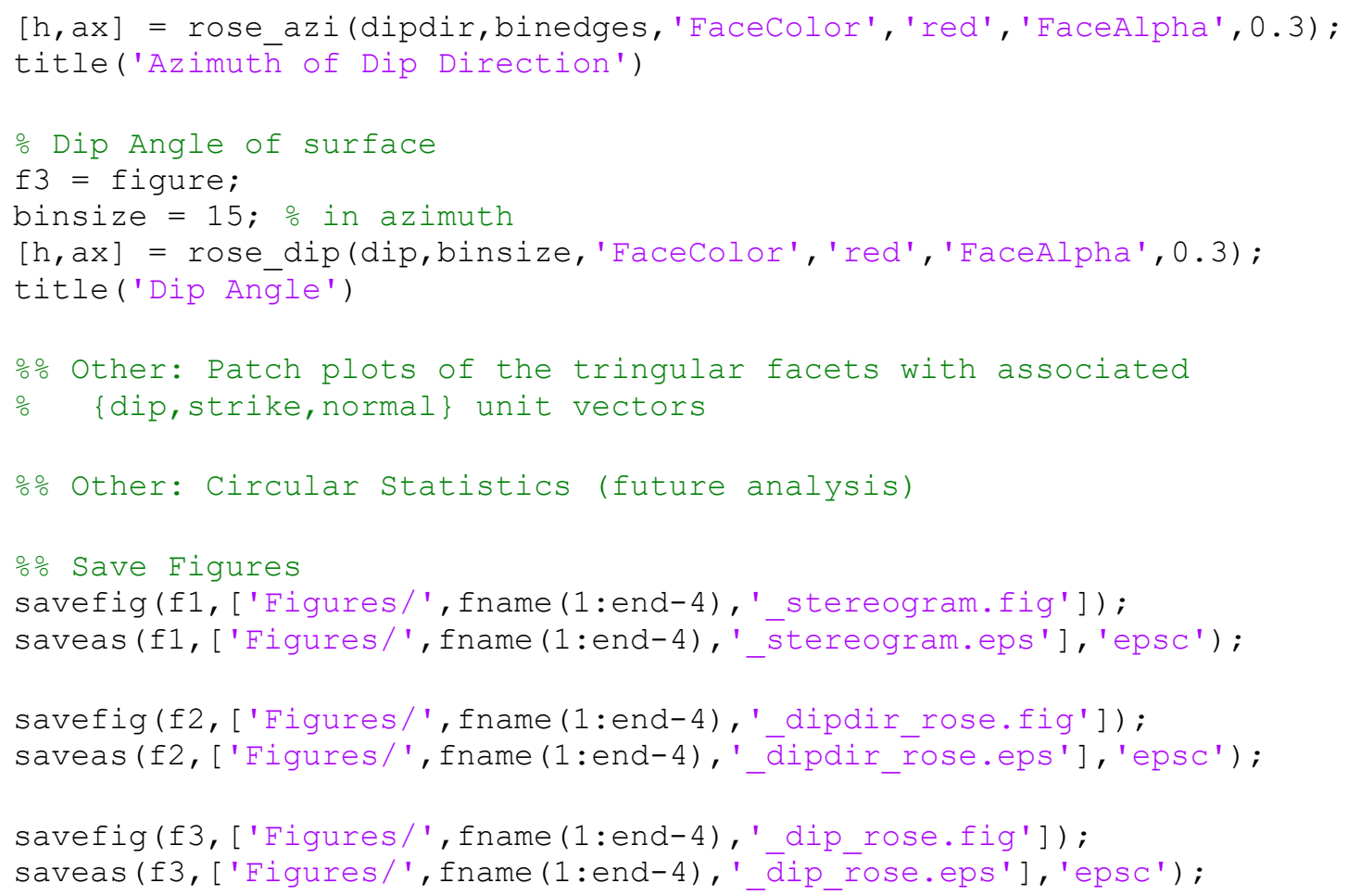




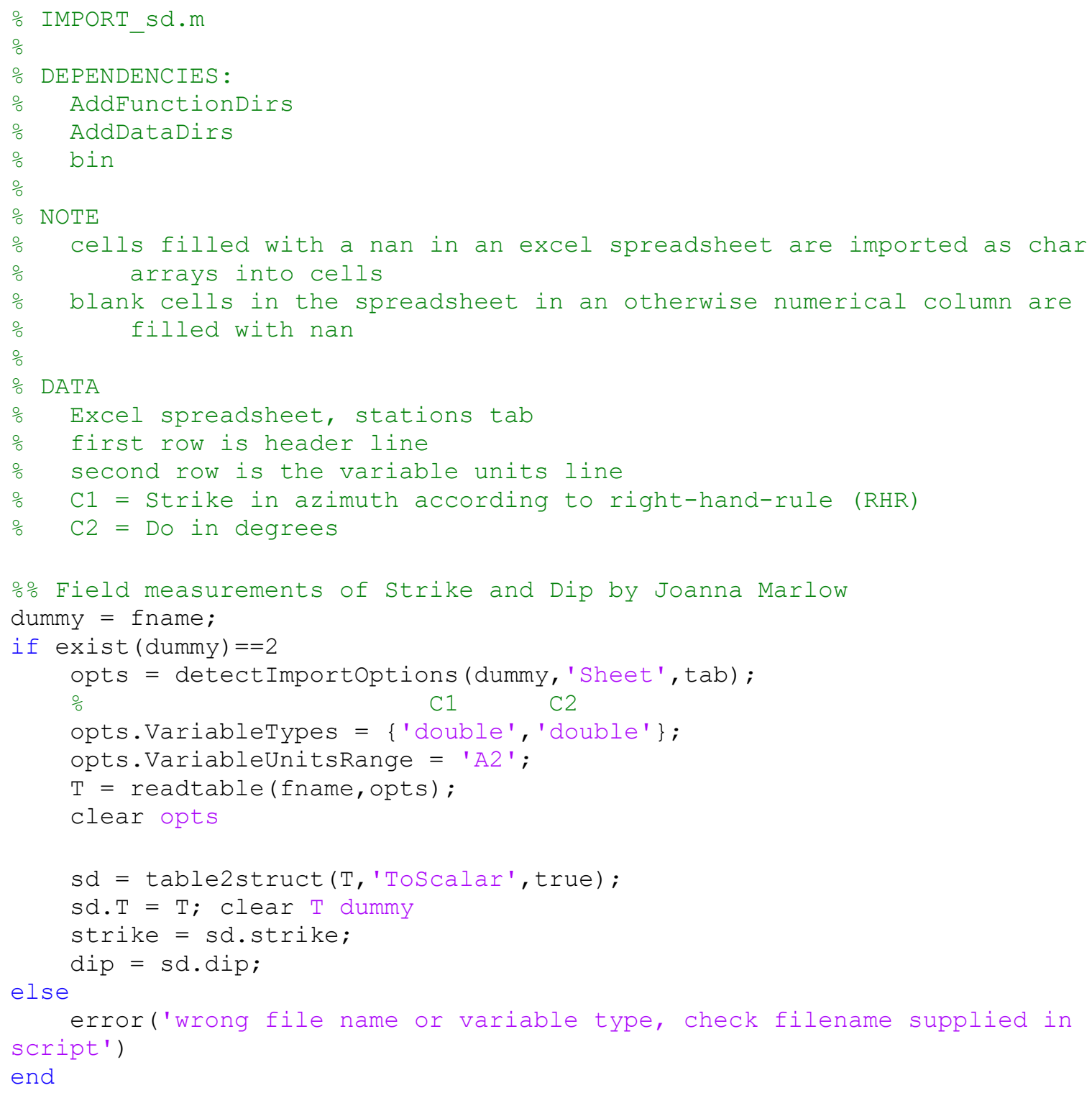




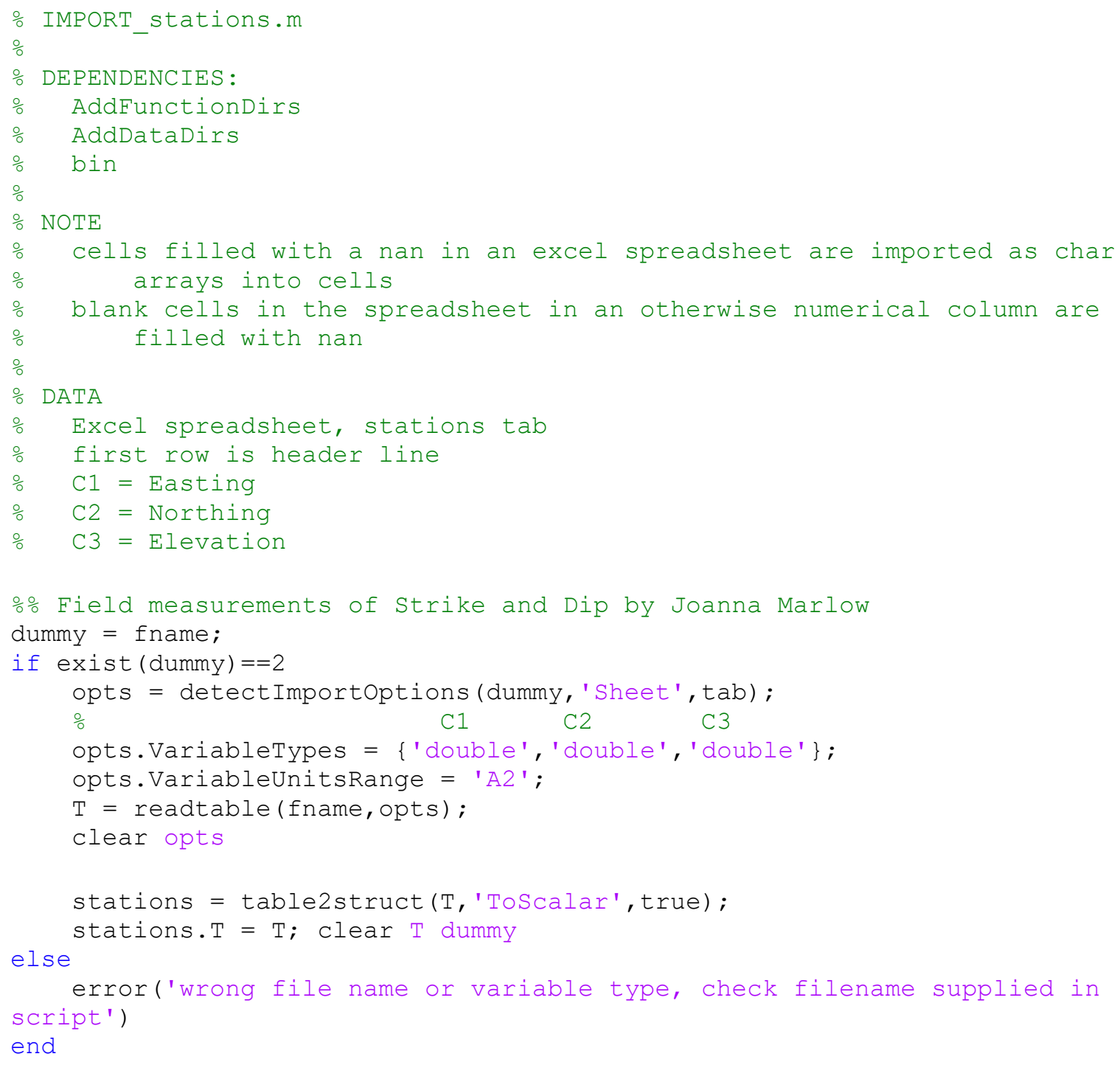




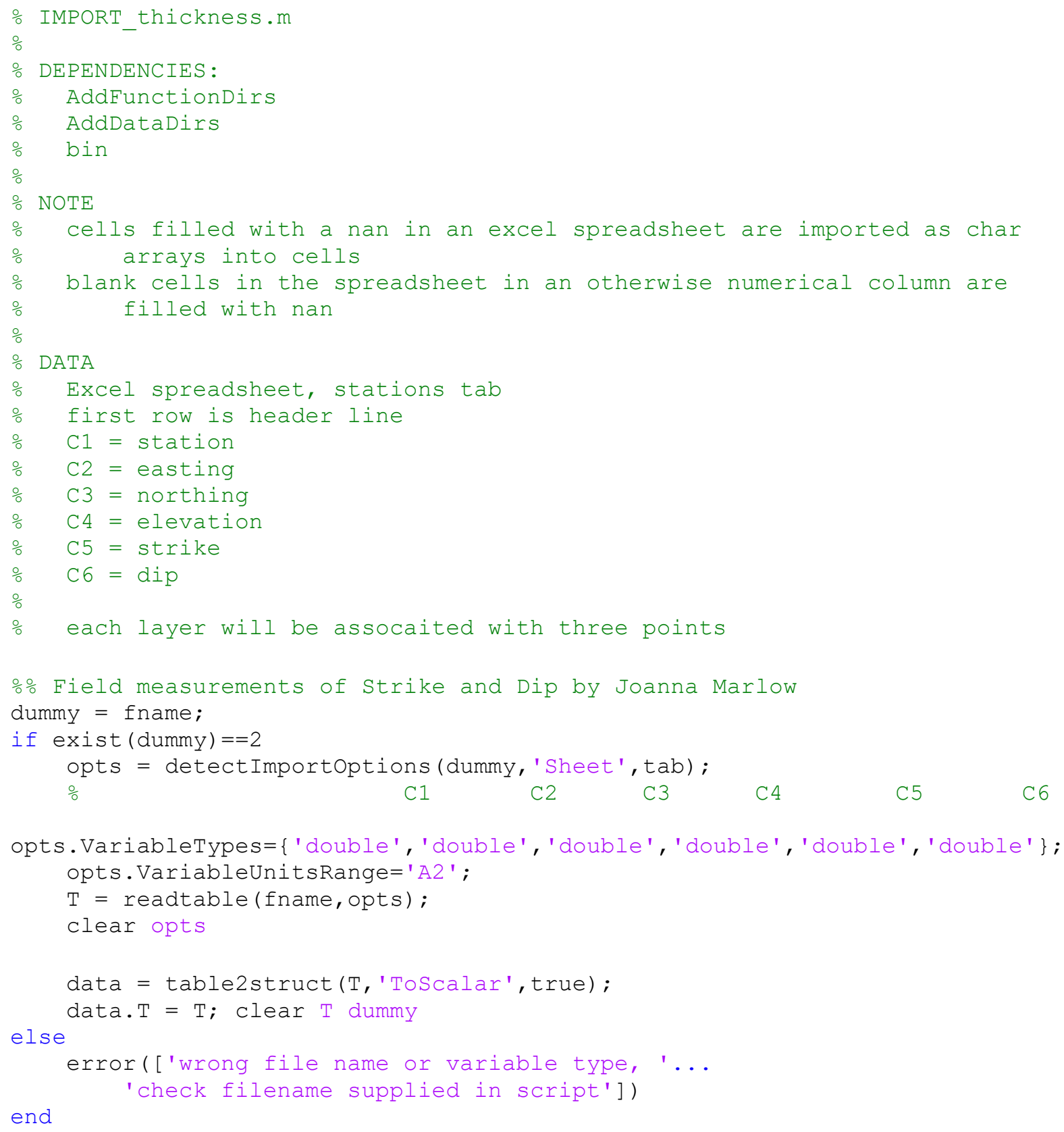




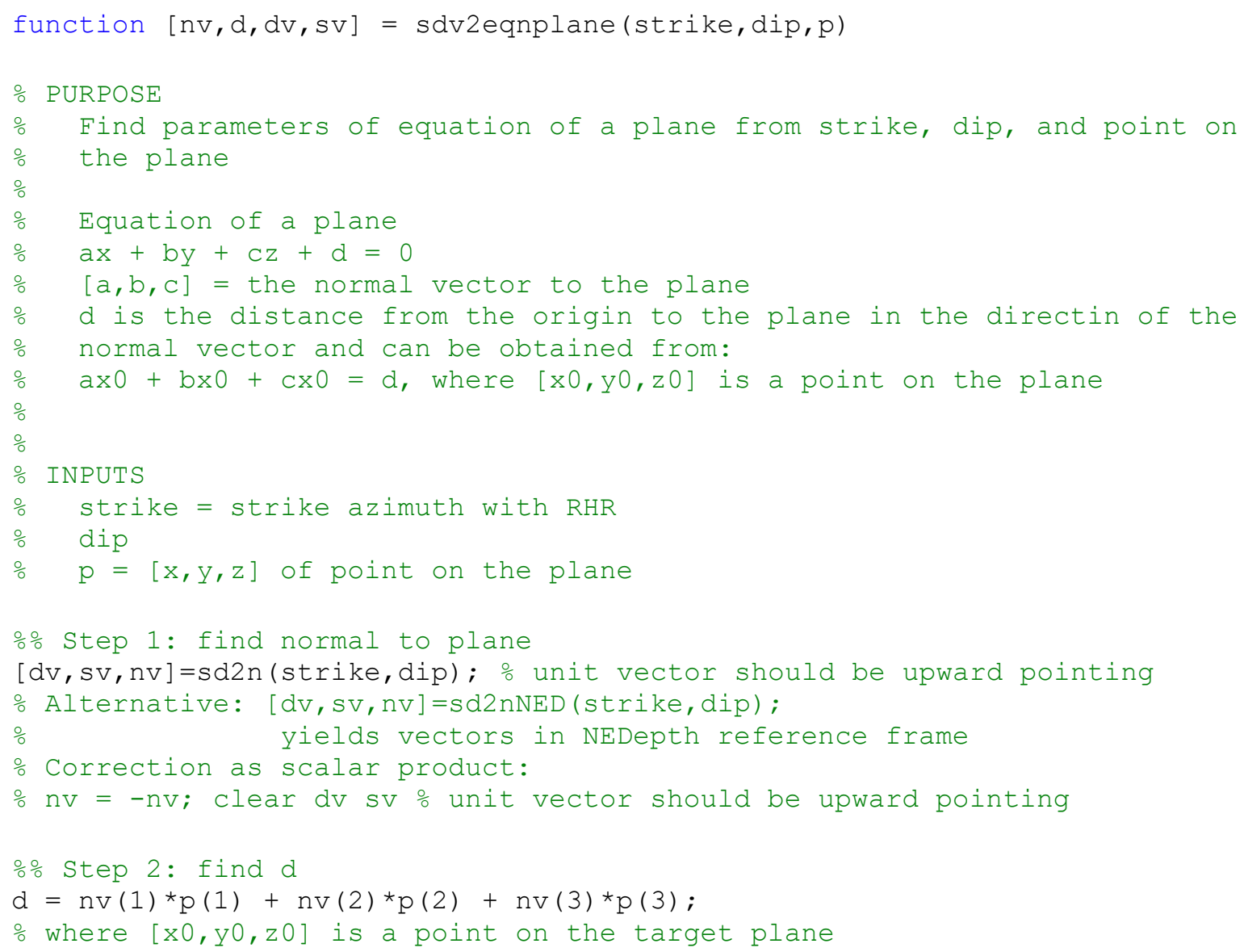




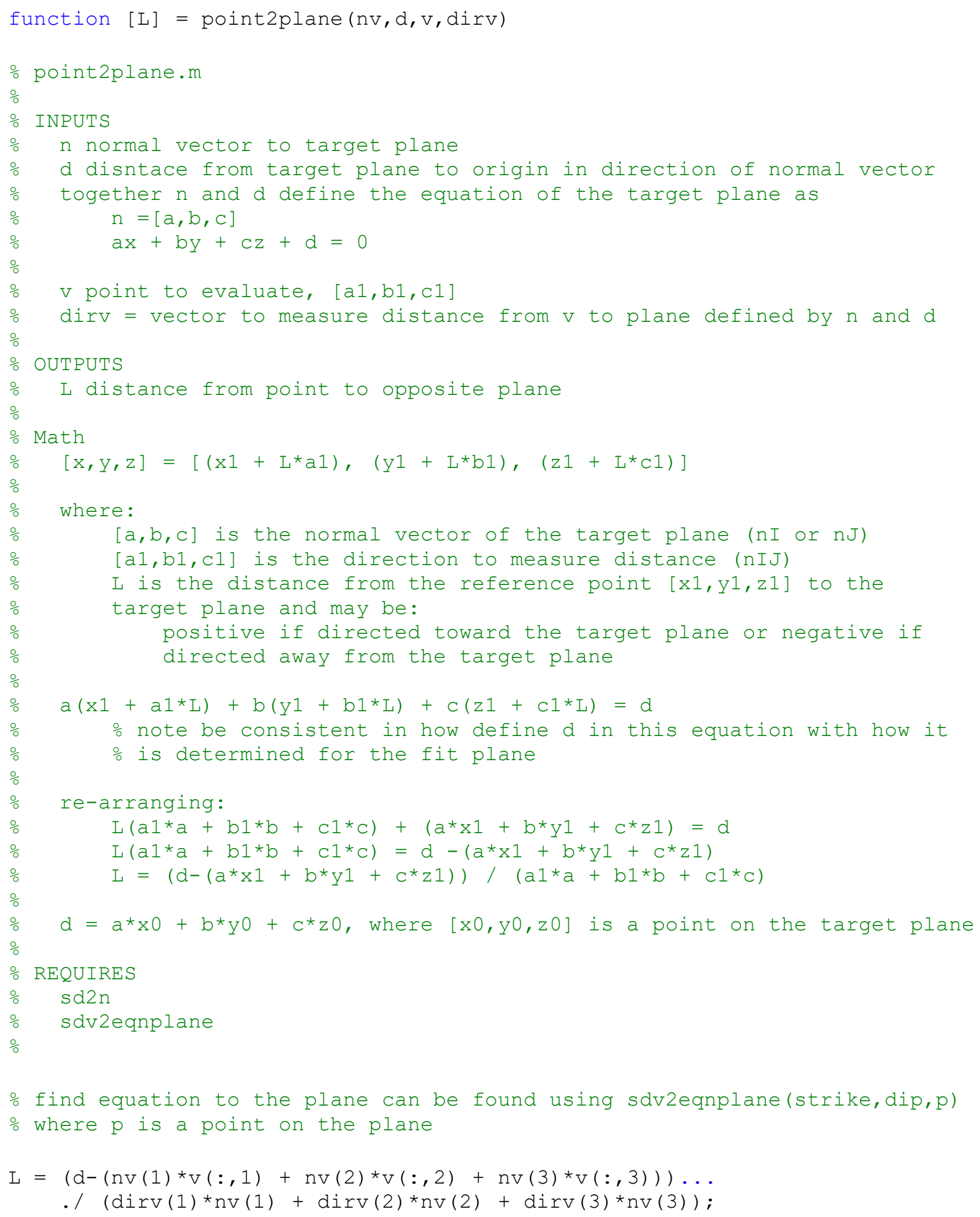




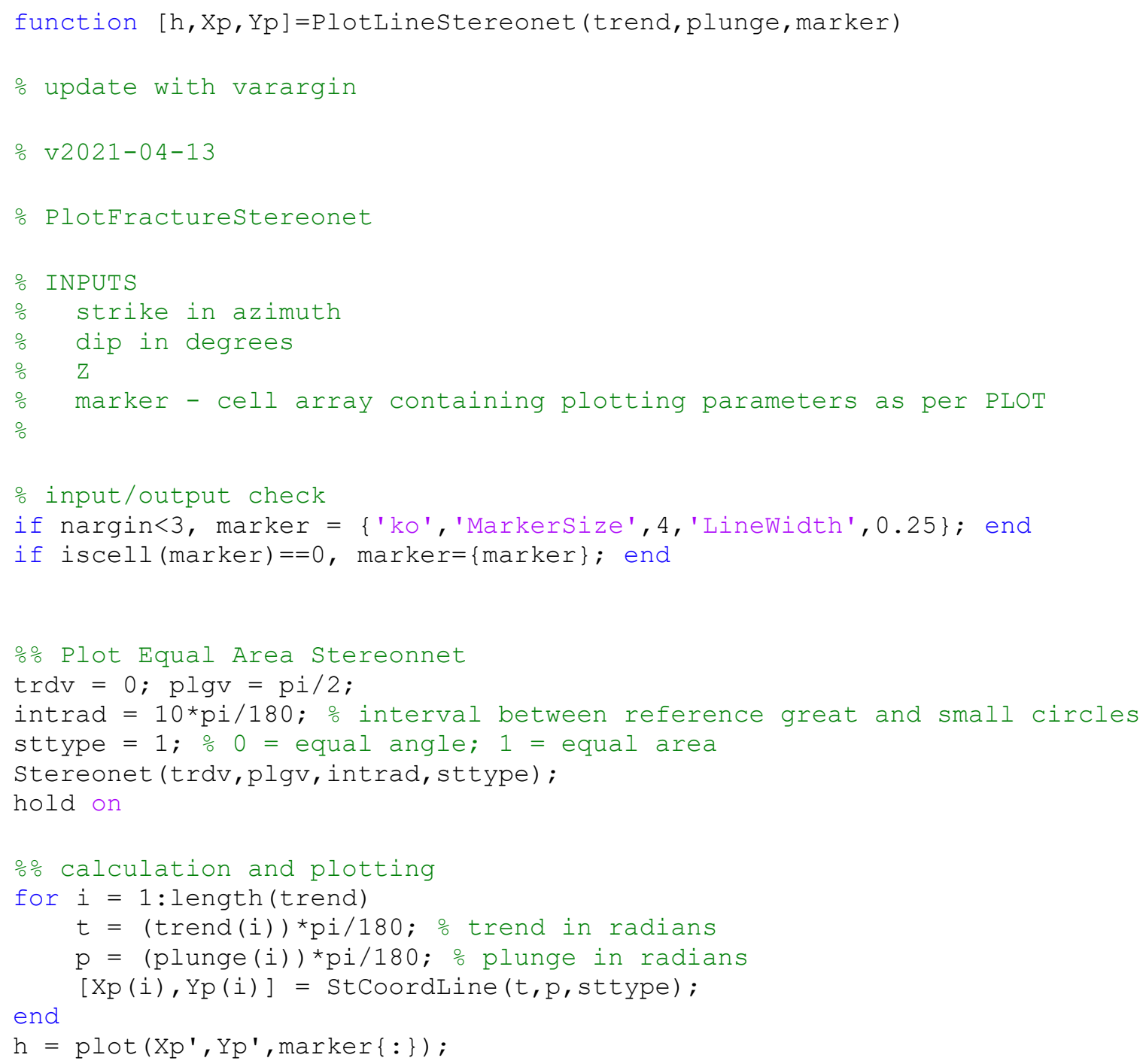




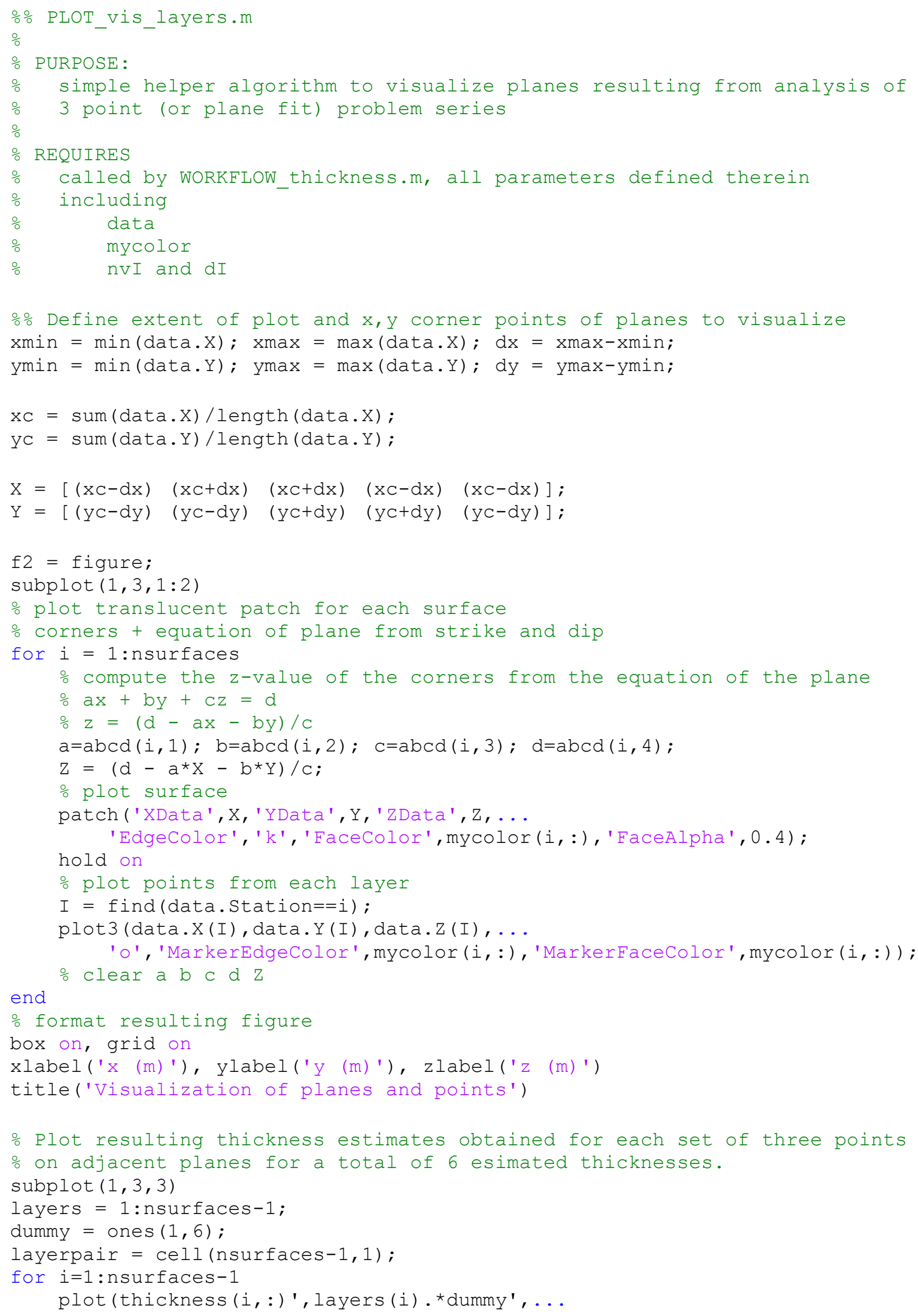




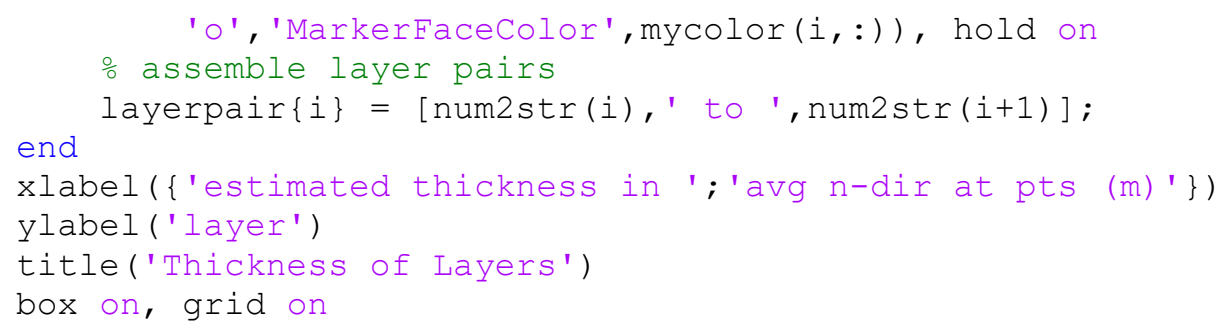




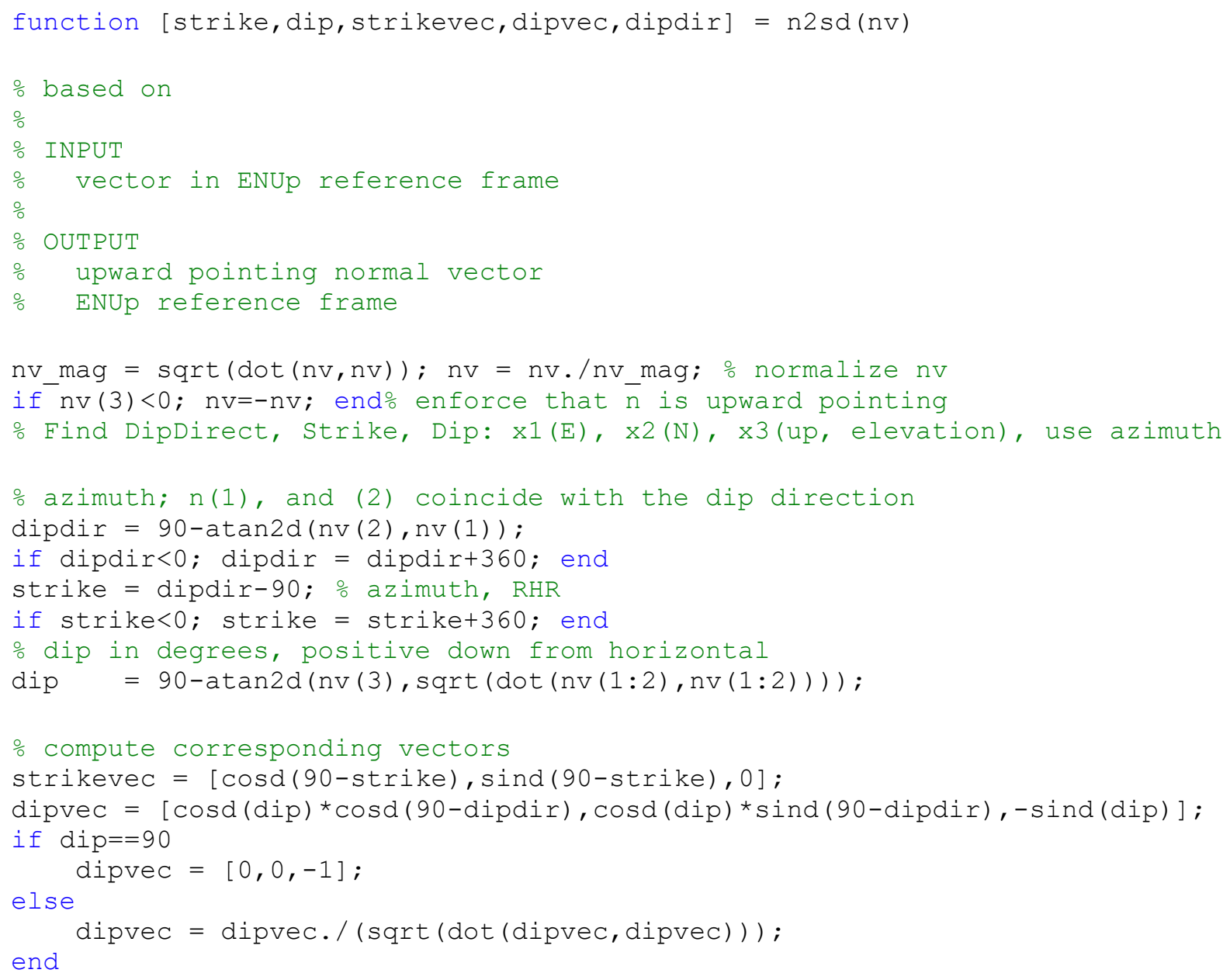




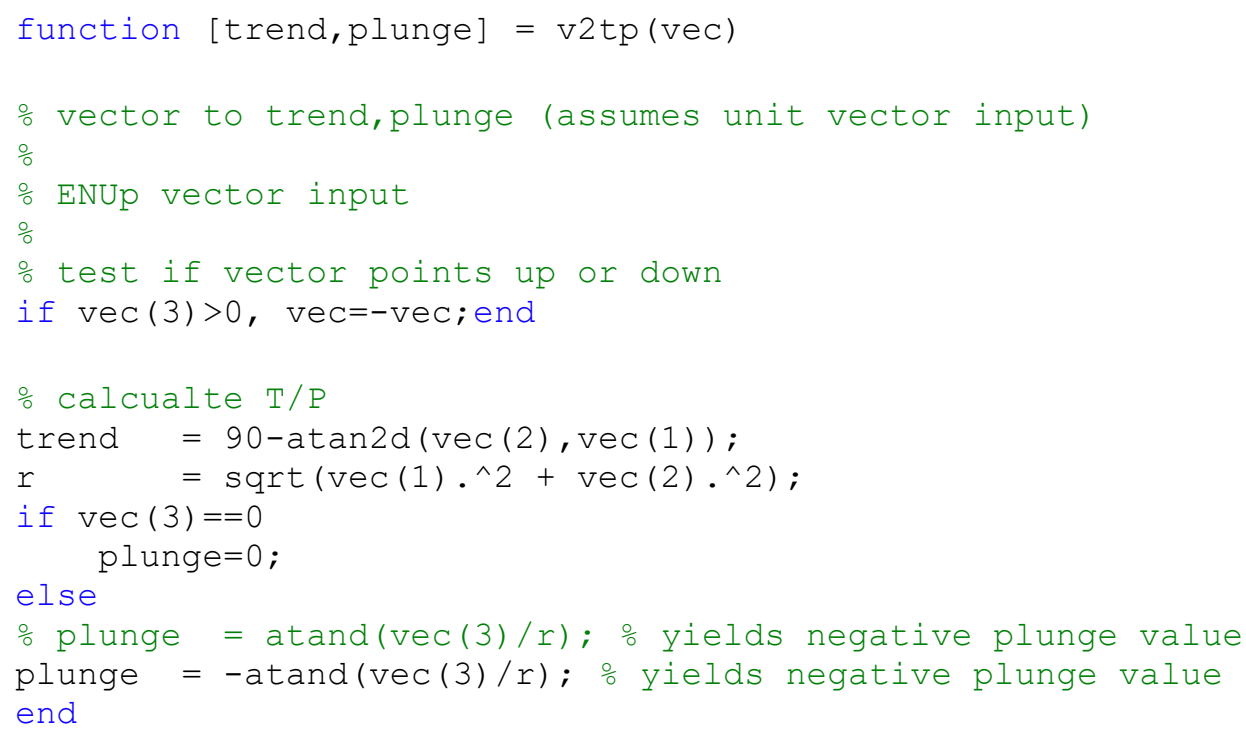




\section{APPENDIX B}

\section{UTM COORDINATES FOR GROUND CONTROL POINTS}

TABLE B1. UTM COORDINATES FOR THE ORANGE GROUND CONTROL POINTS A-H, THE LOW-RESOLUTION DOM, THE HIGH-RESOLUTION DOM, AND THE HIGH-RESOLUTION WITH VIDEO DOM.

\begin{tabular}{|c|c|c|c|c|c|c|c|c|c|c|c|c|}
\hline \multicolumn{4}{|c|}{ Ground Control Points (GPS) } & \multicolumn{2}{|c|}{ Low-resolution DOM } & \multicolumn{4}{|c|}{ High-resolution DOM } & \multicolumn{3}{|c|}{ High-Res + Video DOM } \\
\hline Marker & $x$ & Y & Z & $x$ & Y & $\bar{Z}$ & $x$ & $\bar{Y}$ & Z & $x$ & Y & Z \\
\hline a & 594675.2 & 3716930 & 53.772 & 594675.15 & 3716929.14 & 53.81 & 594675.103 & 3716929.394 & 53.929 & 594675.096 & 3716929.37 & 53.907 \\
\hline$b$ & 594665.2 & 3716930 & 52.1 & 594665.18 & 3716930.08 & 52.06 & 594665.229 & 3716930.268 & 52.096 & 594665.23 & 3716930.267 & 52.095 \\
\hline c & 594653.6 & 3716937 & 53.409 & 594653.61 & 3716937.18 & 53.39 & 594653.595 & 3716937.231 & 53.38 & 594653.601 & 3716937.223 & 53.403 \\
\hline$d$ & 594640.7 & 3716939 & 53.879 & 594640.74 & 3716938.71 & 53.78 & 594640.72 & 3716938.761 & 53.848 & 594640.754 & 3716938.738 & 53.84 \\
\hline e & 594625.9 & 3716940 & 52.778 & 594625.86 & 3716939.85 & 52.81 & 594625.873 & 3716939.918 & 52.783 & 594625.855 & 3716939.891 & 52.779 \\
\hline$f$ & 594614.7 & 3716939 & 53.546 & 594614.6 & 3716938.52 & 53.5 & 594614.634 & 3716938.58 & 53.521 & 594614.632 & 3716938.573 & 53.47 \\
\hline$g$ & 594624.5 & 3716935 & 57.436 & 594624.54 & 3716935.3 & 57.46 & 594624.522 & 3716935.302 & 57.423 & 594624.525 & 3716935.289 & 57.447 \\
\hline $\mathrm{h}$ & 594601.1 & 3716942 & 56.445 & 594601.08 & 3716941.7 & 56.51 & 594601.098 & 3716941.703 & 56.469 & 594601.09 & 3716941.715 & 56.449 \\
\hline
\end{tabular}

